Illinois State University

ISU ReD: Research and eData

Theses and Dissertations

6-11-2014

\title{
Pre-Service School Psychologists' Racial and Weight-Related \\ Biases and the Relationship that Taking Diversity Courses Has on These Biases
}

ShaErica Jackson

Illinois State University, psychology_girl06@yahoo.com

Follow this and additional works at: https://ir.library.illinoisstate.edu/etd

Part of the Educational Psychology Commons, and the Social Psychology Commons

\begin{abstract}
Recommended Citation
Jackson, ShaErica, "Pre-Service School Psychologists' Racial and Weight-Related Biases and the Relationship that Taking Diversity Courses Has on These Biases" (2014). Theses and Dissertations. 234. https://ir.library.illinoisstate.edu/etd/234
\end{abstract}

This Dissertation is brought to you for free and open access by ISU ReD: Research and eData. It has been accepted for inclusion in Theses and Dissertations by an authorized administrator of ISU ReD: Research and eData. For more information, please contact ISUReD@ilstu.edu. 


\title{
PRE-SERVICE SCHOOL PSYCHOLOGISTS' RACIAL AND WEIGHT-RELATED BIASES AND THE RELATIONSHIP THAT TAKING DIVERSITY COURSES HAS ON THESE BIASES
}

\author{
ShaErica R. Jackson
}

155 Pages

December 2014

Past research has shown that racial and weight-related biases are present in school settings and can have a negative impact on students. The purpose of this study was to assess the impact of racial and weight-related biases upon judgments that school psychology graduate students make about Black and overweight students who were having problems in school. The problematic behaviors exhibited by the student in the case study were based on symptoms often seen in children with Attentiondeficit/Hyperactivity Disorder (ADHD). We also examined the extent to which implicit and/or explicit attitudes moderated the degree of school psychology graduate students' attributions of negative personality traits and work habits to Black and overweight students with ADHD. In addition, we wanted to determine the relationship that taking diversity courses have on racial and weight-related biases.

Results indicated that school psychology graduate students have an implicit proBlack bias and an implicit and explicit anti-fat bias. Results also showed that the school psychology graduate students attributed the students in the Black and overweight case studies problems to laziness when they held implicit anti-Black bias. Unfortunately, the 
studies problems to laziness when they held implicit anti-Black bias. Unfortunately, the measure used in this study to examine the relationship between diversity courses and racial and weight-related biases was influenced by the case study manipulations. Therefore, we were unable to test this hypothesis. 
PRE-SERVICE SCHOOL PSYCHOLOGISTS' RACIAL AND WEIGHT-RELATED

BIASES AND THE RELATIONSHIP THAT TAKING DIVERSITY

COURSES HAS ON THESE BIASES

SHAERICA R. JACKSON

A Dissertation Submitted in Partial

Fulfillment of the Requirements for the Degree of

DOCTOR OF PHILOSOPHY

Department of Psychology

ILLINOIS STATE UNIVERSITY

2014 
PRE-SERVICE SCHOOL PSYCHOLOGISTS' RACIAL AND WEIGHT-RELATED BIASES AND THE RELATIONSHIP THAT TAKING DIVERSITY COURSES HAS ON THESE BIASES

SHAERICA R. JACKSON

COMMITTEE MEMBERS:

John B. Pryor, Chair

Steven E. Landau

Mark E. Swerdlik

Anne Wortham 


\section{ACKNOWLEDGMENTS}

I would like to thank Dr. John Pryor for his support, guidance, and patience in completing this project and Drs. Steven Landau, Mark Swerdlik, and Anne Wortham for their input and suggestions. Your knowledge and advice was greatly appreciated. It has helped to improve my writing and research skills and to complete a requirement for my

degree. Thank you!

S. R. J. 


\section{CONTENTS}

\section{Page}

ACKNOWLEDGMENTS

CONTENTS

ii

TABLES

V

FIGURES

viii

\section{CHAPTER}

I. THE PROBLEM AND ITS BACKGROUND 1

II. REVIEW OF LITERATURE 3

What is Prejudice? 3

Stereotypes and Biases $\quad 4$

Weight-Related Stereotypes and Biases $\quad 4$

$\begin{array}{ll}\text { Racial Stereotypes and Biases } & 7\end{array}$

Relationship between Weight-Related and Racial Biases 10

Attention-deficit/Hyperactivity Disorder $\quad 11$

$\begin{array}{ll}\text { Prejudice Reduction } & 14\end{array}$

Suppression of Stereotypes 14

Motivation to Control Prejudice $\quad 16$

$\begin{array}{ll}\text { Multicultural Education } & 17\end{array}$

$\begin{array}{ll}\text { Previous Study } & 21\end{array}$

$\begin{array}{ll}\text { III. CURRENT STUDY } & 24\end{array}$

$\begin{array}{ll}\text { Purpose } & 24\end{array}$

Focusing upon Potential Biases among Pre-Service School
Psychologists 
Multicultural Training in School Psychology

Explicit and Implicit Attitudes $\quad 29$

Hypotheses $\quad 30$

IV. METHOD 31

Pretesting 31

Graduate Schools $\quad 32$

Participants $\quad 33$

$\begin{array}{ll}\text { Procedures } & 38\end{array}$

$\begin{array}{lll}\text { V. RESULTS } & 47\end{array}$

$\begin{array}{ll}\text { Dependent Variables } & 47\end{array}$

Laziness Index $\quad 49$

ADHD Rating Scale-IV 49

Correlations between Dependent Variables $\quad 50$

Measures of Implicit and Explicit Attitudes $\quad 52$

Measures of Motivation to Control Prejudice 54

Measures of Graduate Training Experiences 54

Were the Potential Moderator Variables Related to the Manipulations? 55

Moderation Analyses $\quad 59$

Laziness Index $\quad 59$

ADHD Symptoms $\quad 68$

Ranking the Potential Causes of the Student's School Behavior

Problems

Rank of Lack of Motivation $\quad 77$

Rank of ADHD $\quad 83$

Rank of ODD $\quad 86$

Rank of Inadequate Instruction $\quad 90$

Rank of Lack of Parental Support 97

$\begin{array}{ll}\text { VI. DISCUSSION } & 101\end{array}$

$\begin{array}{ll}\text { VII. CONCLUSSION } & 107\end{array}$

$\begin{array}{lll}\text { VIII. FUTURE RESEARCH } & 111\end{array}$

$\begin{array}{ll}\text { REFERENCES } & 114\end{array}$

$\begin{array}{ll}\text { APPENDIX A: } & \text { Prelim Critique Questionnaire }\end{array}$ 
APPENDIX B: Participation Email

APPENDIX C: $\quad$ Case Study Pictures

APPENDIX E: AMP Rating Scale (Implicit Measure)

APPENDIX F: Examples of AMP Procedure (Implicit Measure)

APPENDIX H: Motivation to Control Weight Prejudice

APPENDIX J: Demographics Questionnaire

APPENDIX L: Debriefing Form 


\section{TABLES}

Table

Page

1. Racial Makeup of Participants (School Psychology Graduate Students) Compared to Racial Makeup of School Psychologists Working in the Field in 2010

2. Type of Program Participants Attended

3. Participants' Year in the Program

4. Regional Locations of the Programs Participants Attended

5. Approval and/or Accreditation Status of the Programs Participants Attended

6. Correlations between Dependent Variables

7. Hierarchical Multiple Regression Analyses Predicting the Laziness Index with Race of Child, Weight of Child, and Implicit RaceRelated Attitudes (Moderator)

8. Hierarchical Multiple Regression Analyses Predicting the Laziness Index with Race of Child, Weight of Child, Implicit Race-Related Attitudes, and Internal Motivation to Control Black Prejudice (Moderator)

9. Hierarchical Multiple Regression Analyses Predicting the Laziness Index with Race of Child, Weight of Child, Explicit Race-Related Attitudes, and Internal Motivation to Control Black Prejudice (Moderator)

10. Hierarchical Multiple Regression Analyses Predicting ADHD Symptoms Ratings with Race of Child, Weight of Child, Implicit Weight-Related Attitudes (Moderator), and Internal Motivation to Control Weight Prejudice (Moderator) 
11. Correlations between ADHD Symptom and Implicit Weightrelated Attitudes for Condition by Weight and Race with Internal Motivation to Control Weight Prejudice

12. Hierarchical Multiple Regression Analyses Predicting ADHD Symptoms Ratings with Race of Child, Weight of Child, Explicit Weight-Related Attitudes, and Internal Motivation to Control Weight Prejudice (Moderator)

13. Hierarchical Multiple Regression Analyses Predicting the Rank of Lack of Motivation with Race of Child, Weight of Child, and Explicit Weight-Related Attitudes (Moderator)

14. Hierarchical Multiple Regression Analyses Predicting the Rank of Lack of Motivation with Race of Child, Weight of Child, Implicit Weight-Related Attitudes, and Internal Motivation to Control Weight Prejudice (Moderator)

15. Correlations between the Rank of Lack of Motivation Implicit Weight-related Attitudes for Condition by Weight with Internal Motivation to Control Weight Prejudice

16. Hierarchical Multiple Regression Analyses Predicting the Rank of ADHD with Race of Child, Weight of Child, and Implicit WeightRelated Attitudes (Moderator)

17. Correlations between the Rank of ADHD and Implicit Weightrelated Attitudes for Condition by Weight and Race

18. Hierarchical Multiple Regression Analyses Predicting the Rank of ODD with Race of Child, Weight of Child, Explicit WeightRelated Attitudes, and Internal Motivation to Control Weight Prejudice (Moderator)

19. Correlation between the Rank of ODD and Explicit WeightRelated Attitudes for Condition by Weight with Internal Motivation to Control Weight Prejudice

20. Hierarchical Multiple Regression Analyses Predicting the Rank of Inadequate Instruction with Race of Child, Weight of Child, and Implicit Race-Related Attitudes (Moderator) 
21. Hierarchical Multiple Regression Analyses Predicting the Rank of Inadequate Instruction with Race of Child, Weight of Child, Implicit Race-Related Attitudes, and Internal Motivation to Control Black Prejudice (Moderator)

22. Correlations between the Rank of Inadequate Instruction and Implicit Race-related Attitudes for Condition by Weight and Race with Internal Motivation to Control Black Prejudice

23. Hierarchical Multiple Regression Analyses Predicting the Rank of Lack of Parental Support with Race of Child, Weight of Child, and Explicit Race-Related Attitudes (Moderator)

24. Summary of Major Findings 


\section{FIGURES}

Figure $\quad$ Page

1. Average Rank Order of Importance of Hypotheses about the Student's School Problems 


\section{CHAPTER I}

\section{THE PROBLEM AND ITS BACKGROUND}

The United States is becoming more diverse (U.S. Census Bureau, 2010).

Diversity may refer to variance, variety, and a range in characteristics including race, social class, ethnicity, sexual orientation, (dis)ability, weight, political affiliation, religion, as well as many other historically underrepresented groups in a particular population or setting (Banks, 2002). Racial diversity, in particular, continues to increase. According to a brief report from the U.S. Census Bureau (2010), one-third of the nation's population includes people of ethnic minority backgrounds, and this number continues to increase. Further, obesity rates are also rising. Obesity affects $17 \%$ of children and adolescents in the United States - triple the rate from one generation ago (Centers for Disease Control and Prevention, n.d.). In 2011-2012, obesity prevalence was higher among Black youth (20.2\%) than White youth (14.1\%).

The school environment is one place where racial and weight diversity is clearly seen. Nearly $47.1 \%$ of school children are of racial minority backgrounds (U.S. Department of Education, 2010). Additionally, the overweight prevalence rates in female children and adolescents increased from $13.8 \%$ in $1999-2000$ to $16.0 \%$ in $2003-2004$, and the overweight prevalence rates in male children and adolescents increased from $14.0 \%$ to $18.2 \%$ in the same time period (Ogden, Carroll, Curtin, McDowell, Tabak, \& Flegal, 2006). However, this diversity is not shown in school personnel. For example, the 
Bureau of Labor Statistics (2010) stated that $82.7 \%$ of preschool and kindergarten teachers, $86.7 \%$ of elementary and middle school teachers, $88.9 \%$ of secondary school teachers, $89.4 \%$ of special education teachers, $81.5 \%$ of teacher assistants, and $87.5 \%$ of librarians are Caucasian. Furthermore, $86 \%$ of school psychologists are Caucasian (Newell et al., 2010).

This lack of diversity in school personnel can have detrimental effects on students. Research has consistently found that teachers hold stereotypes and prejudicerelated attitudes toward students (see Bauer, Yang, \& Austin, 2004; DeMeis \& Turner, 1978; Diamond, Randolph, \& Spillane, 2004; Neumark-Sztainer, Story, \& Harris, 1999). Further, a study conducted by the American Association of Colleges for Teacher Education (2002), found that new teachers are unprepared to work with the diversity of socio-economic statuses, linguistic groups, and other cultural backgrounds represented in their classroom. In the absence of other information, school personnel may depend on weight-related and racial stereotypes and prejudice-related attitudes to develop expectations and to show them how to interact with students who are different from themselves. 


\section{CHAPTER II}

\section{REVIEW OF LITERATURE}

\section{What is Prejudice?}

Prejudice has been defined in many different ways. Allport (1954), a pioneer in researching prejudice, defined it as a feeling, favorable or unfavorable, toward a person or thing that is not based on an actual experience. He believed that prejudice is a result of generalizations and oversimplifications made about an entire group of people based on incomplete or incorrect information. Jones (1997) described prejudice in a similar manner. He stated that prejudice is "a positive or negative attitude, judgment, or feeling about a person that is generalized from attitudes or beliefs held about the group to which the person belongs" (p. 10).

Ford (2013) recently defined prejudice as the preconceived judgments toward a person or group of people because of their race, ethnicity, nationality, gender, age, disability, religion, socioeconomic status, and other sociodemographic characteristics that are grounded in stereotypes that are often negative but can be positive as well. However, some researchers believe that prejudice is inherently negative. According to Brown (2010), prejudice is any attitude, emotion, or behavior towards members of a group, which directly or indirectly, implies some negativity or antipathy towards that group. There are different processes involved in prejudice including stereotypes and biases. 


\section{Stereotypes and Biases}

Stephan (1999) defined stereotypes as generalized traits attributed to a social group and are often developed out of a basic inclination to categorize and synthesize the large amounts of varied information encountered about people in daily life. Further, Young-Bruehl (1996) stated that stereotypes are thought processes that order the world based on expectations and contain both cognitive and affective components. To stereotype someone is to attribute to that person some characteristics which are seen to be shared by all or most of his or her fellow group members (Brown, 2010). Brown (2010) believes that stereotypical expectancies can often mislead people by biasing their search for and receptiveness to information. In other words, when people have stereotypes about groups, they are unlikely to be open to receiving information that is different from what they believe and that may be more truthful. Bias is another underlying process involved in prejudice. It refers to a preference for a particular point of view without having an open mind about alternative points of views (Brown 2010). People may be biased toward or against an individual or group based on their race, religion, socioeconomic status, and other sociodemographic characteristics. Weight-related and racial stereotypes and biases are important for this research study and will be discussed further.

\section{Weight-Related Stereotypes and Biases}

Weight-related stereotypes or bias is one type of prejudice that has been present in school settings. Anti-fat prejudice was defined by Watts and Cranney (2009) as "the tendency to form judgments about people on the basis of excessive body weight" (p. 
110). Danielsdottier et al. (2010) elaborated on this definition. They stated that anti-fat prejudice is "a negative attitude toward (dislike of), belief about (stereotype), or behavior against (discrimination) people perceived as being fat" (p. 47). Overweight individuals are frequent targets of weight stigmatization and prejudice (Puhl \& Brownell, 2001). This may be true given that it is more acceptable to engage in anti-fat prejudice than other forms of prejudice (e.g., race prejudice). Weight bias (Puhl \& Brownell, 2001) and body size (Watts \& Cranney, 2009) is one of the remaining acceptable forms of prejudice. This is particularly troubling given that obesity rates are increasing in the United States.

Obesity is linked to several negative outcomes. The social stigmatization associated with obesity is believed to produce embarrassment, shame, and guilt, all of which may lead to affective disorders (Friedman \& Brownell, 1995). Studies suggest that obesity may also lead to lower self-esteem among children and adolescents. Strauss (2000) examined changes in self-esteem among obese and non-obese 9- and 10-year-old children. He found that obese children relative to normal weight children had declining self-esteem over a 4 year period, and this decline in self-esteem was associated with increased feelings of sadness and loneliness in early adolescence.

Negative outcomes related to obesity can also be seen in the school setting. Two decades ago, the National Education Association (1994) issued a report on size discrimination concluding that the school setting is a venue for ongoing ostracism, stigmatization, and discrimination for overweight and obese youth from nursery school through college (Puhl \& Latner, 2007). Although teachers and other school staff members (e.g., school psychologists) are invested in the well-being of their students, they 
are not immune to societal attitudes that stigmatize obese individuals, and they may perpetuate bias unintentionally through differential treatment of overweight students (Puhl \& Latner, 2007). It is important to examine perceptions of professionals who work with obese children and whether their beliefs about academic achievement (e.g., grades) and obesity could in turn form attributions that fuel weight-based stigmatization. Puhl and Latner (2007) stated that weight-based stigmatization can include "verbal teasing (e.g., name calling, derogatory remarks, being made fun of), physical bullying (e.g., hitting, kicking, pushing, shoving), and relational victimization (e.g., social exclusion, being ignored or avoided, the target of rumors)" (p. 558).

Research suggests that overweight youth are victims of bias and stereotyping by educators (Bauer et al., 2004; Neumark-Sztainer et al., 1999; O’Brien, Hunter, \& Banks, 2007), peers (Kraig \& Keel, 2001; Latner \& Stunkard, 2003; Neumark-Sztainer et al., 2002), and even family members (Crandall, 1991; Crandall, 1995; Davison \& Birch, 2004; O'Brien et al., 2007). So ingrained is the prejudice toward overweight individuals that even parents display anti-fat bias, whether consciously or unconsciously, against their own overweight children (Crandall, 1991).

Most anti-fat biases are related to assumptions that overweight individuals are in control of their weight. Weiner, Perry, and Magnusson (1988) found that the attribution of controllability for fatness leads to obese people being rejected. This was supported by Crandall, D'Anello, Sakalli, Lazarus, Nejtardt, and Feather (2001) who found that anti-fat prejudice is correlated with negative value for fatness and the judgment of responsibility for one's weight. Given that obese individuals are held accountable for their weight, 
many people find it acceptable to hold anti-fat bias. People with negative characteristics such as fatness should be punished, avoided, and stigmatized - in short, they deserve anger and prejudice (Feather, 1996).

\section{Racial Stereotypes and Biases}

Racial bias is another type of prejudice that has been present in school settings. Blackwell, Smith, and Sorenson (2003) defined racial prejudice as the belief that physical characteristics determine cultural traits and that these racial characteristics make some racial groups either inferior or superior. Racism and other forms of prejudice affect a person's behavior, thoughts, and feelings and many factors and outcomes in his or her life (Ford, 2013). In education, this includes expectations, relationships, grading practices, gifted referrals, and special education referrals, to name a few. Racial stereotypes are thought to undermine minority students because these stereotypes may influence the manner in which students are judged or treated by teachers (Wineburg, 1987). This is especially problematic for African Americans in the U.S. school system. According to Fordham (1996) and Perry, Claude, Asa, and Hilliard (2003), stereotypic images suggest that African Americans are not as intelligent as Caucasians. This was supported by Farkas (1996) who found that teachers' perceptions of low-income and African American students' academic capacity are lower than those they hold for middle- and upper-income white students. In addition, Roscigno and Ainsworth-Darnell (1999) found that teachers often viewed low-income and African American students as less capable of high academic achievement than their Caucasian counterparts. 
Stereotypes can also influence the intellectual functioning and identity development of minority individuals (Steele \& Aronson, 1995). Several studies have shown that teacher expectations of student achievement and behavior may lead to selffulfilling prophesies as the result of differential treatment (Brophy \& Good, 1974; Jussim \& Eccles, 1995; Rosenthal \& Jacobson, 1968). If this differential treatment is negative, then the student's self-fulfilling prophesies will be negative (e.g., I cannot do this. I am not smart enough to pass this class.). Additionally, if the student is aware of these prophesies, he or she may react accordingly (e.g., Why study when I am going to fail anyway?).

Steele (1997) noted that student's awareness of stereotypes of his or her minority group may create internal barriers to success and achievement by raising feelings of anxiety and self-doubt. This anxiety and self-doubt causes students to perform lower than their actual abilities. Farkas (1996), Farkas et al. (1990), and Rist (1970) studied the role of the self-fulfilling prophecy. They found that when teachers' had low expectations for their students, it reduced their students' academic self-image, caused students to exert less effort in school, and led teachers to give certain students less challenging coursework. This is especially problematic for African American students. Steele and Aronson (1995) analyzed the stereotype vulnerability of African American students regarding their intellectual performance and academic ability. They found that priming racial identity caused African American students to underperform on standardized test relative to Caucasians. This is particularly troublesome because teachers' expectations 
are a more powerful influence on African American students than they are on Caucasian students (Ferguson, 1998).

Further, stereotypes can also affect how teachers view students' behaviors. Lambert, Puig, Lyubansky, Rowan, and Winfrey (2001) found that teacher tolerance is a primary indicator for identification of behavior problems and teachers are less tolerant of behaviors that are inconsistent with their cultural expectations. This was supported by Puig et al. (1999) who found that Caucasian teachers working in the U. S. may have lower thresholds of tolerance for problem behaviors in African American students and provide exaggerated reports of these symptoms. Puig et al. (1999) also found that teachers' ratings of overall problem behavior in African American students exaggerated their observed levels of problem behavior.

Researchers have generally found that teachers tend to rate African American students less favorably on such measures as personality and behavior, motivation to learn, and classroom performance, they hold lower academic expectations for African American students, and treat African American students less favorably than Caucasian students in the classroom (Keller, 1986; Murray, 1996; Partenio \& Taylor, 1985; Plewis, 1997). Further, an extensive body of literature reveals that teachers rate African American students higher on disruptive behavior problems, provide higher rates of negative verbal feedback to African American students, and disproportionately refer African American students for disciplinary action and special education services compared to their Caucasian peers (Andrews, Wisniewski, \& Mulick, 1997; McFadden, Marsh, Price, \& Hwang, 1992; Plewis, 1997; Ross \& Jackson, 1991; Shaw \& Braden, 
1990; Zimmerman, Khoury, Vega, Gill, \& Warheit, 1995). Further, research on U. S. samples has consistently shown that teachers rate African American children higher on ADHD-related (Attention-deficit/Hyperactivity Disorder) behaviors than Caucasian children (Epstein, March, Conners, \& Jackson, 1998; Reid, Casat, Norton, Anastopoulos, \& Temple, 2001). These behaviors include speaking out of turn, fidgeting, and not following directions.

\section{Relationship between Weight-Related and Racial Biases}

Although we discussed racial and weight-related biases in separate sections, they have many similarities. Crandall (1994) suggests that anti-fat attitudes are similar to symbolic racism, and that anti-fat attitudes appear to be currently at the stage that racism was some 50 years ago: overt, expressible, and widely held. This was supported by Crandall and Biernat (1990) who found that anti-fat prejudice was correlated with authoritarianism, political attitudes, racism, and support for capital punishment and traditional marriages.

Kinder (1986) and Kinder and Sears (1981) have argued that an essential component of anti-Black attitudes is the belief that Blacks have earned their fate and that their economic and social position has resulted from controllable factors. This is the same logic that applies to anti-fat prejudice. Weiner et al. (1988) found that the attribution of controllability for fatness leads to rejection. In addition, Crandall et al. (2001) found that anti-fat prejudice is correlated with the judgment that an individual is responsible for his or her own weight. Therefore, many people feel that an individual chooses to be fat, and it is acceptable to hold anti-fat biases (Feather, 1996). 


\section{Attention-deficit/Hyperactivity Disorder}

As mentioned in the previous section on racial stereotypes and biases, teachers rate African American students higher on ADHD-related behaviors compared to their Caucasian peers (Epstein, March, Conners, \& Jackson, 1998; Reid, Casat, Norton, Anastopoulos, \& Temple, 2001). According to the Diagnostic and Statistical Manual of Mental Disorders (DSM-IV-TR, 2000), ADHD is "a persistent pattern of inattention and/or hyperactivity-impulsivity that is more frequently displayed and more severe than is typically observed in individuals at a comparable level of development"' (p. 85).

Children with ADHD experience difficulties in many different areas of their lives. They experience difficulties in behaviors crucial to academic success, such as maintaining attention, modulating activity levels, inhibiting impulsive responses (e.g., speaking out of turn), and persisting with academic tasks (DuPaul \& Stoner, 2003). Further, Barkley (1998) found that children with ADHD are at a greater risk for interpersonal problems (e.g.,, peer rejection and parent-child conflict) and difficulties in educational functioning (e.g,, learning disabilities, grade retention, low graduation rates, low grade point average). He also found that children with ADHD who were 6 to 12 years of age often had mild cognitive impairments (e.g., working memory, planning, goal-directedness), delayed motor coordination, adaptive functioning (10-30 points below normal), delayed onset of language or impaired speech, and poor emotional selfregulation. ADHD is comorbid with other psychological disorders. Common comorbid conditions include: Oppositional Defiant Disorder (ODD), Conduct Disorder (CD), 
learning disabilities, Tourette syndrome, depression, anxiety disorders, and Bipolar Disorder (Barkley, 1998).

Teachers are often the first to make referrals for ADHD-related assessment, and these referrals have often been used as a predictor of a child's symptoms (Scuitto, Terjesen, \& Bender-Frank, 2000). Teachers play a major role in the assessment of children's academic and behavioral problems, and have been considered one of the most valuable sources of information with regard to ADHD diagnosis because they have daily exposure to children in a variety of clinically relevant situations (Stevens, Quittner, \& Abikoff, 1998).

One way teachers help to assess a child's problems is through rating scales. Teacher ratings are a valued aspect of ADHD assessment because they summarize extensive, accumulated observations of child behavior from individuals who are familiar with developmental expectations (Busse \& Beaver, 2000). These ratings contribute to diagnostic decision-making by clarifying whether ADHD symptoms are inconsistent with developmental level and associated with impairment across two or more settings (APA, 2000). However, teachers' ratings of children's symptoms and their referrals for ADHDrelated assessments can be influenced by their stereotypes and personal prejudices. For example, Epstein et al. (2005) found that African American children must exhibit higher rates of ADHD behaviors before being referred for assessment and treatment than Caucasian children. Teachers instead may believe that the ADHD behaviors are signs of acting out or defiance. If bias occurs in teacher ratings of ADHD symptoms, this may be 
one source of incongruity in special education placements across ethnic groups (Hosterman, DuPaul, \& Jitendra, 2008).

African American students are disproportionately diagnosed and placed into categories of special education in the United States (Coutinho \& Oswald, 2000; Oswald, Coutinho, Best, \& Singh, 1999). This leads to African American students being overrepresented in special education programs designed for students with mild disabilities (Obi \& Obiakor, 2001; Obiakor; 1999). High prevalence rates of ADHD among children in special education programs suggest that children with ADHD may receive school services under the label of having an emotional handicap or a specific learning disability (Mattison, Morales, \& Bauer, 1993; Reid, Maag, Vasa, \& Wright, 1994). Schnoes, Reid, Wagner, and Marder (2006) conducted a study and found that $65.8 \%$ of students receiving services under the category of Other Health Impairment (OHI) had an ADHD diagnosis; 57.9\% receiving services under the category of Emotional Disturbance (ED) had an ADHD diagnosis; 20.6\% receiving services under the category of Mental Retardation (MR) had an ADHD diagnosis; $20.2 \%$ receiving services under the category of Learning Disorder (LD) had an ADHD diagnosis; and $4.5 \%$ receiving services under the category of Speech/Language Impairment (SLI) had an ADHD diagnosis.

Despite the relatively high prevalence of the disorder, only a minority of children with ADHD are identified or receive health care interventions (Szatmari, Offord, \& Boyle, 1989; Sherman \& Hertzig, 1991). Because the disorder's symptoms often impede academic performance, unmet mental health needs of children with ADHD have 
significant implications for professionals in the education sector (Bussing, Zima, Perwien, Belin, \& Widawski, 1998).

\section{Prejudice Reduction}

Because of potential prejudice, in the form of stereotypes and biases, observed in the school environment, prejudice reduction techniques may be needed. Allport (1979) proposed that many prejudices are established in early childhood and that prejudiced students use selective perception, avoidance, and group support strategies to resist confronting and modifying or changing their beliefs about self and others. Prejudice and stereotypes often are automatically activated after encountering group members (Gordijn, Hindriks, Komen, Dijksterhuis, \& Knippenberg, 2004). However, because of personal and/or social standards, many people are motivated to suppress, reduce, and/or control these stereotypes (Monteith, Sherman, \& Devine, 1998). Further, multicultural education is also commonly used to reduce prejudice.

\section{Suppression of Stereotypes}

People may try to banish stereotypic thoughts from their minds in an attempt to suppress prejudiced responses. However, attempts at such thought suppression may have unintended effects. Research has shown that attempting to suppress a thought may lead to that thought becoming more accessible than if suppression had never been attempted (Monteith et al., 1998). Macrae, Bodenhausen, and Milne (1998) suggest that conscious attempts to control prejudice may not meet with success. Even worse, these attempts may backfire; thus, creating an increase in stereotypic thoughts and responses beyond the 
level apparent before any attempt at control was made. In other words, the more people try to suppress their stereotypic thinking, the more they will fail to do so.

Wegner (1994; see also Wegner \& Erber, 1992) developed a provocative model of mental control to explain the effects of stereotype suppression. According to Wegner's model, attempts to suppress unwanted thoughts result in the initiation of two mental processes. First, an intentional operating process begins searching for thoughts that can serve as distracters. The goal of the operating process is to focus attention on something other than the unwanted thought. Second, an ironic monitoring process begins searching consciousness for evidence of the unwanted thought. This "checking" mechanism ensures that the operating process is functioning successfully and, if it is not, signals the operating process of failure and the need for different and better distracters. Through the continuous search for the unwanted thought, this thought presumably is repeatedly primed and thus becomes more and more accessible (Wegner \& Erber, 1992). This results in a "rebound effect," or an increase in the frequency of occurrence of the unwanted thought, relative to if no attempt had been made to suppress the unwanted thought in the first place (Wegner, Schneider, Carter, \& White, 1987).

Gordijn et al. (2004) propose that when stereotype suppression leads to stereotype rebound, this is partly due to depletion of regulatory resources as the result of engaging in self-control. Continuing self-control demands gradually deplete the inner resources available for self-control (Muraven \& Baumeister, 2000). Therefore, when individuals use their cognitive resources to suppress one bias, other biases may become apparent. 
Reeder, Pryor, Park, and Brooks (2008) demonstrated this model of prejudice suppression where suppressing one bias allowed another to become apparent. They tested people's attributions about Barack Obama's political motives. Their results showed that participants' implicit anti-Muslim biases predicted attributions of negative political motives to Obama, whereas their implicit anti-Black biases were not related to attributions of Obama's motives. They also found that when participants were sensitized to their potential anti-Muslim biases, their implicit anti-Muslim attitudes were suppressed. However, when anti-Muslim biases were suppressed, their implicit antiBlack attitudes figured more strongly in their attributions of negative political motives to Obama. This pattern of results seems to suggest a dynamic model of prejudice suppression. When people devote their cognitive resources to the suppression of one form of prejudice, other forms may go unchecked.

\section{Motivation to Control Prejudice}

Prejudice is also reduced when there is a motivation to control it. According to Plant and Devine (1998), it is important to distinguish between internal and external motivation because people may have different reasons to behave in an unprejudiced way. Internal motivation to behave in an unprejudiced way arises from internalized, personally important, nonprejudiced beliefs, whereas external motivation derives from a desire to avoid negative reactions from others. Monteith, Spicer, and Tolman (1998) found that when people are equipped with the personal motivation and desire to avoid stereotypic thinking, they will be able to do so, and they will not incur subsequent costs in the form of heightened stereotype accessibility or increased stereotype use. Further, when 
suppression is examined in the context of stereotypes of social groups for which there are strong personal and social concerns over the use of stereotypes, the usual patterns of stereotype rebound effects are not always observed. Thus, if a person believes that stereotypes are politically incorrect, rebound effects may not occur.

\section{Multicultural Education}

Multicultural education is another form of prejudice reduction. Many individuals believe that prejudice is due to ignorance, and in turn, are open to learning about diverse others (Esses \& Hodson, 2006). Some individuals believe that this ignorance can be eliminated with knowledge about diverse groups. Fiske (1998) conducted a review of stereotyping, prejudice, and discrimination, and suggested that individuals prefer and seek out information consistent with their preconceived notions about outgroups. Therefore, those holding positive and even ambivalent attitudes toward minorities are more likely to seek out and process information about diverse others (Fiske, 1998), making them likely candidates for enrolling in diversity related courses. On the other hand, highly prejudiced individuals are less supportive of educational attempts to decrease bias (Esses \& Hodson, 2006), making them the least likely to enroll in a diversity course.

Multicultural education has been defined in different terms. For instance, Butt and Pahnos' (1995) defined multicultural education as "understanding the needs of every child and responding to each one sensitively, fairly, and effectively" (p. 48), whereas Santrock (2001) defined multicultural education as "education that values diversity and includes the perspectives of a variety of cultural groups on a regular basis" (p. 171). 
Multicultural education has also been defined in terms of curriculum. Howard (1985) suggested that a multicultural curriculum should address five aspects: (1) uniqueness (special qualities); (2) empowerment (believing that you can do what you set out to do); (3) belonging (feeling of being part of something); (4) security (knowing rules will be enforced fairly and equally); and (5) purpose (setting realistic goals and feeling challenged). Dunn (1997) found that the majority of multicultural training programs for school systems focus on two main goals: (1) increasing academic achievement of minority students, and (2) promoting greater understanding and sensitivity to cultural differences in an attempt to reduce bias within the student population (Dunn, 1997). It is unknown whether the five aspects of multicultural curriculum suggested by Howard (1985) are found within the two main goals of multicultural training programs reviewed by Dunn (1997).

Multicultural education is taught within two types of courses. There are diversityfocused courses in which the entire course is devoted to diversity topics such as the psychology of prejudice (Pettijohn \& Walzer, 2008). There are also varying levels of diversity-infused courses in which diversity issues are not the main focus of the course but are integrated through multiple perspectives of historically underrepresented groups (Banks, 2002). According to Banks (2002), there are 4 different levels of inclusion: the contributions approach, the additive approach, the transformation approach, and the social action approach. One level gradually leads to another level. The first level is the contribution approach in which instructors cover holidays celebrated by different cultures and social groups. The second level is the additive approach in which instructors add an 
activity, unit, or module devoted to a diversity-related topic or issue into their lessons. The third level is the transformational approach in which instructors rework their entire curriculum to offer each course topic through multiple, non-dominant perspectives. The final level is the social action approach in which instructors provide opportunities to participate in cultural awareness events and assign projects that require social action.

Required diversity courses in college curricula emerged in response to educational disparities highlighted during the civil rights movement, including the absence of course content about women and racial/ethnic minorities, as well as the need for pedagogical practices reflecting the needs of diverse students (Soldatenko, 2001). One of the main purposes of multicultural education is to promote cultural diversity, ethnic awareness, and a respect for group similarities and differences (Gomez, 1992). There is an assumption that a curriculum with a multicultural focus can lead to respect for social justice and an openness to diversity (Strange \& Alston, 1998). It has been suggested that the inclusion of multicultural perspectives in course curriculum and on the campus is sufficient to inspire students to embrace a variety of social and cultural groups (Ervin, 2001).

A growing body of research suggests that classroom education about minority groups can be effective in reducing stereotypes as well as explicit and implicit prejudice and discrimination (Fiske, 1998; Kernahan \& Davis, 2007; Pettijohn \& Walzer, 2008). These programs are a direct response to the growing need for multicultural education in schools based on the changing notion of the "typical" American public school student (Nikels, Mims, \& Mims, 2007). Several researchers have found that diversity courses are 
effective in decreasing racial prejudice especially against African Americans. It has been found that after taking diversity courses, students reported decreased prejudice based on race and supported race-based initiatives (Hurtado, 2005), increased social action engagement (Laird, Engberg, \& Hurtado, 2005), and had greater empathy and perspective taking (Gurin, Nagda, \& Lopez, 2004). Hogan and Mallott (2005) found students enrolled in a diversity course reported the lowest prejudice against Blacks whereas those never enrolled exhibited the highest prejudice. Further, in a recent meta-analysis of 27 studies, Denson (2009) found that overall, diversity-themed courses had a moderate effect on the reduction of racial bias.

In regards to anti-fat bias, McHugh and Kasardo (2012) believe that the field of psychology lags behind in size acceptance despite concerns about diversity and prejudice in other areas (e.g., race). Multicultural education may also be beneficial for decreasing and/or eliminating anti-fat bias. Connors and Melcher (1993) believe that training and education are needed to help psychologists eradicate their own and others' anti-fat bias. Anti-fat bias has been found to be more pervasive among younger psychologists than those with more experience (Davis-Coelho et al., 2000). This suggests that training regarding awareness and prevention of fat bias should occur early in the training of psychologists.

Brownell and Rodin (1994) also advocate for education as a way to decrease and/or eliminate anti-fat biases. They believe that:

"education is necessary to promote acceptance of different body shapes and sizes, with the aim of alleviating the need to seek a rigidly lean and contoured body. 
Education is needed to communicate that the body cannot be shaped and molded at will, and the pursuit of an unrealistic ideal increases risk for eating disorders, promotes preoccupation with food, and may have untoward physiological consequences" (p. 787).

In addition, because controllability of fatness has been a large reason for bias against fat people, Crandall (1994) believes that one aspect of this training should pertain to this (i.e., the controllability of fatness).

\section{Previous Study}

In the previous study, Jackson (2010) examined how race-related and weightrelated biases of pre-service teachers influenced their impressions of students who were having problems in school. The study was conducted in an effort to understand how to measure negative reactions that people have towards African American overweight students and whether implicit or explicit attitudes moderate the degree to which preservice teachers attribute negative personality traits and work habits to African American overweight students. The study also examined the impact that suppression of negative attitudes had on pre-service teachers' biases.

Pre-service teachers' biases were tested in three different conditions. In each condition, participants read a case study that included a one-page description of the student's problems (the student displayed symptoms of ADHD as defined by the DSMIV-R) and a photograph of the student. The case study either featured a young version (student age 8-10) or an old version (student age 12-14). In condition one, the student depicted in the photograph was an average weight African American male. In conditions 
two and three, the student depicted in the photograph was an overweight African American male. Condition three also included a statement in the one-page description about the student being teased by his classmates because of his weight.

After reading the case study, pre-service teachers rated their impressions of the student on 40 characteristics using 7-point Likert-type scales. The characteristics at the small end of the scale were positive whereas the characteristics at the large end of the scale were negative. Characteristics included Hardworking (1) to Lazy (7) and Motivated (1) to Unmotivated (7).

In addition, pre-service teachers completed implicit and explicit measures to assess their racial and weight-related biases. Implicit attitudes were measured using the Affect Misattribution Procedure (AMP; to be described in more detail below). Explicit race-related attitudes were measured using the Pro-Black and Anti-Black Scales (Katz \& Hass, 1988), the New Racism Scale (Jacobson, 1985), and the Attitudes Toward Blacks Scale (Brigham, 1993). Explicit weight-related attitudes were measured using the AntiFat Attitudes Scale (Crandall, 1994). Pre-service teachers' motivations to control prejudices were measured using the Motivation to Control Race Prejudice Scale (Plant \& Devine, 1998) and the Motivation to Control Weight-Related Prejudice Scale (Pryor, Reeder, Yeadon, \& Hesson-McInnis, 2004). A series of Feeling Thermometers (Campbell, 1971) were completed by the pre-service teachers to measure both explicit racial and weight-related biases. They also completed the Egalitarian Values Scale (Katz \& Hass, 1988), the Social Dominance Orientation Scale (Pratto, Sidanius, Stallworth, \& 
Malle, 1994), the Disgust Sensitivity Scale (Haidt, McCauley, \& Rozin, 1994), and the Big Five Inventory (Benet-Martinez, \& John, 1998).

Given that there were numerous measures of explicit racial and weight-related biases, a Mean Explicit Race Attitude Scale and a Mean Explicit Weight-related Attitude Scale was computed to simplify analyses. Results showed that pre-service teachers' who exhibited stronger implicit anti-Black biases, explicit anti-Black biases, and explicit weight-related biases were more likely to attribute African American overweight students' symptoms of ADHD to laziness.

The results were surprising. It was hypothesized that implicit anti-Black and weight-related biases and explicit weight-related biases would be correlated with attributions of laziness. However, implicit weight-related biases were not found to be correlated with attributions of laziness. In addition, explicit anti-Black related biases were shown to be correlated with attributions of laziness which was not hypothesized given that it is not politically correct to show racial biases. The fact that pre-service teachers were willing to share their anti-Black biases was astonishing. These results indicated that pre-service teachers relied more on stereotypes surrounding the students' race and weight instead of recognizing the students' problems for what they were: a sign of ADHD. 


\section{CHAPTER III}

\section{CURRENT STUDY}

Because of the surprising results of the previous study (i.e., pre-service teachers' explicit anti-Black biases were correlated with attributions of laziness), it was decided to further explore the subject of potential racial and weight-related biases in education. This study builds on the previous study by examining school psychology graduate students' implicit and explicit racial and weight-related biases and the influence of taking diversity courses have on these biases. In the previous study, we examined prejudice reduction examining stereotype suppression and the motivation to control prejudice. For this study, we examined multicultural education and the motivation to control prejudice as prejudice reduction measures.

Furthermore, there were some gaps in the previous study that we hoped to address with this study. First, there was no Caucasian control group for the case study scenarios in the previous study. We remedied this be including a Caucasian average weight and overweight student in the case study scenarios. Second, girls were included in our implicit measure (AMP) although our study focused on pre-service teachers' attitudes about boys. For this study, we only included boys in our implicit measure.

\section{Purpose}

The main purpose of this study assessed the impact of racial and weight-related biases upon judgments that school psychology graduate students make about African 
American and overweight children who are having problems in school. Specifically, when students show symptoms of ADHD, are school psychology graduate students' impressions of them influenced by such biases? We examined school psychology graduate students' implicit and explicit racial and weight-related biases toward students who were having problems in school and the impact, if any, that diversity courses have on these biases. Specifically, we hoped to learn if school psychology graduate students hold racial and/or weight-related biases and if these biases impact their ability to correctly judge the nature of students' problems in school especially related to ADHD. In addition, we hoped to learn whether or not taking diversity courses is related to reduction of racial and/or weight-related biases in pre-service school psychologists.

\section{Focusing upon Potential Biases among Pre-Service School Psychologists}

School psychologists play a major role in meeting the needs of students and establishing communication and collaboration between home and school. They are educational professionals who provide assessments, consultation, systems interventions, and counseling in ways that support schools, teachers, students, and families (Kearns, Ford, \& Linney, 2005). They also seek to understand the functioning of a school to improve the education and social-emotional development of the students.

School psychologists help children and youth succeed academically, socially, behaviorally, and emotionally (NASP, 2011). They collaborate with educators, parents, and other professionals to create safe, healthy, and supportive learning environments that strengthen connections between home, school, and the community for all students. In order to perform effectively, school psychologists must be trained to work with areas and 
issues that may be unfamiliar to them (Wille, McFarland, \& Archwamety, 2009). These areas and issues will most likely involve the diverse background of the students and the parents with whom they work. For African American and other ethnic minority students in particular, school psychologists work to prevent abuse of the special education referral system (Frisby, 1992).

School psychologists also play an important role in the assessment and treatment of children diagnosed with ADHD (Weyandt, Fulton, Schepman, Verdi, \& Wilson, 2009). Not only are school psychologists in a position to work directly with children diagnosed with ADHD, they are also in the position to disseminate current scientific information about the disorder to professionals within the schools (e.g., teachers; Weyandt et al., 2009). This information is only useful if it is not prejudiced in any way. However, this is not always the case. For example, Kearns et al. (2005) examined school psychologists' perceptions about the disproportionate representation of African American students in special education. They found that some school psychologists made prejudiced assumptions about a student's potential based on race and family background. In their study, several participants (i.e., school psychologists) stated that many African American parents' inferior intellect was passed down to their children which resulted in an innate disadvantage for high achievement and success. The participants further stated that African American students contributed to their own school failure because of negative behaviors and lack of motivation to achieve. 


\section{Multicultural Training in School Psychology}

Approximately $75.1 \%$ of U.S. citizens are Caucasian whereas, $86 \%$ of school psychologists are Caucasian, reflecting an overrepresentation of Caucasian school psychologists compared with the general population (Newell et al., 2010). This overrepresentation of Caucasian school psychologists has implications for the need for cross-cultural education. Ecklund and Johnson (2007) stated that "In light of the expanding diversity inherent in the population of children and the significant proportion of children at risk for emotional and behavioral difficulties, it stands to reason that psychologists who render services to children and families require cross-cultural competencies" (p. 356).

Numerous diversity sensitivity training programs have evolved across the nation over the past several years (Keim, Warring, \& Rau, 2001) in response to the growing trend of racial and ethnic diversity in the U.S. Research on multicultural training in school psychology indicates that most trainers in this discipline find multicultural training to be a critical component of the curriculum (Rogers, Conoley, Ponterotto, \& Wiese, 1992). Multicultural training will help school psychologists deliver more effective services to students with diverse backgrounds. One of the most salient reasons multicultural competence is becoming essential to the provision of effective service delivery is that the U.S. population is shifting and expanding in ways that create a wider range or cultural and linguistic differences that are not reflected in the cultural and linguistic profile of current school psychologists (Newell et al., 2010). 
Only a small number of school psychology programs have demonstrated success with preparing their students to be multiculturally-sound clinicians and researchers (individuals who conduct research on multiculturally issues: Rogers, Hoffman, \& Wade, 1998). The vast majority has not (Rogers et al., 1992). Ducker and Tori (2001) explained that whereas many psychology programs have begun to include more multicultural courses in their curricula, progress in applied psychology degree programs, such as school psychology, has been slow.

Kearns et al. (2002) studied the multicultural training (MCT) of APA-accredited school psychology programs. The sample included faculty and students from five programs that were nominated for their strong MCT and five comparison programs that were randomly selected from a list of remaining APA-accredited programs. The five programs were nominated by 45 school psychologists who were recognized for their expertise in working with culturally and linguistically diverse children and youth.

Overall, Kearns et al. (2002) found that nominated programs reported a commitment to multicultural issues in their mission statements or program philosophies. They also reported the use of specific minority recruitment procedures and required cross-cultural and diversity courses as part of their core curriculum. Additionally, four of five nominated programs had faculty members who reported research interests specifically in multicultural and diversity issues. Further, faculty members from the nominated programs were an ethnically diverse group.

On the other hand, Kearns et al. (2002) found that the comparison programs did not address the significance of multicultural training and diversity in their mission 
statements or program philosophies. However, all of the comparison programs reported the integration of multicultural content through course integration and most reported the use of specific minority recruitment procedures. Only one comparison program had a specialization in diversity issues with the goal of increasing ethnic minority individuals into school psychology.

\section{Explicit and Implicit Attitudes}

Explicit attitudes that people hold about racial groups and people who are overweight are typically assessed directly by self-reports. Using such common devices as feeling thermometers and Likert-type scales, participants are asked to report how they feel about people who have various characteristics. Implicit attitudes, in contrast, are assessed through various indirect forms of psychological measurement (Fazio \& Olson, 2003). For example, the AMP asks people to evaluate ambiguous figures that are preceded by priming photographs. When the priming photographs depict members of a disliked group (e.g., people who are overweight or Blacks), the ambiguous figures are evaluated less positively (Payne, Cheng, Govorun, \& Stewart, 2005). Explicit attitude measures have been found to be more influenced by social desirability and political correctness concerns than implicit attitude measures. On the other hand, implicit attitude measures are by definition indirect and may fail to capture the complexities of people's feelings about social groups. By deploying both implicit and explicit measures of racial and weight-related biases (general attitudes) in the current study, we hope to gain a fuller understanding of how biases potentially influence impressions of children who have problems at school. 
By assessing both implicit and explicit biases, we also hope to gain a more complete understanding of the potential impact of diversity education on school psychology graduate students. Do school psychologists who have undergone such educational experiences actually demonstrate less racial bias? How about weight-related bias? Does diversity education have an impact on both implicit and explicit biases? These are among the research questions we pose in this project.

\section{Hypotheses}

(1) We hypothesized that participants would rate the Black students with ADHD as being lazier than the White students, and that these ratings would be moderated by participants' implicit and explicit anti-Black attitudes. (2) Further, we hypothesized that participants would rate the overweight students with ADHD as being lazier than the average weight students with ADHD, and that these ratings would be moderated by participants' implicit and explicit anti-fat biases. (3) We also predicted that participants who are less motivated to control either race-related or weight-related prejudice will be more likely to show evidence of consistency between their race-related or weight attitudes and their ratings of laziness. For example, a participant who is unmotivated to control race-related prejudice and who has negative implicit attitudes about Blacks will be likely to rate a Black student who has ADHD symptoms as lazy. (4) Finally, as a research question, we explored whether more exposure to diversity issues in graduate courses might be related to participants' implicit and explicit biases related to weight and race. In other words, would education moderate the impact of these biases upon impressions of overweight and Black students exhibiting ADHD symptoms in school? 


\section{CHAPTER IV}

\section{METHOD}

\section{Pretesting}

The survey was pretested to determine if there were any problems before it was launched to potential participants. Eighteen graduate students participated in the pretesting of the survey. They completed the survey and afterwards, filled out a form critiquing it. (See Appendix A for a copy of the form.) From this critique, it was determined that the average amount of time for completion of the survey was 23 minutes (from 17 minutes to 31 minutes) and that questions and directions were understandable. However, seven of the participants were unable to see the photographs for the AMP depending on their level of computer security and version of Adobe (which is needed to show the photographs). (AMP photographs were presented in an Adobe video file so that each photograph would automatically be presented for one second without having to rely on the participants to advance the screen at the appropriate time. When using the AMP, photographs are presented for a specific amount of time. For this study, the photographs were presented for one second.) These participants were able to complete the survey by selecting an answer without seeing the photographs. Because of these data, a question was added to determine if participants were able to view the Adobe video. A picture of an elephant was presented in an Adobe video. Participants were then asked what animal 
they saw. If they answered correctly, the participants were directed to the remainder of the AMP videos. If they answered incorrectly or that they didn't see an animal, the participants were directed to the first question after the AMP videos.

\section{Graduate Schools}

A list of graduate schools that have a School Psychology program was obtained from the University of California at Berkley website. According to the website, this list is comprehensive. There were a total of 223 schools on the list. However, only 197 schools actually had a School Psychology program and were included in this research study. The other 26 schools had School Counseling, Educational Counseling, or similar programs and were not included in this research study. Furthermore, a list of graduate schools that had a NASP approved School Psychology program was obtained from the National Association of School Psychology (NASP) website (http://www.nasponline.org/ certification/documents/NASP-Approved-Programs.pdf). A total of 186 schools are NASP approved. In addition, a list of graduate schools that had an APA accredited School Psychology program was obtained from the American Psychological Association (APA) website (http://apps.apa.org/accredsearch/). There were a total of 63 schools on the list. These three lists were compared and combined and four categories were determined: (1) NASP approved only, (2) APA accredited only, (3) Both NASP approved and APA accredited, and (4) Neither NASP approved nor APA accredited. All together, there were 238 schools. One hundred and thirty schools were NASP approved only. Seven schools were APA accredited only. Fifty-six schools were Both NASP approved and APA accredited. Forty-five schools were neither NASP approved nor APA 
accredited. (Illinois State University's School Psychology program is NASP approved and APA accredited. However, they were not included in this study given that most of the students in this program are aware of the nature of this research study.)

\section{Participants}

Two hundred and sixty-three graduate students majoring in School Psychology participated in this study. Two hundred participants were able to complete the entire survey whereas 63 participants were unable to complete the AMP (implicit measure). (Data from these 63 participants were not included when analyzing the results.) Two hundred and twenty-one participants (84\%) were female and $42(16 \%)$ were male. Participants' ages ranged from 21 to 65 and older. Two hundred and seventeen participants (83\%) were White/Caucasian, 18 (7\%) were Black/African American, 15 (6\%) were Asian/Pacific Islander, 14 (5\%) were Hispanic/Latino, two (0.7\%) were American Indian/Alaskan Native, and three (1\%) chose "other". Participants were able to choose more than one racial category. The racial makeup of the participants was comparable to the racial makeup of practicing school psychologists based on data from Curtis, Castillo, and Gelley (2010). (See Table 1.) 
Table 1

Racial Makeup of Participants (School Psychology Graduate Students) Compared to

Racial Makeup of School Psychologists Working in the Field in 2010

\begin{tabular}{lcc}
\hline \multicolumn{1}{c}{ Race } & $\begin{array}{c}\text { Participants (School } \\
\text { Psychology Graduate } \\
\text { Students) }\end{array}$ & $\begin{array}{c}\text { School Psychologists } \\
\text { Working in the Field in } \\
2010\end{array}$ \\
\hline Black/African American & $7 \%$ & $3 \%$ \\
Caucasian & $83 \%$ & $90.7 \%$ \\
American Indian/Alaska & $0.7 \%$ & $0.6 \%$ \\
Native & $6 \%$ & $1.3 \%$ \\
Asian/Pacific Islander & $5 \%$ & $3.4 \%$ \\
Hispanic & $1 \%$ & $1 \%$ \\
Other & & \\
\hline
\end{tabular}

Note. In this study, participants were able to choose more than one racial category. Therefore, the percentages add up to be more than 100 .

The majority of participants were in a Specialist in School Psychology program (102) whereas 98 were in a Ph.D. program, 35 in a Masters program, 23 in a Psy.D. program, and four chose "other". Sixty-five participants were first years, 68 were second years, 60 were third years, 15 were fourth years, 14 were fifth years, 20 were on internship, and 19 chose "other". (See Tables 2 and 3.) 
Table 2

Type of Program Participants Attended

\begin{tabular}{lcc}
\hline & Number of Participants & Percentage \\
\hline Masters Program & 35 & $13 \%$ \\
Specialist Program & 102 & $39 \%$ \\
Psy.D. Program & 23 & $9 \%$ \\
Ph.D. Program & 98 & $37 \%$ \\
Other & 4 & $2 \%$ \\
\hline
\end{tabular}

Table 3

Participants' Year in the Program

\begin{tabular}{lcc}
\hline & Number of Participants & Percentage \\
\hline $1^{\text {st }}$ Year & 65 & $25 \%$ \\
$2^{\text {nd }}$ Year & 68 & $26 \%$ \\
$3^{\text {rd }}$ Year & 60 & $23 \%$ \\
$4^{\text {th }}$ Year & 15 & $6 \%$ \\
$5^{\text {th }}$ Year & 14 & $5 \%$ \\
Intern & 20 & $8 \%$ \\
Other & 19 & $7 \%$ \\
\hline
\end{tabular}


Ninety-two participants attended a school in the Northeast. The Northeast region included the following states: Pennsylvania, Delaware, Maryland, New Jersey, Connecticut, New York, Vermont, New Hampshire, Massachusetts, Rhode Island, and Maine. Fifty-eight participants attended a school in the Midwest. States included in the Midwest region were: North Dakota, South Dakota, Nebraska, Minnesota, Iowa, Wisconsin, Illinois, Indiana, Michigan, and Ohio. Forty-eight participants attended a school in the Southeast. The Southeast region included the following states: Mississippi, Alabama, Georgia, Florida, Kentucky, Tennessee, West Virginia, Virginia, North Carolina, and South Carolina. Thirty-two participants attended a school in the Southwest. States included in the Southwest region were: New Mexico, Texas, Kansas, Oklahoma, Missouri, Arkansas, and Louisiana. Twenty-four participants attended a school in the Pacific. The Pacific region included the following states: Washington, Oregon, California, Idaho, Nevada, and Arizona. Nine participants attended a school in the Northwest. States included in the Northwest region were: Montana, Wyoming, Utah, and Colorado. (See Table 4.) 
Table 4

Regional Locations of the Programs Participants Attended

\begin{tabular}{lcc}
\hline & Number of Participants & Percentage \\
\hline Northeast Region & 92 & $35 \%$ \\
PA, DE, MD, NJ, CT, NY, & & \\
VT, NH, MA, RI, ME & & $22 \%$ \\
Midwest Region & 58 & \\
ND, SD, NE, MN, IA, WI, & $18 \%$ \\
IL, IN, MI, OH & & \\
Southeast Region & 48 & $12 \%$ \\
MS, AL, GA, FL, KY, TN, & & \\
WV, VA, NC, SC & & \\
Southwest Region & 32 & \\
NM, TX, KS, OK, MO, AR, & & \\
LA & & \\
Pacific Region & & \\
WA, OR, CA, ID, NV, AZ & & \\
Northwest Region & & \\
MT, WY, UT, CO & & \\
\hline
\end{tabular}


One hundred and twenty-four participants stated that the school they attended was both APA Accredited and NASP Approved. Ninety-nine participants attended a school that was only NASP Approved. Twenty-five participants attended a school that was only APA Accredited. Twelve participants attended a school that was neither APA Accredited nor NASP Approved. Three participants did not know the status of their school. (See Table 5.)

Table 5

Approval and/or Accreditation Status of the Programs Participants Attended

\begin{tabular}{lcc}
\hline & Number of Participants & Percentage \\
\hline APA Accredited Only & 24 & $9 \%$ \\
NASP Approved Only & 99 & $38 \%$ \\
Both APA Accredited and & 124 & $47 \%$ \\
NASP Approved & 12 & $5 \%$ \\
$\begin{array}{l}\text { Neither APA Accredited } \\
\text { or NASP Approved }\end{array}$ & & \\
Don't Know & 3 & $1 \%$ \\
\hline
\end{tabular}

\section{Procedures}

An email address for the School Psychology program director, program coordinator, or a faculty member was obtained for each of the graduate school, and a two-part email was sent to them (see Appendix B). The first part of the email was addressed to the School Psychology program director, program coordinator, or faculty member. It stated the purpose of the research, asked that they forward the email to their 
students, and asked that they reply stating how many students the email was forwarded to. Thirty-nine schools (16\%) responded to the email stating that they had forwarded it to their students. Out of the 39 schools, 26 also included an approximate number of students that they had forwarded it to - an overall total of approximately 1,020 students. Two hundred and sixty-three students participated in the study. Therefore, the response rate was $26 \%$.

The second part of the email was addressed to the graduate student. It stated the purpose of the research and the potential reward (i.e., a drawing for a Walmart gift card). It also included the hyperlink to the survey. The hyperlink took the participants to the consent form. (See Appendix K.) After clicking that they agreed to participate in the study, the participants were randomly assigned to one of four conditions: (1) average weight Black; (2) overweight Black; (3) average weight White; or (4) overweight White. There were two case studies for each condition.

Participants were first asked to read a case study about a student who was having difficulties in school. Each case study included a description and a photograph. (See Appendices $\mathrm{C}$ and D.) The case study was the same across conditions while the photograph was based on the specific condition. The student in case study displayed symptoms typical of ADHD. These symptoms were modeled after the descriptions found in the DSM-IV-TR (American Psychiatric Association, 2000). The participants were asked to imagine that they were employed as a school psychologist in the school the student in the case study attends. The participants (as the school psychologist) have 
requested a special education staffing with the student's teachers, the principal, and the social worker to discuss the potential causes of the student's problems.

After reading the case study, participants were asked to rate their impression of the student on five characteristics using 7-point scales. There were two characteristics on each scale, antonyms of each other. At the small end of the scale (1), the characteristic was positive. At the large end of the scale (7), the characteristic was negative. Sample characteristics included: Athletic (1) to Avoids physical activity (7) and Self-disciplined (1) and Poor self-disciplined (7). (The complete list is presented in Appendix D.)

Participants then rated on a 7-point Likert scale (1 - strongly disagree to 7 strongly agree) how much they agreed with statements pertaining to the perceived causes of the student's problem (e.g., This student does not try very hard.). (See Appendix D for the complete list.) Furthermore, the participants were asked to rank the different hypotheses for the student's behavior in the order that they would test them (e.g., Inadequate Instructional Practices by the Teacher). (The complete list is presented in Appendix D.)

Participants also completed the ADHD Rating Scale-IV (DuPaul, Power, Anastopoulos, \& Reid, 1998). It is a scale designed to diagnose ADHD in children and adolescents. Participants rated 18 statements on a 4-point scale (1 - Never or Rarely to 4 - Very Often) on their perception of the student's behavior based on what they read in the case study. Sample statements included: "Talks excessively" and "Is easily distracted". These statements are linked directly to DSM-IV diagnostic criteria for ADHD. 
Participants were then told that they were going to "switch gears" and rate the pleasantness of abstract paintings. The participants then completed the Affective Misattribution Procedure (AMP; Payne, Cheng, Govorun, \& Stewart, 2005), a process to measure implicit attitudes. Specific instructions to participants were:

Next, we are going to ask you to "SWITCH GEARS" and do something completely different. In the next few screens, your task is to judge the visual pleasantness of some abstract paintings. Individuals' reactions to abstract paintings vary widely: some people find them visually pleasant, while others don't. We are interested in your judgments of paintings under conditions of very brief exposure (1 second). You are about to see a series of abstract paintings that are presented very rapidly. After each painting, we will ask you to rate how pleasant or unpleasant you found it. Before each painting you will see a signal that the painting is about to appear. Each signal will be a different real-life photo. The real-life image simply will serve as a warning signal that the abstract painting is about to appear. You should do nothing with the signal image. Instead, your job will be to judge the visual pleasantness of each abstract painting. Remember that the real-life images just serve as warning signals. Please do not let them influence your judgments of the abstract paintings. Once you have made your rating, please click on the next button to see the next pair of pictures. Participants were shown "real-life" photographs of children. These photographs served as the warning signals. There were six average weight Black boys; six overweight Black 
boys; six average weight White boys; and six overweight White boys. All photographs were taken from public access web sites.

To control the length of time that the photographs were shown, Adobe video files were created. Each video file contained a real-life photograph that was displayed for one second followed by a photograph of an abstract painting which was also displayed for one second. The last screen of the video file read "Please Click Next" and stayed on the screen until the participants did so. Participants were then asked to rate the pleasantness of the abstract painting on a scale from Very Unpleasant to Very Pleasant. There was no neutral rating. Thus, participants had to choose between positive and negative ratings of the abstract paintings. (See Appendices E and F.)

In the $A M P$, there were four categories of children: (1) average weight Black; (2) overweight Black; (3) average weight White; and (4) overweight White. There were also four variations of each abstract painting: (1) normal; (2) flipped vertically; (3) flipped horizontally; and (4) flipped both vertically and horizontally. The flips were completed using Microsoft PowerPoint. Each category of children was paired with a different variation of the same abstract painting. Therefore, each category of children had the same abstract painting paired with it. For example, one set of children photographs (i.e., normal weight Black, overweight Black, normal weight White, and overweight White) had the same abstract painting assigned to it - just a different variation. The variations of the abstract paintings were randomly assigned to the children photographs to ensure that the same type of variation was not assigned to the same category of children (e.g., not 
every horizontally flipped abstract painting was assigned to every normal weight White boy).

Before the survey was launched, a pre-test was conducted. Results indicated that some participants were unable to view the Adobe video files depending on their level of computer security or version of Adobe. Therefore, an Adobe video question was added before the first AMP video file. The video question showed an elephant for one second followed by the screen "Please Click Next". The participants were then asked to identify the animal that they saw in the picture. If they answered correctly (i.e., elephant), they continued to the first AMP video file. If they answered incorrectly or that they did not see an animal, they were redirected to the next section - the Feeling Thermometers.

Participants then completed a series of Feeling Thermometers (Campbell, 1971) which measure explicit attitudes. (See Appendix G.) The Feeling Thermometers listed several different groups of people. The groups covered: (1) religion (e.g., Muslims and Jews); (2) race (e.g., Blacks and Whites); (3) weight (e.g., People who are Overweight and People with Eating Disorders); (4) sexual orientation (e.g., People who are Gay, Lesbian, Bisexual, Transgender, or Questioning); (5) disabilities (e.g., People with Intellectual Disabilities and People with Physical Disabilities); and (6) race plus weight (e.g., Overweight Blacks and Overweight Whites). Participants were instructed to indicate their feelings about these groups using a $0^{0}$ (extremely unfavorable feelings) to $100^{0}$ (extremely favorable feelings) scale.

After completing the Feeling Thermometers, participants completed two motivation to control prejudice scales. The first scale was the Motivation to Control 
Black Prejudice Scale (MTCBP; Plant \& Devine, 1998). This scale contained statements that concerned reasons/motivations that people may have for trying to control their prejudice towards Black people. Participants were asked to rate on a 7-point Likert scale (1 - strongly disagree to 7 - strongly agree) how much they agreed with each statement. These motivations can be internal (e.g., I attempt to act in non-prejudiced ways towards Black people because it is personally important to me.) or external (e.g., I try to hide any negative thoughts about Black people in order to avoid negative reactions from others.). Item number 5 was recoded to keep the ratings consistent.

The second scale was the Motivation to Control Weight-Related Prejudice Scale (MTCWP; Pryor, Reeder, Yeadon, \& Hesson-McInnis, 2004) which was adapted using the Motivation to Control Race-Related Prejudice Scale (Plant \& Devine, 1998). (See Appendix H.) This scale contained statements that concerned reasons/motivations that people may have for trying to control their prejudice towards people who are overweight, and participants rated on a 7-point Likert scale $(1-$ strongly disagree to 7 - strongly agree) how much they agreed with these statements. These motivations can be internal (e.g., Because of my personal values, I believe that using stereotypes about overweight people is wrong.) or external (e.g., I appear to be non-prejudiced towards fat people in order to avoid disapproval from others.). Item number 5 was recoded to keep the ratings consistent.

Participants then completed two questionnaires about their graduate training relating to multicultural issues/groups. The first questionnaire was a shortened version of the Multicultural Education Inventory (MEI: Pope-Davis, Liu, Nevitt, \& Toporek, 2000). 
The $M E I$ is an instrument designed to measure an individual's perceptions about the degree to which their graduate program address multicultural issues within curriculum, supervision, climate, and research. The original questionnaire contained 27 statements. However, it was shortened to 13 statements to keep the questionnaire relevant to the current study.

The MEI covered four areas: (1) Curriculum and Supervision; (2) Climate and Comfort; (3) Honesty in Recruitment; and (4) Multicultural Research (Pope-Davis, Liu, Nevitt, \& Toporek, 2000). However, only the statements under the Curriculum and Supervision and the Multicultural Research areas were included. The areas of Climate and Comfort and Honesty in Recruitment were not relevant to the current study.

Statements included under Curriculum and Supervision included: "All courses and research conducted by faculty address, at least minimally, how the topic affects diverse populations." and "Multicultural issues are considered an important component in supervision." Multicultural Research statements included: "There is at least one person whose primary research interest is in multicultural issues." and "Faculty members are doing research in multicultural issues."

The second questionnaire (the Diversity Exposure Questionnaire; DEQ) was created to determine the type of exposure students received during their graduate training for different multicultural groups. (See Appendix I.) The groups of people listed in this questionnaire were the same groups listed in the Feeling Thermometers. There were six types of exposure: (1) Case-Centered Presentations; (2) Didactic Seminars; (3) Discussions; (4) Experiential Exercises; (5) Outside/Invited Speakers; and (6) Readings. 
There was also a N/A (Not Applicable) choice. Participants were asked to indicate the area(s) in which the different groups were covered during their graduate training. They were able to choose more than one area.

Finally, participants completed an in-depth demographics questionnaire about themselves, their graduate program, and their experience with multicultural groups. (See Appendix J.) Questions about themselves included: gender; age; race; nationality; and religious affiliation. Questions about their graduate program included: class level; year in program; graduate program type (e.g., APA Accredited or NASP Approved); and location of graduate program. Questions about their experience with multicultural groups included: whether or not they have worked in a school; for how long; and the racial/ethnic make-up of the students in that school. Afterwards, participants read the debriefing statement and were given the opportunity to enter a drawing for one of four $\$ 50$ Walmart gift cards. (See Appendices L and M.) This drawing was optional. Out of the 263 participants, 110 (42\%) entered the drawing. Participants' chances of winning the drawing were 1 out of 28. 


\section{CHAPTER V}

\section{RESULTS}

There were many measures assessed in this study. Some were intended to be dependent variables and others were assessed as potential moderators. The Results Section will begin with an overview of the different measures. First, descriptive analyses of the dependent variables will be presented followed by descriptive analyses of the potential moderator variables. Then, we will go on to analyses of the potential connections of the manipulated variables to the dependent variables and the roles of moderator variables. Across all these analyses, we focused only upon participants who identified themselves as White, Non-Hispanic.

\section{Dependent Variables}

In this study, we were interested in participants' impressions of the student in the case study regarding laziness and ADHD. Therefore, our primary dependent variables were those related to laziness and ADHD. The student was depicted in a photograph as either White or Black and either average weight or overweight. We were interested in examining the extent to which implicit and/or explicit attitudes of school psychology graduate students moderated the degree to which they attributed negative personality traits and work habits (i.e., laziness) to Black and overweight students who showed symptoms of ADHD. We were also interested in examining the potential moderating roles of motivations to control race-related and weight-related prejudice in the 
relationships between race-related and weight-related attitudes and participants' impressions of the student. Finally, we were also interested in exploring how graduate training experiences might also moderate these relationships.

The dependent variables related to laziness included: (1) Hardworking to Lazy rated on a 7-point scale (referred to as Work Skills), (2) Motivated to Unmotivated rated on a 7-point scale (referred to as Motivation), (3) This student does not try very hard rated on a 7 -point Likert scale ( 1 - strongly disagree to 7 - strongly agree; referred to as Does Not Try Hard), (4) This student is lazy rated on a 7 point Likert scale (1 - strongly disagree to 7 - strongly agree; referred to as Lazy), (5) the Rank of Lack of Motivation ranked on a 6-point scale ( 1 - hypothesis to be tested first to 6 - hypothesis to be tested sixth/last), (6) the Rank of Laziness ranked on a 6-point scale (1 - hypothesis to be tested first to 6 - hypothesis to be tested sixth/last), and (7) the Laziness Index (to be discussed later).

The dependent variables related to ADHD included: (1) This student has symptoms of Attention Deficit Hyperactivity Disorder (ADHD) rated on a 7-point Likert scale (1 - strongly disagree to 7 - strongly agree; referred to as ADHD Symptom), (2) the Rank of $A D H D$ ranked on a 6-point scale (1 - hypothesis to be tested first to 6 hypothesis to be tested sixth/last), and (3) the ADHD Rating Scale-IV (to be discussed later; referred to as ADHD Scale).

Other dependent variables included: (1) the Rank of Inadequate Instruction, (2) the Rank of Lack of Parental Support, and (3) the Rank of ODD - all ranked on a 6-point scale ( 1 - hypothesis to be tested first to 6 - hypothesis to be tested sixth/last). These 
were included as dependent variables given that they are part of a list that includes variables related to laziness and ADHD.

\section{Laziness Index}

The primary dependent variable in this study concerned participants' ratings of laziness as an explanation for the student's problems in the case studies they read. In order to simplify data analyses, we converted all ratings of laziness contributed to the student in the case study into standard scores. Then, we computed a laziness index by averaging the ratings of these standard scores. Included in the Laziness Index were four impression scales: (1) Hardworking to Lazy rated on a 7-point scale, (2) Motivated to Unmotivated rated on a 7-point scale, (3) This student does not try very hard rated on a 7point Likert scale (1 - strongly disagree to 7 - strongly agree), and (4) This student is lazy rated on a 7-point Likert scale ( 1 - strongly disagree to 7 - strongly agree). The items on this Laziness Index showed sufficient reliability $(\alpha=.79)$.

\section{ADHD Rating Scale-IV}

The ADHD Rating Scale-IV (DuPaul, Power, Anastopoulos, \& Reid, 1998) is a scale used to diagnose ADHD in children and adolescents. Participants rated 18 statements on a 4-point scale on their perception of the student's behavior based on what they read in the case study. These statements are linked directly to DSM-IV diagnostic criteria for ADHD. Internal consistency for this scale showed sufficient reliability $(\alpha=.86)$. 


\section{Correlations between Dependent Variables}

We examined the correlations between each of the dependent variables to determine which variables were similar. Only the Laziness Index will be described in this section given that it is our primary dependent. However, the complete list can be found in Table 6. The Laziness Index was correlated with four other dependent variables. They included: (1) the Rank of Laziness, $r(187)=-.22, p=.002,(2)$ the Rank of Lack of Motivation, $r(187)=-.40, p<.001$, (3) the Rank of ADHD, $r(187)=.27, p<.001$, and (4) the Rank of Inadequate Instruction, $r(187)=.34, p<.001$.

Table 6

Correlations between Dependent Variables

\begin{tabular}{|c|c|c|c|c|c|c|c|c|c|c|c|c|c|}
\hline & 1 & 2 & 3 & 4 & 5 & 6 & 7 & 8 & 9 & 10 & 11 & 12 & 13 \\
\hline $\begin{array}{l}1 . \\
\text { Lazi- } \\
\text { ness } \\
\text { Index }\end{array}$ & --- & $\begin{array}{l}758 \\
* * *\end{array}$ & $\begin{array}{l}790 \\
* * *\end{array}$ & $\begin{array}{l}837 \\
* * *\end{array}$ & $\begin{array}{l}757 \\
* * *\end{array}$ & 048 & 022 & $\begin{array}{c}224 \\
* *\end{array}$ & $\begin{array}{c}- \\
\\
403 \\
* * *\end{array}$ & $\begin{array}{l}271 \\
* * *\end{array}$ & 007 & $\begin{array}{l}340 \\
* * *\end{array}$ & $\begin{array}{c}- \\
057\end{array}$ \\
\hline 2. Lazy & $\begin{array}{r}. \\
758 \\
* * *\end{array}$ & --- & $\begin{array}{l}519 \\
* * *\end{array}$ & $\begin{array}{l}531 \\
* * *\end{array}$ & $\begin{array}{l}345 \\
* * *\end{array}$ & $\begin{array}{c}- \\
082\end{array}$ & 012 & $\begin{array}{l}333 \\
* * *\end{array}$ & $\begin{array}{c}- \\
. \\
197 \\
* *\end{array}$ & $\begin{array}{c}158 \\
*\end{array}$ & 068 & $\begin{array}{l}335 \\
* * *\end{array}$ & $\begin{array}{c}- \\
044\end{array}$ \\
\hline $\begin{array}{l}3 . \\
\text { Does } \\
\text { Not } \\
\text { Try } \\
\text { Hard }\end{array}$ & $\begin{array}{l}790 \\
* * *\end{array}$ & $\begin{array}{c}\dot{519} \\
* * *\end{array}$ & --- & $\begin{array}{l}493 \\
* * *\end{array}$ & $\begin{array}{l}484 \\
* * *\end{array}$ & $\begin{array}{c}- \\
. \\
* \\
*\end{array}$ & - & $\begin{array}{c}179 \\
* *\end{array}$ & $\begin{array}{c}- \\
\dot{3} \\
* * 3 \\
* *\end{array}$ & $\begin{array}{l}223 \\
* * *\end{array}$ & 128 & $\begin{array}{l}225 \\
* * *\end{array}$ & $\begin{array}{c}- \\
075\end{array}$ \\
\hline $\begin{array}{l}4 . \\
\text { Work } \\
\text { Skills }\end{array}$ & $\begin{array}{l}837 \\
* * *\end{array}$ & $\begin{array}{l}531 \\
* * *\end{array}$ & $\begin{array}{c}\dot{ } \\
493 \\
* * *\end{array}$ & --- & $\begin{array}{l}581 \\
* * *\end{array}$ & 035 & 040 & 130 & $\begin{array}{c}298 \\
* * *\end{array}$ & $\begin{array}{c}183 \\
* *\end{array}$ & 061 & $\begin{array}{l}249 \\
* * *\end{array}$ & $\dot{003}$ \\
\hline
\end{tabular}




\begin{tabular}{|c|c|c|c|c|c|c|c|c|c|c|c|c|c|}
\hline & 1 & 2 & 3 & 4 & 5 & 6 & 7 & 8 & 9 & 10 & 11 & 12 & 13 \\
\hline $\begin{array}{l}5 . \text { Moti- } \\
\text { vation }\end{array}$ & $\begin{array}{c}\cdot \dot{757} \\
* * *\end{array}$ & $\begin{array}{l}345 \\
* * *\end{array}$ & $\begin{array}{l}484 \\
* * *\end{array}$ & $\begin{array}{c}\dot{581} \\
* * *\end{array}$ & --- & 016 & 057 & $\begin{array}{c}- \\
089\end{array}$ & $\begin{array}{c}- \\
\dot{4} \\
\dot{4} 7 \\
* * *\end{array}$ & $\begin{array}{l}282 \\
* * *\end{array}$ & $\begin{array}{c}- \\
025\end{array}$ & $\begin{array}{l}230 \\
* * *\end{array}$ & $\begin{array}{c}- \\
003\end{array}$ \\
\hline $\begin{array}{l}6 . \\
\text { ADHD } \\
\text { Symp- } \\
\text { tom }\end{array}$ & $\begin{array}{c}- \\
048\end{array}$ & $\begin{array}{c}- \\
082\end{array}$ & $\begin{array}{c}- \\
\dot{150} \\
*\end{array}$ & 035 & 016 & --- & $\begin{array}{l}318 \\
* * *\end{array}$ & $\begin{array}{c}214 \\
* *\end{array}$ & $\begin{array}{c}183 \\
* *\end{array}$ & $\begin{array}{c}- \\
\text {. } \\
471 \\
* * *\end{array}$ & $\begin{array}{c}- \\
122\end{array}$ & $\begin{array}{c}170 \\
*\end{array}$ & $\begin{array}{c}152 \\
*\end{array}$ \\
\hline $\begin{array}{l}7 . \\
\text { ADHD } \\
\text { Scale }\end{array}$ & $\dot{022}$ & 012 & $\begin{array}{c}- \\
048\end{array}$ & $\begin{array}{c}- \\
040\end{array}$ & 057 & $\begin{array}{l}318 \\
* * *\end{array}$ & --- & 002 & $\begin{array}{l}228 \\
* * *\end{array}$ & $\begin{array}{c}- \\
. \\
317 \\
* * *\end{array}$ & $\begin{array}{c}- \\
033\end{array}$ & $\begin{array}{l}226 \\
* * *\end{array}$ & - \\
\hline $\begin{array}{l}\text { 8. Rank } \\
\text { Lazi- } \\
\text { ness }\end{array}$ & $\begin{array}{c}- \\
\dot{244} \\
* *\end{array}$ & $\begin{array}{c}- \\
. \\
333 \\
* * *\end{array}$ & $\begin{array}{c}- \\
. \\
179 \\
* *\end{array}$ & $\begin{array}{c}- \\
\dot{130}\end{array}$ & 089 & $\begin{array}{c}214 \\
* *\end{array}$ & 002 & --- & $\begin{array}{l}269 \\
* * *\end{array}$ & $\begin{array}{c}- \\
318 \\
* * *\end{array}$ & $\begin{array}{c}- \\
\dot{4} \\
\dot{4} 7 \\
* * *\end{array}$ & $\begin{array}{c}- \\
\text { - } \\
337 \\
* * *\end{array}$ & $\begin{array}{c}- \\
\dot{2} \\
* * * \\
* *\end{array}$ \\
\hline $\begin{array}{l}\text { 9. Rank } \\
\text { Lack of } \\
\text { Moti- } \\
\text { vation }\end{array}$ & $\begin{array}{c}- \\
. \\
403 \\
* * *\end{array}$ & $\begin{array}{c}- \\
. \\
197 \\
* *\end{array}$ & $\begin{array}{c}- \\
\text { - } \\
343 \\
* * *\end{array}$ & $\begin{array}{c}- \\
. \\
298 \\
* * *\end{array}$ & $\begin{array}{l}467 \\
* * *\end{array}$ & $\begin{array}{c}183 \\
* *\end{array}$ & $\begin{array}{l}228 \\
* * *\end{array}$ & $\begin{array}{l}269 \\
* * *\end{array}$ & --- & $\begin{array}{c}- \\
\text {. } \\
502 \\
* * *\end{array}$ & $\begin{array}{c}- \\
\dot{2} 33 \\
* * *\end{array}$ & $\begin{array}{c}- \\
\dot{2} \\
299 \\
* * *\end{array}$ & $\begin{array}{c}- \\
. \\
190 \\
* *\end{array}$ \\
\hline $\begin{array}{l}10 . \\
\text { Rank } \\
\text { ADHD }\end{array}$ & $\begin{array}{l}\dot{271} \\
* * *\end{array}$ & $\begin{array}{c}158 \\
*\end{array}$ & $\begin{array}{l}223 \\
* * *\end{array}$ & $\begin{array}{c}183 \\
* *\end{array}$ & $\begin{array}{l}282 \\
* * *\end{array}$ & $\begin{array}{l}\dot{4} \dot{11} \\
* * *\end{array}$ & $\begin{array}{l}317 \\
* * *\end{array}$ & $\begin{array}{l}318 \\
* * *\end{array}$ & $\begin{array}{c}- \\
. \\
502 \\
* * *\end{array}$ & --- & 108 & $\begin{array}{c}- \\
\dot{2} \\
274 \\
* * *\end{array}$ & $\begin{array}{c}- \\
\text {. } \\
316 \\
* * *\end{array}$ \\
\hline $\begin{array}{l}11 . \\
\text { Rank } \\
\text { ODD }\end{array}$ & $\begin{array}{c}- \\
007\end{array}$ & $0 \dot{6} 8$ & $\dot{128}$ & $\begin{array}{c}- \\
061\end{array}$ & $\begin{array}{c}- \\
025\end{array}$ & $\dot{-}$ & $\begin{array}{c}- \\
033\end{array}$ & $\begin{array}{c}- \\
\dot{4} \\
447 \\
* * *\end{array}$ & $\begin{array}{c}- \\
\dot{2} \\
\dot{2} 3 \\
* * *\end{array}$ & $\dot{108}$ & --- & 019 & $\begin{array}{c}- \\
214 \\
* *\end{array}$ \\
\hline
\end{tabular}




\begin{tabular}{|c|c|c|c|c|c|c|c|c|c|c|c|c|c|}
\hline & 1 & 2 & 3 & 4 & 5 & 6 & 7 & 8 & 9 & 10 & 11 & 12 & 13 \\
\hline $\begin{array}{l}12 . \\
\text { Rank } \\
\text { Inade- } \\
\text { quate } \\
\text { Instruc- } \\
\text { tion }\end{array}$ & $\begin{array}{l}340 \\
* * *\end{array}$ & $\begin{array}{l}335 \\
* * *\end{array}$ & $\begin{array}{l}225 \\
* * *\end{array}$ & $\begin{array}{l}249 \\
* * *\end{array}$ & $\begin{array}{l}230 \\
* * *\end{array}$ & $\begin{array}{c}170 \\
*\end{array}$ & $\begin{array}{l}226 \\
* * *\end{array}$ & $\begin{array}{l}337 \\
* * *\end{array}$ & $\begin{array}{c}- \\
\dot{2} \\
\dot{2} 9 \\
* * *\end{array}$ & $\begin{array}{l}274 \\
* * *\end{array}$ & 019 & --- & 038 \\
\hline $\begin{array}{l}13 . \\
\text { Rank } \\
\text { Lack of } \\
\text { Paren- } \\
\text { tal Sup- } \\
\text { port }\end{array}$ & $0 \dot{5} 7$ & 044 & $\begin{array}{c}- \\
075\end{array}$ & 003 & $\begin{array}{c}- \\
0 \\
003\end{array}$ & $\begin{array}{c}152 \\
*\end{array}$ & $\begin{array}{c}- \\
012\end{array}$ & $\begin{array}{c}- \\
\dot{2} 20 \\
* * *\end{array}$ & $\begin{array}{c}- \\
\dot{190} \\
* *\end{array}$ & $\begin{array}{c}- \\
316 \\
* * *\end{array}$ & $\begin{array}{c}- \\
214 \\
* *\end{array}$ & 038 & --- \\
\hline
\end{tabular}

$* p<.05 . * * p<.01 . * * * p<.001$

\section{Measures of Implicit and Explicit Attitudes}

The pleasantness ratings of the abstract paintings were used as indices of implicit attitudes regarding the three social groups whose photographs preceded them: (1) average weight Black boys, (2) average weight White boys, and (3) overweight White boys. Internal consistency of the abstract paintings pleasantness ratings within each category showed sufficient reliability (average weight Black boys $\alpha=.92$, average weight White boys $\alpha=.91$, and overweight White boys $\alpha=.92$ ). Results indicated that there was a significant difference between participants' implicit ratings of Black and White average weight boys, $F(1,205)=35.36, p<.001$. Participants generally showed an implicit proBlack bias. They rated the pleasantness of the abstract paintings higher when they appeared after photographs of average weight Black boys compared to photographs of average weight White boys, $M(206)=3.92, S D=.82$ versus $M(206)=3.75, S D=.74$. 
There was also a significant difference between participants' implicit ratings of White average weight and overweight boys, $F(1,202)=32.92, p<.001$. Participants generally showed an implicit anti-fat bias. They rated the pleasantness of the abstract paintings lower when they appeared after overweight White boys compared to photographs of average weight White boys, $M(206)=3.52, S D=.82$ versus $M(206)=3.75, S D=.74$.

It was decided to use the average weight White boys as a baseline control. Therefore, to explore implicit racial attitudes, the mean ratings of the average weight Black boys were subtracted from the mean ratings of the average weight White boys. To explore implicit weight attitudes, the mean ratings of the overweight White boys were subtracted from the mean ratings of the average weight White boys.

Turning to explicit attitudes, participants rated Black People, White People, People who are Overweight, Overweight Black People, and Overweight White People on $0^{\circ}$ (Extremely Unfavorable Feelings) to $100^{\circ}$ (Extremely Favorable Feelings) feeling thermometers. Results indicated that there was a significant difference between participants' explicit ratings of average weight White People and overweight White People, $F(1,197)=161.23, p<.001$. Participants showed an explicit anti-fat bias. Their ratings of overweight White People were significantly lower than those of average weight White People, $M(201)=6.08, S D=1.89$ versus $M(201)=7.70, S D=1.73$. However, there was no significant difference between participants' explicit ratings of average weight White People and average weight Black People, $F(1,197)=2.14, p=.145$. So, while the feeling thermometers indicated an explicit weight bias, they did not indicate an explicit race bias. 
Comparing to implicit attitude indices, an analogous set of difference scores were used as indices of explicit attitudes. Feeling thermometer ratings of White People were considered the baseline. Feeling thermometer ratings of Black People were subtracted from the baseline to measure explicit race-related attitudes. Feeling thermometer ratings of Overweight White People were subtracted from the baseline to measure explicit weight- related attitudes.

\section{Measures of Motivation to Control Prejudice}

For this study, two measures of motivation to control prejudice were used: the Motivation to Control Black Prejudice Scale (MTCBP; Plant \& Devine, 1998) and the Motivation to Control Weight-Related Prejudice Scale (MTCWP; Pryor, Reeder, Yeadon, \& Hesson-McInnis, 2004). Each measure contained two types of motivation: internal and external. There were five items for each type of motivation. Internal consistency for the MTCBP scale showed sufficient reliability (internal $\alpha=.76$ and external $\alpha=.86$ ). Internal consistency for the MTCWP scale also showed sufficient reliability (internal $\alpha=$ .85 and external $\alpha=.89$ ).

\section{Measures of Graduate Training Experiences}

Two measures of graduate training experiences were used in this study. The first measure was the Multicultural Education Inventory (MEI: Pope-Davis, Liu, Nevitt, \& Toporek, 2000). It was designed to measure students' perceptions of how well their graduate program address multicultural concerns. Thirteen of the twenty-seven statements from this inventory were used in this study. Internal consistency for the $M E I$ showed sufficient reliability $(\alpha=.88)$. The second measure of graduate training 
experience was the Diversity Exposure Questionnaire (DEQ). It was created to determine the type of exposure students received during their graduate training for different multicultural groups. Internal consistency for the $D E Q$ also showed sufficient reliability $(\alpha=.92)$.

\section{Were the Potential Moderator Variables Related to the Manipulations?}

One of the goals of this research was to examine the roles of various potential moderators in the relationships between the manipulations of race and weight to the dependent variables. For example, we wanted to assess how race and weight-related attitudes might moderate the degree to which the case study manipulations might affect participants' judgments of laziness. We also wanted to assess motivations to control prejudice as second order moderators - for example, would participants with low motivations to control prejudice manifest more consistency between their attitudes and attributions about laziness? In addition, we wanted to explore the role educational experiences have as moderators in these relationships. By definition, measures of moderator variables represent individual differences, and therefore, they should not be influenced by any of the manipulations that we implemented. Since the measures of the potential moderators were assessed after the manipulations occurred, it was important to establish that the moderator measures were not reactive to the manipulations. The potential moderator variables of interest for this study were participants' implicit and explicit race and weight-related attitudes, participants' motivations to control racial and weight-related prejudices, and participants' graduate training related to multicultural concerns/groups. 
To ensure that these variables were not influenced by our manipulations, a multivariate analysis of variance was conducted where the case study manipulations were used as independent variables. Results indicated that there were no significant differences in any of the implicit attitudes with regard to the case study manipulation by race: (1) average weight Black Boys, $F(1,202)=.27, p=.605 ; M(99)=3.95, S D=.75$ for the White case study versus $M(107)=3.89, S D=.87$ for the Black case study, (2) average weight White Boys, $F(1,202)=.01, p=.948 ; M(99)=3.75, S D=.70$ for the White case study versus $M(107)=3.75, S D=.77$ for the Black case study, and (3) overweight White Boys, $F(1,202)=.02, p=.900 ; M(99)=3.53, S D=.82$ for the White case study versus $M(107)=3.51, S D=.82$ for the Black case study.

There were also no significant differences in any of the implicit attitudes with regard to the case study manipulation by weight: (1) average weight Black Boys, $F(1$, $202)=.11, p=.736 ; M(107)=3.94, S D=.82$ for the average weight case study versus $M(99)=3.90, S D=.81$ for the overweight case study, (2) average weight White Boys, $F(1,202)=.05, p=.831 ; M(107)=3.76, S D=.73$ for the average weight case study versus $M(99)=3.74, S D=.75$ for the overweight case study, and (3) overweight White Boys, $F(1,202)=.36, p=.549 ; M(107)=3.56, S D=.75$ for the average weight case study versus $M(99)=3.48, S D=.90$ for the overweight case study. Given that there were no significant differences for any of the implicit attitudes, they can serve as moderator variables.

For explicit attitudes, results indicated that there were no significant differences with regard to the case study manipulation by race: (1) average weight Black People, $F(1$, 
$197)=.02, p=.902,(2)$ average weight White People, $F(1,197)=.78, p=.377$, and (3) overweight White People, $F(1,197)=.11, p=.742$. Results also indicated that there were no significant differences in any of the explicit attitudes with regard to the case study manipulation by weight: (1) average weight Black People, $F(1,197)=.34, p=$ .563, (2) average weight White People, $F(1,197)=3.23, p=.074$, and (3) overweight White People, $F(1,197)=.31, p=.581$. The explicit attitudes can serve as moderator variables given that there were no significant differences with regard to the case study manipulations.

This study included two measures of motivations to control prejudice: race and weight-related. For the motivations to control Black prejudice, results indicated that there were no significant differences with regard to the case study manipulation by race: Internal Motivation, $F(1,191)=.95, p=.330$, and External Motivation, $F(1,191)=1.40$, $p=.239$. There was also no significant difference with regard to the case study manipulation by weight for Internal Motivation, $F(1,191)=.64, p=.424$. However, results indicated that there was a significant difference with regard to the case study manipulation by weight for External Motivation, $F(1,191)=4.35, p=.038$. Therefore, both Internal and External Motivations can potentially serve as moderator variables when examining the race manipulation of the case study. However, only the Internal Motivation can potentially serve as a moderator variable for the weight manipulation of the case study given that the External Motivation was affected by our manipulations.

For the motivations to control weight prejudice, results indicated that there were no significant differences with regard to the case study manipulation by race: Internal 
Motivation, $F(1,191)=.01, p=.978$, and External Motivation, $F(1,191)=.95, p=.331$. Results also indicated that there were no significant differences with regard to the case study manipulation by weight: Internal Motivation, $F(1,191)=.02, p=.877$, and External Motivation, $F(1,191)=.86, p=.355$. Given that there were no significant differences for the motivations to control weight prejudice, they can serve as moderator variables. However, since the external motivation to control Black prejudice for the weight manipulation of the case study cannot be used as a moderator, to keep things consistent, the external motivation to control weight prejudice for the weight manipulation of the case study will also not be used.

Two questionnaires were used to examine participants' exposure to multicultural concerns/groups in their graduate training: the Multicultural Education Inventory (MEI) and the Diversity Exposure Questionnaire (DEQ). For the MEI, results indicated that there was no significant difference with regard to the case study manipulation by race, $F(1,188)=.16, p=.694$. However, there was a significant difference with regard to the case study manipulation by weight, $F(1,188)=4.67, p=.032$. For the DEQ, results indicated that there was a significant difference with regard to the case study manipulation by race, $F(1,188)=6.38, p=.012$. However, there was no significant difference with regard to the case study manipulation by weight, $F(1,188)=2.71, p=$ .101. Thus, both of these measures were reactive to the manipulations and cannot properly be considered as potential moderator variables. 


\section{Moderation Analyses}

To determine whether the manipulations affected ratings of laziness and the potential roles of moderator variables, we conducted a series of hierarchical multiple regression analyses following the guidelines in Baron and Kenny (1986). Similar analyses were performed for each of the various dependent variables (Laziness Index, ADHD Symptom, the Rank of Lack of Motivation, the Rank of ADHD, the Rank of ODD, the Rank of Inadequate Instruction, and the Rank of Lack of Parental Support). A separate analysis was performed for implicit and explicit measures of both race-related and weight-related attitudes. Internal motivations to control prejudice were examined as second order moderators in conjunction with each of the attitude measures. Results will be presented by dependent variable.

\section{Laziness Index}

We used a regression approach to assess moderation. A hierarchical multiple regression analysis was used to examine the impact of the case study manipulations upon the Laziness Index ratings and to test the role of implicit race-related attitudes as a potential moderator of these manipulations. On the first step, the race and weight manipulations (scored -1 and +1 ) were entered along with the centered scores on the centered AMP index of implicit race-related attitudes. On the second step, the products representing the two-way interactions of these variables were entered. On the third step, the three-way interaction was entered. Table 7 shows the results of this analysis. 
Table 7

Hierarchical Multiple Regression Analyses Predicting the Laziness Index with Race of Child, Weight of Child, and Implicit Race-Related Attitudes (Moderator)

\begin{tabular}{lcc}
\hline \multicolumn{1}{c}{ Predictor } & $\Delta \mathrm{R}^{2}$ & $\beta$ \\
\hline Step 1 & .013 & \\
Race of Child (R) & .039 \\
Weight of Child (W) & .074 \\
Implicit Race-Related Attitudes (IRA) & .077 \\
Step 2 & .040 & \\
R X W & & .005 \\
R X IRA & & $.146^{*}$ \\
W X IRA & & $.154^{*}$ \\
Step 3 & & \\
R X W X IRA & .004 & .067 \\
\hline
\end{tabular}

$* p<.05$.

As shown in Table 7, significant interactions were detected between each manipulated variable and the measure of implicit race-related attitudes. These two-way interactions indicated that implicit race-related attitudes moderated the impact of each manipulation upon the Laziness Index. When the photograph of the student described in the case study was Black, participants who held more implicit anti-Black attitudes perceived the student's problems as more a function of his laziness, $r(95)=.20, p=.05$. When the student was White, implicit race-related attitudes were unrelated to perceiving 
the student to be lazy, $r(92)=-.04, p=.68 ; z=1.63, p=.05$, one-tailed test. This finding is consistent with the hypothesis that implicit race-related attitudes influenced the interpretation of the student's symptoms and school problems when he was Black.

Another finding shown in Table 7 is that implicit race-related attitudes also seemed to moderate the impact of the weight manipulation upon the Laziness Index. When the student was overweight, participants with more implicit anti-Black attitudes rated him as more lazy, $r(89)=.24, p=.03$. When the student was average weight, implicit race-related attitudes were unrelated to perceiving the student to be lazy, $r(98)=$ $-.05, p=.62 ; z=1.98, p=.05$. Since the three-way interaction was not significant, this latter result suggests that regardless of whether the student was Black or White, implicit race-related attitudes moderated the impact of the weight manipulation upon the ratings of the Laziness Index. While it was predicted that implicit race-related attitudes would moderate the relationship between race manipulation and participants' scores on the Laziness Index, that implicit race-related attitudes would also moderate the relationship of the weight manipulation and scores on the Laziness Index was not predicted.

A series of similar hierarchical multiple regression analyses was also used to examine the roles of implicit weight-related attitudes, explicit race-related attitudes, and explicit weight-related attitudes as potential moderators of the relationships between race and weight manipulations and the Laziness Index. None of the interactions relevant to moderation were significant.

Prior research has shown that motivations to control prejudice can interact with implicit racial attitudes in predicting explicit expressions of racial attitudes (Payne et al., 
2005). To examine similar predictions, a hierarchical multiple regression analysis was used to test the combined roles of Internal Motivations to Control Black Prejudice (IMTCBP) and implicit race-related attitudes as potential moderators of the race and weight manipulations upon the Laziness Index ratings. On the first step, the race and weight manipulations (scored -1 and +1 ) were entered along with the centered scores on the centered AMP index of implicit race-related attitudes and the centered IMTCBP. On the second step, the products representing the two-way interactions of these variables were entered. On the third step, the three-way interactions were entered. On the fourth step, the four-way interaction was entered. Table 8 shows the results of this analysis. 
Table 8

Hierarchical Multiple Regression Analyses Predicting the Laziness Index with Race of

Child, Weight of Child, Implicit Race-Related Attitudes, and Internal Motivation to

Control Black Prejudice (Moderator)

\begin{tabular}{lcc}
\hline \multicolumn{1}{c}{ Predictor } & $\Delta \mathrm{R}^{2}$ & $\beta$ \\
\hline Step 1 & .013 & \\
Race of Child (R) & .038 \\
Weight of Child (W) & .073 \\
Implicit Race-Related Attitudes (IRA) & .079 \\
Internal Motivation to Control Black Prejudice & .017 \\
(IMTCP_B)
\end{tabular}

Step 2

.054

R X W

.010

R X IRA

.142

R X IMTCP_B

$-.083$

W X IRA

.141

W X IMTCP_B

$-.045$

IRA X IMTCP_B

.080

Step 3

.036

R X W X IRA

.003

R X W X IMTCP B

.038

R X IRA X IMTCP_B

$.197 *$

W X IRA X IMTCP_B

.115 


\begin{tabular}{|c|c|c|}
\hline Predictor & $\Delta \mathrm{R}^{2}$ & $\beta$ \\
\hline Step 4 & .000 & \\
\hline R X W X IRA X IMTCP_B & & -.007 \\
\hline
\end{tabular}

$* p<.05$.

As shown in Table 8, results indicated a significant three-way interaction. This three-way interaction indicated that IMTCBP (Internal Motivations to Control Black Prejudice) and implicit race-related attitudes moderated the impact of the race manipulation upon the Laziness Index. In order to try to gain a better understanding of the meaning of the three-way interaction, a median split was used to divide the participants into high and low IMTCBP groups. When the student in the case study was Black and participants had high IMTCBP, those participants who held more implicit antiBlack attitudes perceived the student's problems as more a function of his laziness, $r(50)$ $=.43, p=.002$. When the student in the case study was Black and participants had low IMTCBP, those participants who held more implicit anti-Black race-related attitudes were unrelated to perceiving the student to be lazy, $r(45)=-.20, p=.20$. Further, when the student was White, implicit race-related attitudes were unrelated to perceiving the student to be lazy regardless of participants' IMTCBP level: low IMTCBP, $r(49)=.01, p$ $=.99$, and high IMTCBP, $r(43)=-.08, p=.61$. This finding is inconsistent with the hypothesis that implicit race-related attitudes influenced the interpretation of the student's symptoms and school problems when he was Black and participants had low internal motivations to control prejudice. 
A similar hierarchical multiple regression analysis was also used to examine the potential moderating role of Internal Motivations to Control Weight Prejudice (IMTCWP). On the first step, the race and weight manipulations (scored -1 and +1$)$ were entered along with the centered scores on the centered AMP index of implicit weightrelated attitudes and the IMTCWP. On the second step, the products representing the two-way interactions of these variables were entered. On the third step, the three-way interaction was entered. On the fourth step, the four-way interaction was entered. None of these interactions were significant.

To examine the impact of the case study manipulations upon the Laziness Index ratings and to test the combined roles of IMTCBP and explicit race-related attitudes as potential moderators of these manipulations, a similar hierarchical multiple regression analysis was conducted. Table 9 shows the results of this analysis. 
Table 9

Hierarchical Multiple Regression Analyses Predicting the Laziness Index with Race of

Child, Weight of Child, Explicit Race-Related Attitudes, and Internal Motivation to

Control Black Prejudice (Moderator)

\begin{tabular}{lcc}
\hline \multicolumn{1}{c}{ Predictor } & $\Delta \mathrm{R}^{2}$ & $\beta$ \\
\hline Step 1 & .027 & \\
Race of Child (R) & .055 \\
Weight of Child (W) & .094 \\
Explicit Race-Related Attitudes (ERA) & .156 \\
Internal Motivation to Control Black Prejudice & .069 \\
$\quad$ (IMTCP_B)
\end{tabular}

Step 2

.051

R X W

.001

R X ERA

.038

R X IMTCP_B

$-.089$

W X ERA

.221

W X IMTCP_B

$-.059$

ERA X IMTCP_B

$-.220 *$

Step 3

.002

R X W X ERA

.008

R X W X IMTCP_B

.052

R X ERA X IMTCP_B

$-.008$

W X ERA X IMTCP_B

$-.008$ 


\begin{tabular}{|c|c|c|}
\hline Predictor & $\Delta \mathrm{R}^{2}$ & $\beta$ \\
\hline Step 4 & .004 & \\
\hline R X W X ERA X IMTCP_B & & -.104 \\
\hline
\end{tabular}

$* p<.05$.

As shown in Table 9, a significant two-way interaction was detected. This twoway interaction indicated that IMTCBP moderated the impact of explicit race-related attitudes upon the Laziness Index. However, when we conducted a median split of the IMTCBP and examined the correlation between explicit race-related attitudes across high and low IMTCBP groups, we found no significant correlations: low IMTCBP, $r(94)=$ $.14, p=.19$, and high IMTCBP, $r(93)=.09, p=.37$. This suggests that the pattern implied by the two-way interaction was relatively weak and possibly the product of error.

We also examined the impact of the case study manipulations upon the Laziness Index ratings and the combined roles of IMTCWP and explicit weight-related attitudes as potential moderators of these manipulations by conducting a hierarchical multiple regression analysis. On the first step, the race and weight manipulations (scored -1 and +1 ) were entered along with the centered scores on the index of explicit weight-related attitudes and the IMTCWP. On the second step, the products representing the two-way interactions of these variables were entered. On the third step, the three-way interaction was entered. On the fourth step, the four-way interaction was entered. None of these interactions were significant. 


\section{ADHD Symptoms}

A similar set of hierarchical regression analyses were used to examine the predictors of ADHD symptoms. The analyses of implicit and explicit race and weightrelated attitudes as moderators of the case study manipulations did not show any evidence of moderation effects. When we included IMTCBP in the regression analyses with racerelated attitudes, we also found no significant results. We did find a significant four-way interaction when examining the two manipulations in combination with the implicit weight-related attitudes (AMP) and motivation to control weight prejudice (IMTCWP). Table 10 shows the results of this analysis. 
Table 10

Hierarchical Multiple Regression Analyses Predicting ADHD Symptoms Ratings with Race of Child, Weight of Child, Implicit Weight-Related Attitudes (Moderator), and Internal Motivation to Control Weight Prejudice (Moderator)

\begin{tabular}{|c|c|c|}
\hline Predictor & $\Delta \mathrm{R}^{2}$ & $\beta$ \\
\hline Step 1 & .041 & \\
\hline Race of Child (R) & & -.127 \\
\hline Weight of Child (W) & & .081 \\
\hline Implicit Weight-Related Attitudes (IWA) & & -.137 \\
\hline Internal Motivation to Control Weight Prejudice & & .012 \\
\hline (IMTCP_W) & & \\
\hline Step 2 & .020 & \\
\hline $\mathrm{R} X \mathrm{~W}$ & & .013 \\
\hline R X IWA & & .003 \\
\hline R X IMTCP_W & & .109 \\
\hline W X IWA & & .064 \\
\hline W X IMTCP_W & & -.035 \\
\hline IWA X IMTCP_W & & -.063 \\
\hline Step 3 & .016 & \\
\hline R X W X IWA & & .095 \\
\hline R X W X IMTCP_W & & -.067 \\
\hline R X IWA X IMTCP_W & & .030 \\
\hline W X IWA X IMTCP_W & & .108 \\
\hline
\end{tabular}




\begin{tabular}{|c|c|c|}
\hline Predictor & $\Delta \mathrm{R}^{2}$ & $\beta$ \\
\hline Step 4 & $.040 * *$ & \\
\hline R X W X IWA X IMTCP_W & & $.247 * *$ \\
\hline
\end{tabular}

$* * p<.01$.

As shown in Table 10, a significant four-way interaction was detected between each manipulated variable, measure of implicit weight-related attitudes, and IMTCWP. This four-way interaction indicated that implicit weight-related attitudes and IMTCWP seemed to moderate the impact of both race and weight manipulation upon ADHD Symptoms ratings. Table 11 shows a breakdown of the correlations between implicit weight-related attitudes and ADHD Symptom ratings across the two manipulated variables and a median split of the IMTCWP. Because there were 8 cells produced from this breakdown, the small sample size made it unlikely that any of the correlations would reach statistical significance. However, one did. Participants who held more anti-fat implicit weight-related attitudes and had low IMTCWP were less likely to perceive the student's problems as exhibiting ADHD symptoms, $r(24)=-.39, p=.05$, when they read the overweight Black case study. This finding is consistent with the hypothesis that implicit weight-related attitudes influenced the interpretation of the student's symptoms and school problems when he was overweight. This relationship only emerged when the overweight student was also Black. 
Table 11

Correlations between ADHD Symptom and Implicit Weight-related Attitudes for

Condition by Weight and Race with Internal Motivation to Control Weight Prejudice

\begin{tabular}{ll}
\hline ADHD Symptom & AMPweight \\
\hline
\end{tabular}

Average Weight, White Case Study with Low IMTCWP

$$
(n=24)
$$
ADHD Symptom
$---\cdot-313$

AMPweight

$-.313$

Average Weight, White Case Study with High IMTCWP

$$
(n=25)
$$

ADHD Symptom

AMPweight

$-.115$
$-.115$

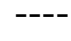

Overweight, White Case Study with Low IMTCWP

$$
(n=25)
$$
ADHD Symptom
$----$
.032

AMPweight

.032 


\section{ADHD Symptom AMPweight}

Overweight, White Case Study with High IMTCWP

$$
(n=21)
$$
ADHD Symptom
$---$
$-.267$

AMPweight

$-.267$

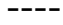

Average Weight, Black Case Study with Low IMTCBP

$$
(n=33)
$$
ADHD Symptom
$---$
$-.008$

AMPweight

$-.008$

Average Weight, Black Case Study with High IMTCBP

$$
(n=20)
$$

ADHD Symptom

AMPweight

$-.392$
$-.392$

Overweight, Black Case Study with Low IMTCBP

$$
(n=24)
$$
ADHD Symptom
$----$
$-.392 *$

AMPweight

$-.392 *$ 


\begin{tabular}{|c|c|c|}
\hline & ADHD Symptom & AMPweight \\
\hline \multicolumn{3}{|c|}{$\begin{array}{l}\text { Overweight, Black Case Study with High IMTCBP } \\
\qquad(n=22)\end{array}$} \\
\hline ADHD Symptom & ---- & .311 \\
\hline AMPweight & .311 & ---- \\
\hline
\end{tabular}

$* p<.05$.

We also conducted a similar analysis of ADHD Symptoms ratings where the predictor variables were the case study manipulations, explicit weight-related attitudes, and motivations to control weight prejudice. Table 12 shows the results of this analysis. 
Table 12

Hierarchical Multiple Regression Analyses Predicting ADHD Symptoms Ratings with Race of Child, Weight of Child, Explicit Weight-Related Attitudes, and Internal Motivation to Control Weight Prejudice (Moderator)

\begin{tabular}{lcc}
\hline \multicolumn{1}{c}{ Predictor } & $\Delta \mathrm{R}^{2}$ & $\beta$ \\
\hline Step 1 & .023 & \\
Race of Child (R) & -.127 \\
Weight of Child (W) & .077 \\
Explicit Weight-Related Attitudes (EWA) & -.025 \\
Internal Motivation to Control Weight Prejudice & .006 \\
(IMTCP_W) & .049 & \\
Step 2 & .037 \\
R X W & & \\
R X EWA & .110 \\
R X IMTCP_W & .026 & .003 \\
W X EWA & & .135 \\
W X IMTCP_W & & .007 \\
EWA X IMTCP_W & & \\
Rtep 3 & & .037 \\
R X W X EWA & & \\
\hline
\end{tabular}




\begin{tabular}{lcc}
\hline \multicolumn{1}{c}{ Variable } & $\Delta \mathrm{R}^{2}$ & $\beta$ \\
\hline W X EWA X IMTCP_W & & -.036 \\
Step 4 & .003 & \\
R X W X EWA X IMTCP_W & & -.066 \\
\hline
\end{tabular}

$* p<.05$.

As shown in Table 12, a two-way interaction indicated that explicit weight-related attitudes moderated the impact of weight manipulation upon ADHD Symptoms ratings. However, further analyses showed that explicit weight-related attitudes were unrelated to perceiving the student as exhibiting ADHD symptoms regardless of weight manipulation: average weight case study, $r(104)=-.14, p=.16$, and overweight case study, $r(96)=.16$, $p=.12$. This suggests that the pattern implied by this interaction was weak and inconsequential.

\section{Ranking the Potential Causes of the Student's School Behavior Problems}

Participants were asked to rank several hypotheses about the student's school behavior problems according to which they would investigate first, second, and so on. The average rank order of each of these conditions is shown in Figure 1. Lack of Motivation received the lowest rank order indicating that participants generally chose it to investigate before the others. ODD received the highest rank order indicating that participants generally chose to investigate it last. We performed a $\chi^{2}$ analysis on the frequency distribution across the four experimental conditions for the ranking of each of these hypotheses. Unfortunately, none of these analyses produced significant results. 
We then turned to a different analytic strategy in examining possible moderating effects of individual differences upon these choices. These moderation analyses parallel the moderation analyses reported for previous dependent variables. As before, these analyses will be organized by dependent variable. Only those analyses showing significant results will be reported.

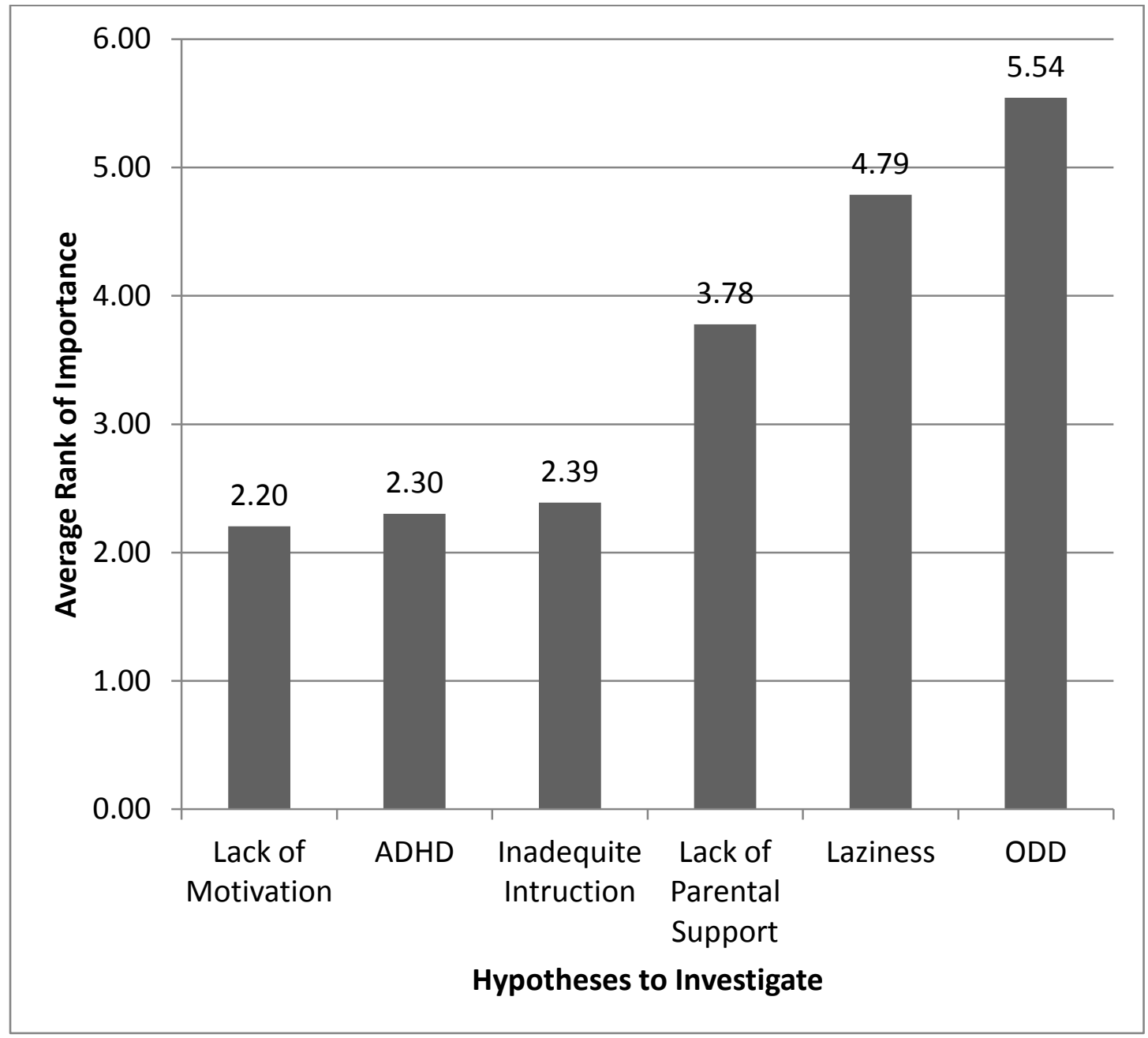

Figure 1: Average Rank Order of Importance of Hypotheses about the Student's School Problems 


\section{Rank of Lack of Motivation}

For Rank of Lack of Motivation, the manipulations involving the photo of the student in the case study (Black vs. White and Overweight vs. Average Weight) did not produce main effects or a significant interaction. Considering one moderator at a time, moderation analyses involving implicit race-related attitudes, implicit weight-related attitudes, and explicit race-related attitudes also did not find any significant results. However, we did find a significant interaction between explicit weight-related attitudes and the manipulation of weight in the photos. Table 13 shows the results of this analysis. 
Table 13

Hierarchical Multiple Regression Analyses Predicting the Rank of Lack of Motivation with Race of Child, Weight of Child, and Explicit Weight-Related Attitudes (Moderator)

\begin{tabular}{lcc}
\hline \multicolumn{1}{c}{ Predictor } & $\Delta \mathrm{R}^{2}$ & $\beta$ \\
\hline Step 1 & .014 & \\
Race of Child (R) & -.096 \\
Weight of Child (W) & .053 \\
Explicit Weight-Related Attitudes (EWA) & -.041 \\
Step 2 & .031 & \\
R X W & & .064 \\
R X EWA & & -.078 \\
W X EWA & & $-.142^{*}$ \\
Step 3 & & \\
R X W X EWA & .001 & \\
\hline
\end{tabular}

$* p<.05$.

As shown in Table 13, a two-way interaction indicated that explicit weight-related attitudes moderated the impact of weight manipulation upon the ranking of Lack of Motivation. However, when we examined the correlations between explicit weightrelated attitudes and the ranking of Lack of Motivation across the two photo conditions, neither correlation was statistically significant: average weight case study, $r(104)=.11, p$ $=.29$, and overweight case study, $r(96)=-.18, p=.08$. This suggests that the moderation effect was weak and possibly spurious. 
Turning to the regression analyses where we examined second order moderation effects involving measures of motivation to control prejudice, only one of these analyses showed significant results. This one involved IMTCWP and implicit weight-related attitudes. Table 14 shows the results of this analysis.

Table 14

Hierarchical Multiple Regression Analyses Predicting the Rank of Lack of Motivation with Race of Child, Weight of Child, Implicit Weight-Related Attitudes, and Internal Motivation to Control Weight Prejudice (Moderator)

\begin{tabular}{lcc}
\hline \multicolumn{1}{c}{ Predictor } & $\Delta \mathrm{R}^{2}$ & $\beta$ \\
\hline Step 1 & .008 & \\
Race of Child (R) & -.128 \\
Weight of Child (W) & .016 \\
Implicit Weight-Related Attitudes (IWA) & -.077 \\
Internal Motivation to Control Weight Prejudice & .038 \\
(IMTCP_W) & .061 & \\
Step 2 & & \\
R X W & .024 \\
R X IWA & .057 \\
R X IMTCP_W & .070 \\
W X IWA & & .057 \\
W X IMTCP_W & & \\
IWA X IMTCP_W & & .118 \\
\hline
\end{tabular}




\begin{tabular}{lcc}
\hline \multicolumn{1}{c}{ Predictor } & $\Delta \mathrm{R}^{2}$ & $\beta$ \\
\hline Step 3 & $.053^{*}$ & \\
R X W X IWA & -.082 \\
R X W X IMTCP_W & -.096 \\
R X IWA X IMTCP_W & .037 \\
W X IWA X IMTCP_W & $-.239^{*}$ \\
Step 4 & .014 & \\
R X W X IWA X IMTCP_W & & .118 \\
\hline
\end{tabular}

$* p<.05$.

As shown in Table 14, a significant three-way interaction was detected between the weight manipulation in the photos, the measure of implicit weight-related attitudes, and IMTCWP. This three-way interaction indicated that implicit weight-related attitudes and IMTCWP seemed to moderate the impact of weight manipulation upon the ranking of Lack of Motivation. In order to interpret this effect, we performed a median split upon the IMTCWP variable and examined correlations between the implicit weight-related attitudes and the ranking of Lack of Motivation across the four resulting cells. Correlations are presented in Table 15. Participants who held more anti-fat implicit weight-related attitudes and had low IMTCWP ranked Lack of Motivation higher, $r(51)=$ $.38, p=.007$, when they read the overweight case study. This means that they were less likely to pursue lack of motivation as a hypothesis for the student's problems. However, when the student in the case study was overweight, participants who held more anti-fat implicit weight-related attitudes and had high IMTCWP, implicit weight-related attitudes 
were unrelated to the ranking of Lack of Motivation, $r(43)=-.18, p=.24$. Further, when the student was average weight, implicit weight-related attitudes were unrelated to the ranking of Lack of Motivation regardless of participants' IMTCBP level: low IMTCBP, $r(63)=-.18, p=.19$, and high IMTCBP, $r(47)=-.19, p=.21$. This finding is inconsistent with our hypothesis. It was predicted that participants who were low in motivation to control weight prejudice and held implicit weight-related attitudes would be more likely to pursue lack of motivation as a hypothesis for the student's problems given that lack of motivation is a negative stereotype about overweight people. 
Table 15

Correlations between the Rank of Lack of Motivation Implicit Weight-related Attitudes

for Condition by Weight with Internal Motivation to Control Weight Prejudice

Rank of Lack of
Motivation

Average Weight Case Study with Low IMTCWP $(n=57)$

Rank of Lack of $\quad$---- $\quad-.176$

Motivation

AMPweight

$-.176$

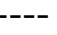

Average Weight Case Study with High IMTCWP $(n=45)$

Rank of Lack of

$-.191$

Motivation

AMPweight

$-.191$

Overweight Case Study with Low IMTCWP $(n=49)$

Rank of Lack of

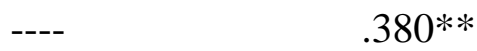

Motivation

AMPweight

$.380 * *$ 


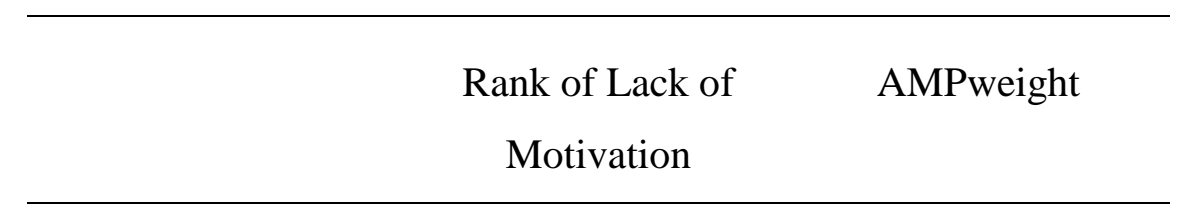

Overweight Case Study with High IMTCWP $(n=43)$

\begin{tabular}{lll}
$\begin{array}{l}\text { Rank of Lack of } \\
\text { Motivation }\end{array}$ & ---- & -.183 \\
AMPweight & -.183 & --- \\
\hline$* * p<.01$ & & \\
\hline
\end{tabular}

\section{Rank of ADHD}

Of all the hierarchical multiple regression analyses of the ranking of ADHD, only one showed significant results: the one involving implicit weight-related attitudes as a moderator. Table 16 shows the results of this analysis. 
Table 16

Hierarchical Multiple Regression Analyses Predicting the Rank of ADHD with Race of Child, Weight of Child, and Implicit Weight-Related Attitudes (Moderator)

\begin{tabular}{lcc}
\hline \multicolumn{1}{c}{ Predictor } & $\Delta \mathrm{R}^{2}$ & $\beta$ \\
\hline Step 1 & $.032 *$ & \\
Race of Child (R) & .123 \\
Weight of Child (W) & -.050 \\
Implicit Weight-Related Attitudes (IWA) & .173 \\
Step 2 & .006 & \\
R X W & & -.069 \\
R X IWA & & -.012 \\
W X IWA & & -.010 \\
Step 3 & .018 & \\
R X W X IWA & & $.133 *$ \\
\hline
\end{tabular}

$* p=.05$.

As shown in Table 16, a three-way interaction indicated that implicit weightrelated attitudes and seemed to moderate the effects of the race and weight manipulations upon the ranking of ADHD. Table 17 shows the correlations between the implicit weight-related attitudes and the ranking of ADHD across the four conditions of the $2 \times 2$ factorial. Participants who held more anti-fat implicit weight-related attitudes ranked ADHD higher (i.e., less likely to be pursued as a hypothesis for the student's behavior) when they read the average weight White case study, $r(51)=.35, p=.01$, and the 
overweight Black case study, $r(52)=.28, p=.04$. However, implicit anti-fat weightrelated attitudes were unrelated to ADHD ranking when they read the overweight White case study, $r(47)=.04, p=.79$, and the average weight Black case study, $r(55)=.04, p=$ .76. This seems like a puzzling pattern of results. It will be discussed further in the discussion.

Table 17

Correlations between the Rank of ADHD and Implicit Weight-related Attitudes for Condition by Weight and Race

\begin{tabular}{lc}
\hline \multicolumn{1}{c}{ Rank of ADHD } & AMPweight \\
\multicolumn{2}{c}{ Average Weight, White Case Study $(n=51)$} \\
Rank of ADHD \\
AMPweight \\
$.347^{*}$
\end{tabular}

Overweight, White Case Study $(n=47)$

Rank of ADHD

.040

AMPweight

.040 


\begin{tabular}{lc}
\hline \multicolumn{1}{c}{ Rank of ADHD } & AMPweight \\
\hline \multicolumn{2}{c}{ Average Weight, Black Case Study $(n=55)$} \\
Rank of ADHD \\
AMPweight \\
\hline
\end{tabular}

Overweight, Black Case Study $(n=52)$

Rank of ADHD

- $\quad .282^{*}$

AMPweight $.282 * \quad---$

$* p<.05$

Rank of ODD

Of all the analyses of the ranking of ODD as a hypothesis to pursue, only one analysis showed a significant result. This analysis involved two manipulations, explicit weight-related attitudes and IMTCWP. Table 18 shows the results of this analysis. 
Table 18

Hierarchical Multiple Regression Analyses Predicting the Rank of ODD with Race of Child, Weight of Child, Explicit Weight-Related Attitudes, and Internal Motivation to Control Weight Prejudice (Moderator)

\begin{tabular}{|c|c|c|}
\hline Predictor & $\Delta \mathrm{R}^{2}$ & $\beta$ \\
\hline Step 1 & $.050 *$ & \\
\hline Race of Child (R) & & .166 \\
\hline Weight of Child (W) & & .075 \\
\hline Explicit Weight-Related Attitudes (EWA) & & -.095 \\
\hline Internal Motivation to Control Weight Prejudice & & .042 \\
\hline \multicolumn{3}{|l|}{ (IMTCP_W) } \\
\hline Step 2 & .059 & \\
\hline R X W & & .001 \\
\hline R X EWA & & .091 \\
\hline R X IMTCP_W & & .000 \\
\hline W X EWA & & .041 \\
\hline W X IMTCP_W & & -.077 \\
\hline EWA X IMTCP_W & & $.207 * *$ \\
\hline Step 3 & $.055^{*}$ & \\
\hline R X W X EWA & & -.003 \\
\hline R X W X IMTCP_W & & .163 \\
\hline R X EWA X IMTCP_W & & -.114 \\
\hline
\end{tabular}




\begin{tabular}{lcc}
\hline \multicolumn{1}{r}{ Variable } & $\Delta \mathrm{R}^{2}$ & $\beta$ \\
\hline W X EWA X IMTCP_W & & $-.160^{*}$ \\
Step 4 & .001 & \\
R X W X EWA IMTCP_W & & -.042 \\
\hline
\end{tabular}

${ }^{*} p<.05 . * * p<.01$

As shown in Table 18, a significant two-way interaction was detected between the measure of explicit weight-related attitudes and IMTCWP. This two-way interaction seems best understood in the context of a three-way interaction involving these same two variables plus the manipulation of the weight of the student in the photo. Table 19 shows the correlations between explicit weight-related attitudes and the ranking of ODD across the two photo conditions where weight was manipulated and a median split of IMTCWP. When the student in the case study was average weight and participants had low IMTCWP explicit weight-related attitudes were negatively correlated with the ranking of ODD, $r(57)=-.30, p=.03$. This negative relationship indicates that participants who held more negative explicit weight-related attitudes were more likely to view ODD as a hypothesis to be explored. However, when the student in the case study was average weight and participants had high IMTCWP, explicit weight-related attitudes were unrelated to perceiving the student's problems as being closely related to ODD, $r(45)=.09, p=.57$. Further, when the student was overweight, explicit weight-related attitudes were unrelated to perceiving the student's problems as being closely related to ODD regardless of participants' IMTCWP level: low IMTCWP, $r(49)=.02, p=.89$, and high IMTCWP, $r(43)=-.01, p=.96$. These results suggest that participants who have 
anti-fat biases and low motivations to control these biases believe that the average weight student's school problems are likely caused by ODD.

Table 19

Correlation between the Rank of ODD and Explicit Weight-Related Attitudes for Condition by Weight with Internal Motivation to Control Weight Prejudice

\begin{tabular}{lc}
\hline \multicolumn{1}{c}{ Rank of ODD } & EXPLweight \\
\hline Average Weight Case Study with Low IMTCWP $(n=57)$ \\
Rank of ODD \\
EXPLweight \\
\hline
\end{tabular}

Average Weight Case Study with High IMTCWP $(n=45)$

Rank of ODD

EXPLweight

.086
.086

Overweight Case Study with Low IMTCWP $(n=49)$ 


\begin{tabular}{ll}
\hline Rank of ODD $\quad$ EXPLweight \\
\hline
\end{tabular}

Overweight Case Study with High IMTCWP $(n=43)$

\begin{tabular}{lll} 
Rank of ODD & ---- & -.007 \\
EXPLweight & -.007 & --- \\
\hline
\end{tabular}

${ }^{*} p<.05$

\section{Rank of Inadequate Instruction}

Two analyses found significant results for the ranking of Inadequate Instruction from Teachers. The first looked at implicit race-related attitudes as a single moderator. Table 20 shows the results of this analysis. 
Table 20

Hierarchical Multiple Regression Analyses Predicting the Rank of Inadequate Instruction with Race of Child, Weight of Child, and Implicit Race-Related Attitudes (Moderator)

\begin{tabular}{lcc}
\hline \multicolumn{1}{c}{ Predictor } & $\Delta \mathrm{R}^{2}$ & $\beta$ \\
\hline Step 1 & .023 & \\
Race of Child (R) & -.061 \\
Weight of Child (W) & .118 \\
Implicit Race-Related Attitudes (IRA) & .075 \\
Step 2 & .022 & \\
R X W & & .025 \\
R X IRA & & $-.146^{*}$ \\
W X IRA & & .060 \\
Step 3 & & \\
R X W X IRA & .008 & \\
\hline
\end{tabular}

$* p<.05$.

As shown in Table 20, a significant interaction indicated that implicit race-related attitudes moderated the impact of race manipulation upon the ranking of Inadequate Instruction. When the photograph of the student described in the case study was White, participants who held more implicit anti-Black attitudes ranked Inadequate Instruction high, $r(98)=.20, p=.04$, meaning that they were less likely to pursue it as a hypothesis for the student's problems. When the student was Black, implicit race-related attitudes were unrelated to perceiving the student's problems as being related to inadequate 
instruction, $r(107)=-.04, p=.68$. These results suggest that participants who hold antiBlack biases do not believe that the White student's problems in school are likely caused by Inadequate Instruction.

The second analysis for the ranking of Inadequate Instruction from Teachers found statistically significant results that involved the two manipulated variables plus implicit race-related attitudes and IMTCBP (motivations to control prejudices against Blacks). Table 21 shows the results of this analysis.

Table 21

Hierarchical Multiple Regression Analyses Predicting the Rank of Inadequate Instruction with Race of Child, Weight of Child, Implicit Race-Related Attitudes, and Internal Motivation to Control Black Prejudice (Moderator)

\begin{tabular}{lcc}
\hline \multicolumn{1}{c}{ Predictor } & $\Delta \mathrm{R}^{2}$ & $\beta$ \\
\hline Step 1 & .039 & \\
Race of Child (R) & -.040 \\
Weight of Child (W) & .148 \\
Implicit Race-Related Attitudes (IRA) & .113 \\
Internal Motivation to Control Black Prejudice & -.051 \\
(IMTCP_B) & \\
\hline
\end{tabular}




\begin{tabular}{lcc}
\hline \multicolumn{1}{c}{ Predictor } & $\Delta \mathrm{R}^{2}$ & $\beta$ \\
\hline Step 2 & .055 & \\
R X W & .051 \\
R X IRA & -.045 \\
R X IMTCP_B & -.146 \\
W X IRA & .085 \\
W X IMTCP_B & -.156 \\
IRA X IMTCP_B & .005 \\
Step 3 & .014 & \\
R X W X IRA & & \\
R X W X IMTCP_B & .095 \\
R X IRA X IMTCP_B & .038 \\
W X IRA X IMTCP_B & .065 \\
Step 4 & & .093 \\
R X W X IRA X IMTCP_B & $.022^{*}$ & \\
\hline
\end{tabular}

$* p<.05$.

As shown in Table 21, a four-way interaction indicated that implicit race-related attitudes and IMTCBP combined to moderate the interaction of race and weight manipulations upon the ranking of Inadequate Instruction. A breakdown of the correlations between implicit race-related attitudes and the ranking of Inadequate Instruction across the two manipulated variables and a median split of IMTCBP produced the 8 cells shown in Table 22. Unfortunately, the small sample size resulted from this 
breakdown made it unlikely that any of the correlations would reach statistical significance and none did. The only correlation to approach statistical significance was in the cell where participants with low IMTCBP ranked the overweight Black case study, $r(14)=-.47, p=.09$. When participants with low motivations to control racial prejudice rated an overweight Black student, those who held more negative implicit racial attitudes tended to rank inadequate teacher instruction as a more important hypothesis to explore suggesting that they believe inadequate teacher instruction may be the cause of the student's problems. 
Table 22

Correlations between the Rank of Inadequate Instruction and Implicit Race-related Attitudes for Condition by Weight and Race with Internal Motivation to Control Black Prejudice

\begin{tabular}{|c|c|c|c|}
\hline & $\begin{array}{c}\text { Rank of Inadequate } \\
\text { Instruction }\end{array}$ & \multicolumn{2}{|c|}{ AMPrace } \\
\hline Average Weight, & $\begin{array}{l}\text { ite Case Study with L } \\
\qquad 24)\end{array}$ & TCBP & $(n=$ \\
\hline $\begin{array}{l}\text { Rank of Inadequate } \\
\text { Instruction }\end{array}$ & ---- & -.137 & \\
\hline AMPrace & -.137 & ---- & \\
\hline Average Weight, & $\begin{array}{l}\text { ite Case Study with } \mathrm{H} \\
\text { 23) }\end{array}$ & TCBP & $(n=$ \\
\hline $\begin{array}{l}\text { Rank of Inadequate } \\
\text { Instruction }\end{array}$ & ---- & .053 & \\
\hline AMPrace & .053 & ---- & \\
\hline
\end{tabular}

Overweight, White Case Study with Low IMTCBP $(n=25)$

Rank of Inadequate

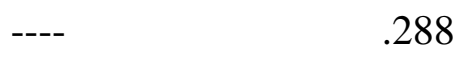

Instruction

AMPrace 


\begin{tabular}{cc}
\hline $\begin{array}{c}\text { Rank of Inadequate } \\
\text { Instruction }\end{array}$ & AMPrace \\
\hline
\end{tabular}

Overweight, White Case Study with High IMTCBP $(n=20)$

\begin{tabular}{lcc} 
Rank of Inadequate & ---- & .286 \\
Instruction & & \\
AMPrace & .286 & ---- \\
\hline
\end{tabular}

Average Weight, Black Case Study with Low IMTCBP $(n=31)$

Rank of Inadequate $\quad$---- $\quad .079$

Instruction

AMPrace $\quad .079 \quad---$

Average Weight, Black Case Study with High IMTCBP $(n=20)$

Rank of Inadequate $\quad$---- $\quad .004$

Instruction

AMPrace $\quad .004 \quad---$ 


\begin{tabular}{cc}
\hline $\begin{array}{c}\text { Rank of Inadequate } \\
\text { Instruction }\end{array}$ & AMPrace \\
\hline
\end{tabular}

Overweight, Black Case Study with Low IMTCBP $(n=14)$

\begin{tabular}{llc} 
Rank of Inadequate & ---- & -.471 \\
Instruction & & \\
AMPrace & -.471 & ---- \\
\hline
\end{tabular}

Overweight, Black Case Study with High $\operatorname{IMTCBP}(n=30)$

Rank of Inadequate $\quad$---- $\quad .219$

Instruction

AMPrace $\quad .219 \quad---$

\section{Rank of Lack of Parental Support}

For the ranking of Lack of Parental Support as a hypothesis to explore produced only one significant result. This result was in the analysis of explicit race-related attitudes as a simple moderator. Table 23 shows the results of this analysis. 
Table 23

Hierarchical Multiple Regression Analyses Predicting the Rank of Lack of Parental Support with Race of Child, Weight of Child, and Explicit Race-Related Attitudes (Moderator)

\begin{tabular}{lcc}
\hline \multicolumn{1}{c}{ Predictor } & $\Delta \mathrm{R}^{2}$ & $\beta$ \\
\hline Step 1 & .033 & \\
Race of Child (R) & -.078 \\
Weight of Child (W) & -.165 \\
Explicit Race-Related Attitudes (ERA) & -.063 \\
Step 2 & .032 & \\
R X W & & -.023 \\
R X ERA & & $-.173 *$ \\
W X ERA & & -.059 \\
Step 3 & & \\
R X W X ERA & .002 & \\
\hline
\end{tabular}

$* p<.05$.

As shown in Table 23, a significant interaction indicated that explicit race-related attitudes moderated the impact of race manipulation upon the ranking of Lack of Parental Support. When the photograph of the student described in the case study was Black, participants who held more explicit anti-Black race-related attitudes ranked Lack of Parental Support low, $r(104)=-.25, p=.01$, meaning that they were more likely to pursue it as a hypothesis for the student's problems. When the student was White, 
explicit race-related attitudes were unrelated to perceiving the student's problems as being related to lack of parental support, $r(96)=.12, p=.23$. (All major findings can be found in Table 24.)

Table 24

Summary of Major Findings

\begin{tabular}{ll}
\hline \multicolumn{1}{c}{$\begin{array}{c}\text { Dependent } \\
\text { Variable }\end{array}$} & \multicolumn{1}{c}{ Findings } \\
\hline Laziness Index & 1) $\begin{array}{l}\text { Participants who held implicit anti-Black attitudes rated laziness } \\
\text { higher when the child was Black. }\end{array}$ \\
& 2) $\begin{array}{l}\text { Participants who held implicit anti-Black attitudes rated laziness } \\
\text { higher when the child was overweight }\end{array}$ \\
& 3) $\begin{array}{l}\text { Participants who held implicit anti-Black attitudes and had high } \\
\text { motivations to control Black prejudice rated laziness higher } \\
\text { when the child was Black }\end{array}$ \\
ADHD & 1) $\begin{array}{l}\text { Participants who held implicit anti-fat attitudes and had low } \\
\text { motivations to control weight-related prejudice did not see the } \\
\text { overweight, Black child as exhibiting symptoms of ADHD. } \\
\text { Rank of Lack } \\
\text { of Motivation }\end{array}$ \\
& 1) $\begin{array}{l}\text { Participants who held implicit anti-fat attitudes and low } \\
\text { motivations to control weight-related prejudice were less likely } \\
\text { to pursue lack of motivation as a hypothesis for the child's } \\
\text { problems when he was overweight. }\end{array}$
\end{tabular}




\begin{tabular}{|c|c|c|}
\hline $\begin{array}{l}\text { Dependent } \\
\text { Variable }\end{array}$ & & Findings \\
\hline Rank of ADHD & 1) & $\begin{array}{l}\text { Participants who held implicit anti-fat attitudes were less likely } \\
\text { to pursue ADHD as a hypothesis when the child was average } \\
\text { weight and White. }\end{array}$ \\
\hline & 2) & $\begin{array}{l}\text { Participants who held implicit anti-fat attitudes were less likely } \\
\text { to pursue ADHD as a hypothesis for the child's problems when } \\
\text { the child was overweight and Black. }\end{array}$ \\
\hline Rank of ODD & 1) & $\begin{array}{l}\text { Participants who held explicit anti-fat attitudes and had low } \\
\text { motivations to control weight-related prejudice were more likely } \\
\text { to pursue ODD as a hypothesis for the average weight child's } \\
\text { problems. }\end{array}$ \\
\hline $\begin{array}{l}\text { Rank of } \\
\text { Inadequate } \\
\text { Instruction }\end{array}$ & 1) & $\begin{array}{l}\text { Participants who held implicit anti-Black attitudes were less } \\
\text { likely to pursue inadequate instruction as a hypothesis for the } \\
\text { White child's problems. }\end{array}$ \\
\hline $\begin{array}{l}\text { Rank of Lack of } \\
\text { Parental Support }\end{array}$ & 1) & $\begin{array}{l}\text { Participants who held explicit anti-Black attitudes were more } \\
\text { likely to pursue lack of parental support as a hypothesis for the } \\
\text { Black child's problems. }\end{array}$ \\
\hline
\end{tabular}




\section{CHAPTER VI \\ DISCUSSION}

The main purpose of this study assessed the impact of racial and weight-related biases upon judgments that school psychology graduate students make about Black and overweight students who are having problems in school, specifically, when students show symptoms of ADHD. We also examined the extent to which school psychology graduate students' implicit and explicit attitudes and internal motivations to control prejudice moderated the degree to which they attributed negative personality traits and work habits to Black and overweight students with symptoms of ADHD.

We hypothesized that participants would attribute higher ratings of laziness to the Black students with ADHD compared to White students with ADHD, and that these ratings would be correlated with participants' implicit and explicit anti-Black biases. Further, we hypothesized that participants would attribute higher ratings of laziness to overweight students with ADHD compared to average weight students with ADHD, and that these ratings would be correlated with participants' implicit and explicit anti-fat biases. Finally, we hypothesized that the more diversity courses participants attended the less implicit and explicit race and weight-related biases they would exhibit.

Participants were tested in four conditions: (1) average weight White case study, (2) overweight White case study, (3) average weight Black case study, and (4) overweight Black case study. They read a case study that included a photograph of a 
student and was asked questions about the student's personality traits and work habits. The Laziness Index was the primary dependent variable. The other dependent variables included: ADHD Symptom, the Rank of Lack of Motivation, the Rank of ADHD, the Rank of ODD, the Rank of Inadequate Instruction, and the Rank of Lack of Parental Support. Results will be presented by condition (e.g., overweight Black case study) as well as by individual case manipulation (e.g., overweight case study and Black case study).

We predicted that there would be no correlations between laziness ratings and either weight or race-related biases in the average weight White case study. The student in the photograph is average weight which would not invoke weight-related biases. Further, the student in the photograph is White which would not invoke race-related bias. Results showed that neither participants' implicit or explicit attitudes nor weight or racerelated biases were correlated with the degree to which they attributed the students' symptoms to laziness. This finding corresponded to our predictions.

For the Black case study, results showed that participants' implicit race-related attitudes as measured by the $A M P$ were significantly correlated with ratings on the Laziness Index. Participants with anti-Black implicit race-related attitudes rated the student in the Black case study higher on the Laziness Index. Further, participants with anti-Black implicit race-related attitudes who had high internal motivation to control Black prejudice also rated the student in the case study higher on the Laziness Index. However, participants' explicit race-related attitudes as measured by the Feelings Thermometers did not correlate with ratings on the Laziness Index. 
This pattern of results is consistent with our prediction that participants would attribute higher ratings of laziness to the Black case study compared to the White case study. However, the pattern of results is inconsistent with our prediction that the ratings of laziness to the student in the Black case study would be correlated with participants' implicit and explicit anti-Black biases. Laziness ratings were correlated with implicit anti-Black attitudes but not explicit anti-Black attitudes. This was surprising given that results also indicated that overall, participants had an implicit pro-Black bias. It would seem that if participants' attitudes about Blacks were positive, they would not attribute a negative personality trait (i.e., laziness) to the Black student. Further, although participants were highly, internally motivated to control their Black prejudice, it came through with their attributions of laziness to the Black student in the case study. This was inconsistent with the hypothesis that implicit race-related attitudes would be influenced by participants who had low internal motivations to control prejudice. It was thought that if participants were not motivated to control their prejudice, they would attribute laziness ratings to the Black case study. However, the opposite was found.

For the overweight case study, results indicated that participants' implicit racerelated attitudes were significantly correlated with ratings on the Laziness Index. Participants with anti-Black race-related attitudes attributed higher laziness ratings to the student in the overweight case study regardless of race. This finding was not predicted. It was not considered that racial attitudes would influence laziness ratings in the weight manipulation of the case study. Further, although it was participants' racial attitudes, race did not affect laziness ratings, only weight. Results also indicated that participants' 
implicit weight-related attitudes were significantly correlated with the Rank of Lack of Motivation. Participants with anti-fat implicit weight-related attitudes were less likely to pursue lack of motivation as the student's problems. This pattern of results is inconsistent with our prediction that participants would pursue lack of motivation as a hypothesis for the student in the overweight case study compared to the average weight case study. Results also indicated that overall, participants had both an implicit and explicit anti-fat bias.

We also predicted that the more diversity courses participants attended the less implicit and explicit race and weight-related biases they would exhibit. The Diversity Exposure Questionnaire $(D E Q)$ was created to analyze this hypothesis. A multivariate analysis of variance was conducted where the case study manipulations were used as independent variables to determine if the $D E Q$ could be used as a moderator variable. Unfortunately, the $D E Q$ was influenced by our case study manipulations and could not be used as a moderator variable. Therefore, we were unable to conduct moderation analyses to test this hypothesis.

A secondary purpose of this study was to determine if school psychology graduate students could recognize the symptoms of ADHD if they read them in a case study. Results indicated that participants' implicit weight-related attitudes were correlated with their ratings of ADHD Symptoms. When the student in the case study was an overweight Black boy, participants with implicit anti-fat attitudes about weight who had low internal motivation to control weight prejudice were less likely to see the student as exhibiting ADHD Symptoms. 
Results also showed that participants' implicit weight-related attitudes were correlated with their ranking of ADHD. The results suggested that participants were less likely to pursue ADHD as a hypothesis of the student's problems when the student was either an average weight White male or an overweight Black male. These results are very confusing. They are very specific in regards to weight and race. It is not just one race or body type but different combinations of the two. Further, they are on the opposite ends of a spectrum. On one hand is the average weight White male who would not invoke weight or race-related bias. On the other hand is the overweight Black male who would invoke both weight and race-related bias. It can also be said that participants' biases about weight and race (i.e., overweight and Black individuals are lazy) clouded their perceptions about the student's true problem (i.e., exhibiting symptoms of ADHD). However, this cannot be said about the average weight White student. This phenomenon should be examined further.

The rankings of ODD, Inadequate Instruction, and the Lack of Parental Support were also examined to determine the order in which participants would test these hypotheses. Participants with more anti-fat implicit weight-related attitudes and low IMTCWP were more likely to pursue ODD as a hypothesis for the average weight student. This implies that if a student is average weight, participants believe that his behavior problems may be attributed to ODD. For the rank of Inadequate Instruction, participants with more anti-Black implicit race-related attitudes were less likely to pursue Inadequate Instruction as a hypothesis when the student was White. This implies that participants do not believe that the student's behavior problems were attributable to 
Inadequate Instruction. For the rank of Lack of Parental Support, participants with more anti-Black implicit race-related attitudes were more likely to pursue it as a hypothesis when the student was Black. 


\section{CHAPTER VII}

\section{CONCLUSION}

The results of this study indicate that school psychology graduate students have an implicit pro-Black bias. They rated abstract paintings shown directly after photographs of Black boys as being more pleasant than the abstract paintings shown directly before White boys. Further, the results indicate that school psychology graduate student have an implicit anti-fat bias. They rated abstract paintings shown directly after photographs of overweight White boys as being less pleasant than the abstract paintings shown directly before average weight White boys. In addition, the school psychology graduate students also have an explicit anti-fat bias. They rated their feelings about overweight White people lower than their feelings about average weight White people.

Results showed that the school psychology graduate students believed that the student's problems in the Black case studies were related to laziness when they held antiBlack implicit race-related attitudes. They also believed that the student's problems in the overweight case studies were also related to laziness when they held implicit antiBlack attitudes.

One of the characteristics that the school psychology graduate students could have chosen to describe the student's problem was ADHD. The problematic behaviors exhibited by the students in the case studies were based on symptoms often seen in 
students with ADHD (e.g., problems keeping his desk clean, completing his work, and following directions). Instead of the school psychologist graduate students choosing this characteristic, they chose laziness-related variables more often than not.

A lot of children are diagnosed with ADHD and other disorders. The general public tends to stigmatize children with mental illness, maintains strong views about the types of treatment, and perceives children with disorders like major depression or ADHD as posing a danger (Pescosolido, Fettes, Martin, Monahan, \& McLeod, 2007). These attitudes may also appear in the school environment. How teachers and other professionals (e.g., school psychologists) perceive children and their individual differences, especially those with academic or emotional disabilities, may affect children's self-perception, opportunities, and academic success (Janz \& Banbury, 2009). Therefore, it is important for school psychologists to be aware of students who have this diagnosis or other mental health needs, because students with mental health needs may need more individualized instruction and services (e.g., counseling).

The importance of the findings that school psychologist graduate students' perceptions of a student's problems are influenced by the his race and weight demonstrate how much further they have to work to rid themselves of stereotypes and biases in order to recognize students' problems for what they are. Further, these findings have implications for diversity courses in graduate training. Unfortunately, this study was unable to examine the relationship that taking diversity courses have on race and weight-related biases. However, $94 \%$ of participants stated that they attend a graduate program that is NASP approved, APA accredited, or both. In order to obtain NASP 
approval, programs have to meet NASP standards (NASP, 2010). Standard 2.8 relates to Diversity in Development and Learning. It states that:

"School psychologists have knowledge of individual differences, abilities, disabilities, and other diverse characteristics; principles and research related to diversity factors for children, families, and schools, including factors related to culture, context, and individual and role differences; and evidence-based strategies to enhance services and address potential influences related to diversity. School psychologists demonstrate skills to provide professional services that promote effective functioning for individuals, families, and schools with diverse characteristics, cultures, and backgrounds and across multiple contexts, with recognition that an understanding and respect for diversity in development and learning and advocacy for social justice are foundations of all aspects of service delivery."

In order to obtain APA accreditation, programs have to meet APA's Guidelines and Principles for Accreditation (APA, 2013). Domain A5 states that:

"The program engages in actions that indicate respect for and understanding of cultural and individual diversity. The phrase "cultural and individual diversity" refers to diversity with regard to personal and demographic characteristics. These include, but are not limited to, age, disability, ethnicity, gender, gender identity, language, national origin, race, religion, culture, sexual orientation, and social economic status. Respect for and understanding of cultural and individual diversity is reflected in the program's policies for the recruitment, retention, and 
development of faculty and students, and in its curriculum and field placements. The program has nondiscriminatory policies and operating conditions, and it avoids any actions that would restrict program access or completion on grounds that are irrelevant to success in graduate training or the profession." Therefore, to obtain both NASP approval and APA accreditation, graduate programs have to address diversity issues. Based on the results of this study, even though participants are enrolled in programs that address diversity issues, they still have race and weight-related biases. Hopefully, school psychologist graduate students will recognize the biases that they may hold and the stereotypes that they may rely on when interacting with students who are of a different culture than themselves in order to evaluate and treat students equally and to recognize when students have mental health needs. 


\section{CHAPTER VIII}

\section{FUTURE RESEARCH}

This study examined race- and weight-related stereotypes using Black and White boys who were either average weight or overweight. Implicit attitudes were measured using the $A M P$. Photographs used in the $A M P$ were obtained from public access web sites. In our previous study, we used before and after weight loss photographs of White boys. We were able to compare the average weight photograph with the overweight photograph of the same boy. Given that the comparison is to same boy, the results obtained was more likely due to the boy's weight and not anything else (e.g., hair color or attractiveness).

For this study, we did not use any before and after weight loss photographs. We used photographs where the Black and White boys were similarly dressed, groomed, and posed. Unfortunately, we did not pre-test our photographs to determine if people perceived their attractiveness to be similar. Therefore, future research should use before and after weight-loss photographs of Black and White boys or pre-test different photographs for attractiveness to determine if the individuals see the photographs as being similar.

Further, $24 \%$ of participants were unable to complete the implicit attitudes section (the $A M P$ ) of the study. Due to their computer security or version of Adobe, they were unable to see the $A M P$ videos. Therefore, we did not have complete data for $24 \%$ of 
participants. At the time of this study, using Adobe video files were the best solution for showing the $A M P$ photographs of both real-life boys and abstract paintings to participants for one second. Future research should investigate other software that can display photographs for a certain amount of time. Other software may increase the likelihood that participants can view the $A M P$ which will give a more complete picture of the participants (i.e., their implicit attitudes).

Future research should also include more than just Blacks when examining race. The United States is becoming more diverse. Hispanics/Latinos are now the leading minority population. Researching this racial group also has the added benefit of examining language. Major consideration should also be given to Asian Americans and Native Americans given that they are minority groups within the United States. Future research can compare these minority groups to determine if school personnel (e.g., school psychologist or teacher) hold stereotypes about them and what those stereotypes are. Further, future research can also determine if there is a difference among individuals in which minority group they perceive is the most and least academically inclined and why.

This study examined laziness as a dependent variable for Black boys who showed symptoms of ADHD. Future research should examine other racial stereotypes (e.g., Asian Americans being smart in the areas of Science and Mathematics). Further, many different disorders appear in school systems. Sample disorders include: Autism Spectrum Disorder, Cognitive Disability, and Mood Disorders (e.g., Bipolar, Depression, and Anxiety). Mental disorders are generally frowned upon and misunderstood. It could be 
beneficial to understand the stereotypes surrounding these disorders and determine if there are ways to suppress or combat them especially in a school system.

This study also examined the potential impact that taking diversity courses have on race and weight-related stereotypes and sought to determine if the type of exposure students received in these diversity courses (e.g., readings only versus case-centered presentations) made a difference. To assess this, the Diversity Exposure Questionnaire $(D E Q)$ was created. The $D E Q$ was affected by our case study manipulations. Therefore, we were unable to conduct moderation analyses to examine our hypothesis. Future research should further examine this hypothesis (i.e., the impact that taking diversity courses have on race and weight-related biases). The $D E Q$ contained 19 diversity groups - those that were listed for the Feeling Thermometers - to keep the questionnaires consistent. However, future research should only use groups that are relevant to hypotheses being tested. This may help increase the likelihood that the $D E Q$ will not be affected by manipulations of the study. 


\section{REFERENCES}

Allport, G. W. (1954). The nature of prejudice (25th ed.). Reading, MA: AddisonWesley.

American Association of Colleges for Teacher Education. (2002). Minority teacher recruitment and retention: A public policy issue. Racine, WI. Washington, DC: Proceedings and Background Materials of the Wingspread Conference. (ERIC Document Reproduction Service No. 298 123, 1987). Retrieved December 29, 2012 from http://www.aacte.org

American Psychiatric Association (2000). Diagnostic and statistical manual of mental disorder. ( $4^{\text {th }}$ ed., text revision) Washington, DC: Author.

American Psychiatric Association (2013). Guidelines and principles for accreditation of programs in professional psychology. Retrieved from http://www.apa.org/ed/accreditation/about/policies/guiding-principles.pdf

Andrews, T. J., Wisniewski, J. J., \& Mulick, J. A. (1997). Variables Influencing Teachers' Decisions to Refer Children for School Psychological Assessment Services. Psychology in the Schools, 34, 239-244. doi:10.1002/(SICI)15206807(199707)34:3<239::AID-PITS6>3.0.CO;2-J

Banks, J. A. (2002). An introduction to multicultural education (3rd ed.). Boston: Allyn and Bacon.

Barkley, R. A. (1998). Attention deficit hyperactivity disorder: A handbook for diagnosis and treatment ( $2^{\text {nd }}$ ed.). New York: Guilford.

Bauer, K. W., Yang, Y. W., \& Austin, S. B. (2004). "How can we stay healthy when you're throwing all of this in front of us?" Findings from Focus Groups and Interviews in Middle Schools on Environmental Influences on Nutrition and Physical Activity. Health Education \& Behavior, 31, 34-46. doi:10.1177/1090198103255372

Benet-Martinez, V., \& John, O. P. (1998). Los Cinco Grandes across cultures and ethnic groups: Multitrait-multimethod analyses of the Big Five in Spanish and English. Journal of Personality and Social Psychology, 75, 729-750. doi:10.1037/00223514.75.3.729 
Blackwell. J., Smith, M., \& Sorenson, J. (2003). Culture of prejudice: Arguments in critical social science. Ontario, Canada: Broadview Press.

Brigham, J. C. (1993). College Students' Racial Attitudes. Journal of Applied Social Psychology. 23, 1933. doi:10.1111/j.1559-1816.1993.tb01074.x

Brophy, I. E., \& Good, T. L. (1974). Teacher-student relationships: Causes and consequences. NewYork: Holt, Rinehart and Winston.

Brown, R. (2010). Prejudice: Its social psychology. Retrieved from http://www.eblib.com

Brownell, K., \& Rodin, J. (1994). The dieting maelstrom: Is it possible and advisable to lose weight? The American Psychologist, 49, 781-791. doi:10.1037/0003066X.49.9.781

Busse, R. T., \& Beaver, B. R. (2000). Informant report: Parent and teacher interviews. In E. S. Shapiro \& T. R. Kratochwill (Eds.), Conducting school-based assessments of child and adolescent behavior (pp. 235-273). New York: Guilford Press.

Bussing, R., Zima, B. T., Perwien, A. R., Belin, T. R., \& Widawski, M. (1998). Children in Special Education Programs: Attention-deficit/Hyperactivity Disorder, Use of Services, and Unmet Needs. American Journal of Public Health, 88, 880-886. doi:10.2105/AJPH.88.6.880

Butt, K. L., \& Pahnos, M. L. (1995). Why we need a multicultural focus in our schools. Journal of Physical Education, Recreation, and Dance, 66, 48-53. doi:10.1080/07303084.1995.10607024

Campbell, D. T. (1971). White attitudes toward Black people. Ann Arbor, MI: Institute for Social Research.

Center for Disease Control and Prevention. (n.d.). Childhood Overweight and Obesity. Retrieved December 30, 2012 from http://www.cdc.gov/obesity/childhood/index.html

Connors, M. E., \& Melcher, S. A. (1993). Ethical issues in the treatment of weight dissatisfied clients. Professional Psychology: Research and Practice, 24, 404408. doi:10.1037/0735-7028.24.4.404

Coutinho, M. J., \& Oswald, D. P. (2000). Disproportionate Representation in Special Education: A Synthesis and Recommendations. Journal of Child and Family Studies, 9, 135-156. doi:10.1023/A:1009462820157 
Crandall, C. S. (1991). Do Heavy-Weight Students have More Difficulty Paying for College? Personality and Social Psychology Bulletin, 17, 606-611. doi:10.1177/0146167291176002

Crandall, C. S. (1994). Prejudice against fat people: ideology and self-interest. Journal of Personality and Social Psychology, 66(5), 882-894. doi:10.1037/00223514.66.5.882

Crandall, C. S. (1995). Do Parents Discriminate against Their Heavyweight Daughters? Personality and Social Psychology Bulletin, 21, 724-735. doi:10.1177/0146167295217007

Crandall, C. S., \& Biernat, M. R. (1990). The ideology of anti-fat attitudes. Journal of Applied Social Psychology, 20, 227-243. doi:10.1111/j.15591816.1990.tb00408.x

Crandall, C. S., D’Anello, S., Sakalli, N., Lazarus, E., Nejtardt, G. W., \& Feather, N. T. (2001). An attribution-value model of prejudice: Anti-fat attitudes in six nations. Personality and Social Psychology Bulletin 27(1), 30-37. doi:10.1177/0146167201271003

Curtis, M. J., Castillo, J. M., \& Gelley, C. (2010). School psychology 2010:

Demographics, employment, and the context for professional practices-part 1 . Retrieved from http://www.nasponline.org/publications/cq/40/7/schoolpsychology-demographics.aspx

Danielsdottir, S., O'Brien, K. S., \& Ciao, A. (2010). Ant-fat prejudice reduction: A review of published studies. Obesity Facts, 3, 47-58. doi:10.1159/000277067

Davis-Coelho, K., Waltz, J., \& Davis-Coelho, B. (2000). Awareness and prevention of bias Against fat clients in psychotherapy. Professional Psychology: Research and Practice, 31, 682-684. doi:10.1037/0735-7028.31.6.682

Davison, K. K., \& Birch, L. L. (2004). Predictors of Fat Stereotypes among 9-year-old Girls and Their Parents. Obesity Research, 12, 86-94. doi:10.1038/oby.2004.12

DeMeis, D., \& Turner, R. (1978). Effects of students' race, physical attractiveness, and dialect on teacher evaluations. Contemporary Educational Psychology, 3, 77-86. doi:10.1016/0361-476X(78)90012-7

Denson, N. (2009). Do curricular and co-curricular diversity activities influence racial bias? A meta-analysis. The Review of Educational Research, 79, 805-838. doi:10.3102/0034654309331551 
Diamond, J. B., Randolph, A. \& Spillane, J. P. (2004). Teachers' Expectations and Sense of Responsibility for Student Learning: The Importance of Race, Class, and Organizational Habitus. Anthropology \& Education Quarterly, 35, 75-98. doi:10.1525/aeq.2004.35.1.75

Ducker, D. G., \& Tori, C. D. (2001). The reliability and validity of multicultural assessment instrument developed for a graduate program in psychology. Professional Psychology: Research and Practice, 32, 425-431. doi:10.1037/07357028.32.4.425

Dunn, R. (1997). The goals and track record of multicultural education. Educational Leadership, 54, 74-77.

DuPaul, G. J., Power, T. J., Anastopoulos, A. D., \& Reid, R. (1998). ADHD rating scaleIV: Checklists, norms, and clinical interpretation. New York: Guilford Press.

DuPaul, G., \& Stoner, G. (2003). ADHD in the schools: Assessment and practice. New York: Guilford.

Ecklund, K., \& Johnson, B. W. (2007). Toward cultural competencies in child intake assessments. Professional Psychology: Research and Practice, 38, 356-361. doi:10.1037/0735-7028.38.4.356

Epstein, J. N., March, J. S., Connors, C. K., \& Jackson, D. L. (1998). Racial Differences on the Conners Teacher Rating Scale. Journal of Abnormal Child Psychology, 26, 109-118. doi:10.1023/A:1022617821422

Epstein, J. N., Valencia, E. Y., Tonev, S. T., Arnold, L. E., Willoughby, M., Abikoff, H. B., \& Hinshaw, S. P. (2005). The Role of Children's Ethnicity in the Relationship Between Teacher Ratings of Attention-deficit/Hyperactivity Disorder and Observed Classroom Behavior. Journal of Consulting and Clinical Psychology, 73, 424-434. doi:10.1037/0022-006X.73.3.424

Ervin, K. S. (2001). Multiculturalism, diversity, and African American college students: Receptive, yet skeptical? Journal of Black Studies, 31, 764-776. doi:10.1177/002193470103100604

Esses, V. M., \& Hodson, G. (2006). The role of lay perceptions of ethnic prejudice in the maintenance and perpetuation of ethnic bias. Journal of Social Issues, 62, 453468. doi:10.1111/j.1540-4560.2006.00468.x

Farkas, G. (1996). Human capital or cultural capital? Ethnicity and poverty groups in an urban district. New York: Aldine de Gruyter. 
Farkas, G., Robert G., Sheehan. D., \& Shaun, Y. (1990). Cultural Resources and School Success: Gender, Ethnicity, and Poverty Groups within an Urban District. American Sociological Review, 55, 127-142. doi:10.2307/2095708

Fazio, R. H., \& Olson, M. A. (2003). Implicit measures in social cognition research: Their meaning and use. Annual Review of Psychology, 54, 297-327. doi:10.1146/annurev.psych.54.101601.145225

Feather, N. T. (1996). Reactions to penalties for an offense in relation to authoritarianism, values, perceived responsibility, perceived seriousness, and deservingness. Journal of Personality and Social Psychology, 71, 571-587. doi:10.1037/00223514.71.3.571

Ferguson, R. (1998). Teacher perceptions and expectations and the Black-White test score gap. In Jencks, C. \& M. Philips, (Eds.), The Black-White Test Score Gap (pp.273-317). Washington, DC: Brookings Institution Press.

Fiske, S. T. (1998). Stereotyping, prejudice, and discrimination (pp. 357-411). In D. T. Gilbert, S. T. Fiske, \& G. Lindzey (Eds.), The handbook of social psychology: Vol 2,. (4th ed.). New York: McGraw-Hill.

Ford, D. Y. (2013). Multicultural Issues. Gifted Child Today, 36(1), 62-68. doi:10.1177/1076217512465285

Fordham, S. (1996). Blacked out: Dilemmas of race, identity, and success at Capital High. Chicago: University of Chicago Press.

Friedman, M. A., \& Brownell, K. D. (1995). Psychological correlates of obesity: moving to the next research generation. Psychological Bulletin, 117, 3-20.

Frisby, C. (1992). Issue and Problems in the Influence of Culture on the PsychoEducational Needs of African-American Children. School Psychology Review, 21, $532-551$.

Gomez, M. (1992). Diversity 101. Hispanic, 5, 50-52.

Gordijn, E. H., Hindriks, I., Koomen, W., Dijksterhuis, A., \& van Knippenberg, A. (2004). Consequences of Stereotype Suppression and Internal Suppression Motivation: A Self-Regulation Approach. Society for Personality and Social Psychology, 30, 212-224. doi:10.1177/0146167203259935

Gurin, P., Nagda, B., \& Lopez, G. (2004). The benefits of diversity in education for democratic citizenship. Journal of Social Issues, 60, 17-34. doi:10.1111/j.00224537.2004.00097.x 
Haidt, J., McCauley, C., \& Rozin, P. (1994). Individual differences in sensitivity to disgust: A scale sampling seven domains of disgust elicitors. Personality and Individual Differences, 16, 701-713. doi:10.1016/0191-8869(94)90212-7

Hogan, D. E., \& Mallott, M. (2005). Changing racial prejudice through diversity education. Journal of College Student Development, 46, 115-125. doi:10.1353/csd.2005.0015

Hosterman, S. J., DuPaul, G. J., \& Jitendra, A. K. (2008). Teacher Ratings of ADHD Symptoms in Ethnic Minority Students: Bias or Behavioral Difference? School Psychology Quarterly, 23, 418-435. doi:10.1037/a0012668

Howard, G. (1985). Project REACH. Teacher guide and training manual. Arlington, VA: REACH Center.

Hurtado, S. (2005). The next generation of diversity and intergroup relations research. Journal of Social Issues, 61, 595-610. doi:10.1111/j.1540-4560.2005.00422.x

Jackson, S. R. (2010). Race and weight biases: Factors that influence teachers' perceptions of student performance.

Jacobson, C. K. (1985). Resistance to affirmative action: Self-interest or racism? Journal of Conflict Resolution, 29, 306-329. doi:10.1177/0022002785029002007

Janz, J. R., \& Banbury, M. M. (2009). Challenges in classifying students with emotional disturbance: perspective of appraisal professionals. Spaces for Difference: An Interdisciplinary Journal, 2(1), 16-34.

Jones, J. M. (1997). Prejudice and racism. (2 ${ }^{\text {nd }}$ ed.). New York: McGraw Hill.

Jussim, L. J., \& Eccles, J. E. (1995). Are teacher expectations biased by students' gender, social class, or ethnicity? In Y. T. Lee, L. J. Jussim \& C. R. McCauley (Eds.), Stereotype accuracy: Toward appreciating group differences (pp.245271).Washington, DC: American Psychological Association.

Katz, I., \& Hass, R. G. (1988). Racial ambivalence and American value conflict: Correlational and priming studies of dual cognitive structures. Journal of Personality and Social Psychology, 55, 893-905. doi:10.1037/0022-3514.55.6.893

Kearns, T., Ford, L., \& Brown, K. (2002). Multicultural training in doctoral school psychology programs: In search of the model program? Retrieved from http://www.eric.ed.gov/PDFS/ED465930.pdf 
Kearns, T., Ford, L., \& Linney, J. A. (2005). African American Student Representation in Special Education Programs. Journal of Negro Education, 74, 297-310.

Keim, J., Warring, D. F., \& Rau, R. (2001). Impact of multicultural training on school psychology and education students. Journal of Instructional Psychology, 28, 249253.

Keller, H. (1986). In-School Adaptive Behavior; Assessment Domains of Behavior Rating Scales and Child Characteristics. Journal of Psychoeducational Assessment, 4, 1-12. doi:10.1177/073428298600400101

Kernahan, C., \& Davis, T. (2007). Changing perspectives: How learning about racism influences student awareness and emotion. Teaching of Psychology, 34, 49-52. doi:10.1207/s15328023top3401_12

Kinder, D. (1986). The continuing American dilemma: Whites resistances to change 40 years after Myrdal. Journal of Social Issues, 42, 151-172. doi:10.1111/j.15404560.1986.tb00230.x

Kinder, D., \& Sears, D. O., (1981). Prejudice and politics: Symbolic racism versus racial threats to the good life. Journal of Personality and Social Psychology, 40, 414431. doi:10.1037/0022-3514.40.3.414

Kraig, K. A., \& Keel, P. K. (2001). Weight-Based Stigmatization in Children. International Journal of Obesity, 25, 1661-1666. doi:10.1038/sj.ijo.0801813

Laird, T. F. N., Engberg, M. E., \& Hurtado, S. (2005). Modeling accentuation effects: Enrolling in a diversity course and the importance of social action engagement. Journal of Higher Education, 76, 448-476. doi:10.1353/jhe.2005.0028

Lambert, M. C., Puig, M., Lyubansky, M., Rowan, G. T., \& Winfrey, T. (2001). Adult Perspectives on Behavior and Emotional Problems in African American Children. Journal of Black Psychology, 27, 64-85. doi:10.1177/0095798401027001004

Latner, J. D., \& Stunkard, A. J. (2003). Getting Worse: The Stigmatization of Obese Children. Obesity Research, 11, 452-456. doi:10.1038/oby.2003.61

Macrae, C. N, Bodenhausen, G. V., \& Milne, A. B. (1998). Saying no to unwanted thoughts: Self-focus and the regulation of mental life. Journal of Personality and Social Psychology, 74, 578-589. doi:10.1037/0022-3514.74.3.578

Mattison, R. E., Morales, J., \& Bauer, M. A. (1993). Adolescent Schoolboys in SED Classes: Implications for Child Psychiatry. Journal of American Academic Child and Adolescent Psychiatry, 32, 27-29. doi:10.1097/00004583-199311000-00016 
McFadden, A. C., Marsh, G. E., Price, B. J., \& Hwang, Y. (1992). A Study of Race and Gender Bias in the Punishment of School Children. Education and Treatment of Children, 15, 140-146.

McHugh, M., \& Kasardo, A. (2012). Anti-fat Prejudice: The Role of Psychology in Explication, Education and Eradication. Sex Roles, 66(9/10), 617-627. doi:10.1007/s11199-011-0099-x

Monteith, M. J., Sherman, J. W., \& Devine, P. G. (1998). Suppression as a Stereotype Control Strategy. Personality and Social Psychology Review, 2, 63-82. doi:10.1207/s15327957pspr0201_4

Monteith, M. J., Spicer, C. V., and Tolman, G. D. (1998). Consequences of stereotype suppression: Stereotypes on and not on the rebound. Journal of Experimental Social Psychology, 34, 355-377. doi:10.1006/jesp.1998.1355

Muraven, M., \& Baumeister, R. F. (2000). Self-Regulation and Depletion of Limited Resources: Does Self-Control Resemble a Muscle? Psychological Bulletin, 126, 247-259. doi:10.1037/0033-2909.126.2.247

Murray, C. B. (1996). Estimating Achievement Performance: A Confirmation Bias. Journal of Black Psychology, 22, 67-85. doi:10.1177/00957984960221006

National Association of School Psychologists. (n.d.). What is a School Psychologist? Retrieved November 5, 2011, from http://www.nasponline.org/about_sp/whatis.aspx

National Association of School Psychologists. (2010). Standards for graduate preparation of school psychologists. Retrieved from http://www.nasponline.org/standards/2010standards/1_Graduate_Preparation.pdf

Neumark-Sztainer, D., Falkner, N., Story, M., Perry, C., Hannan, P. J., \& Mulert, S. (2002). Weight-Teasing among Adolescents: Correlations with Weight Status and Disordered Eating Behaviors. International Journal of Obesity, 26, 123-131. doi:10.1038/sj.ijo.0801853

Neumark-Sztainer, D., Story, M., \& Harris, T. (1999). Beliefs and attitudes about obesity among teachers and school health care providers working with adolescents. Journal of Nutrition Education, 31(1), 3-9. doi:10.1016/S0022-3182(99)70378-X

Newell, M. L., Hatzichristou, C., Schanding, G. T., Jr., Nastasi, B. K., Jones, J. M., \& Yetter, G. (2010). Evidence on multicultural training in school psychology: Recommendations for future directions. School Psychology Quarterly, 25, 249278. doi:10.1037/a0021542 
Nikels, H. J., Mims, G. A., \& Mims, M. J. (2007). Allies against hate: A school-based diversity sensitivity training experience. The Journal for Specialists in Group Work, 32, 126-138. doi:10.1080/01933920701227117

O’Brien, K. S., Hunter, J. A., \& Banks, M. (2007). Implicit Anti-Fat Bias in Physical Educators: Physical Attributes, Ideology, and Socialization. International Journal of Obesity, 31, 308-314. doi:10.1038/sj.ijo.0803398

Obi, S. O., \& Obiakor, F. E. (2001). Empowering African American Exceptional Learners: Vision for The New Millennium. The Western Journal of Black Studies, 25, 93-100.

Obiakor, F. E. (1999). Teacher Expectations of Minority Exceptional Learners: Impact on "Accuracy" of Self-Concepts. Exceptional Children, 66, 39-53.

Ogden, C. L., Carroll, M. D., Curtin, L. R., McDowell, M. A., Tabak, C. J., \& Flegal, K. M. (2006). Prevalence of Overweight and Obesity in the United States, 19992004. JAMA, 295, 1549-1555. doi:10.1001/jama.295.13.1549

Oswald, D. P., Coutinho, M. J., Best, A. M., \& Singh, N. N. (1999). Ethnic Representation in Special Education: The Influence of School-Related Economic and Demographic Variables. Journal of Special Education, 32, 194-206. doi:10.1177/002246699903200401

Partenio, I., \& Taylor, R. (1985). The Relationship of Teacher Ratings and IQ: A Question of Bias? School Psychology Review, 14, 79-83.

Payne, B. K., Cheng, C. M., Govorun, O., \& Stewart, B. D. (2005). An inkblot for attitudes: Affect misattribution as implicit measurement. Journal of Personality and Social Psychology, 89(3), 277-293. doi:10.1037/0022-3514.89.3.277

Perry, T., Claude S., \& Asa G. Hilliard A. G. (2003) Young, gifted, and black: Promoting high achievement among African American students. Boston: Beacon Press.

Pescosolido, B. A., Fettes, D. L., Martin, J. K., Monahan, J., \& Jensen, P. S. (2007). Stigmatizing attitudes and beliefs about treatment and psychiatric medications for children with mental illness: special section on the National Stigma Study Children. Psychiatric Services, 58(5), 613-618. doi:10.1176/appi.ps.58.5.613

Pettijohn, T. F., \& Walzer, A. S. (2008). Reducing racism, sexism, and homophobia in college students by completing a psychology of prejudice course. College Student Journal, 42, 459-468. 
Plant E. A., \& Devine, P. G. (1998). Internal and External Motivation to Respond without Prejudice. Journal of Personality and Social Psychology, 75, 811-832. doi:10.1037/0022-3514.75.3.811

Plewis, I. (1997). Inferences about Teacher Expectations from National Assessment at Key Stage One. British Journal of Educational Psychology, 67, 235-247. doi:10.1111/j.2044-8279.1997.tb01240.x

Pope-Davis, D. B., Liu, W. M., Nevitt, J., \& Toporek, R. L. (2000). The development and initial validation of the multicultural environmental inventory: A preliminary investigation. Cultural Diversity and Ethnic Minority Psychology, 6, 57-64. doi:10.1037//1099-9809.6.1.5

Pratto, F., Sidanius, J., Stallworth, L. M., \& Malle, B. F. (1994). Social dominance orientation: A personality variable predicting social and political attitudes. Journal of Personality and Social Psychology, 67, 741-763. doi:10.1037/00223514.67.4.741

Pryor, J. B., Reeder, G. D., Yeadon, C., \& Hesson-McInnis, M. (2004). A dual-process model of reactions to perceived stigma. Journal of Personality and Social Psychology, 87, 436-452. doi:10.1037/0022-3514.87.4.436

Puhl, R., \& Brownell, K. D. (2001). Bias, discrimination, and obesity. Obesity Research 9(12), 788-805. doi:10.1038/oby.2001.108

Puhl, R. M., \& Latner, J. D. (2007). Stigma, Obesity, and the Health of the Nation's Children. Psychological Bulletin, 133, 557-580. doi:10.1037/00332909.133.4.557

Puig, M., Lambert, M. C., Rowan, G. T., Winfrey, T., Lyubansky, M., Hannah, S. D., \& Hill, M. F. (1999). Behavioral and Emotional Problems among Jamaican and African American Children, Ages 6 To 11: Teacher Reports Versus Direct Observations. Journal of Emotional and Behavioral Disorders, 7, 240-250. doi:10.1177/106342669900700406

Reeder, G. D., Pryor, J. B., Park, C., \& Brooks, J. E. (2008). Multiple forms of implicit prejudice influence how people perceive Barack Obama. Presentation at the meetings of the Association for Psychological Science, Chicago, IL.

Reid, R., Casat, C. D., Norton, H. J., Anastopoulos, A. D., \& Temple, E. P. (2001). Using behavior rating scales for ADHD across ethnic groups: The IOWA Conners. Journal of Emotional and Behavioral Disorders, 9, 210-218. doi:10.1177/106342660100900401 
Reid, R., Maag, J. W., Vasa, S. F., \& Wright, G. (1994). Who are the Children with ADHD: A School-Based Survey. Journal of Special Education, 28, 117-137. doi:10.1177/002246699402800201

Rist, R. (1970). Student social class and teacher expectation: The self-fulfilling prophesy of ghetto education. Harvard Education Review 40(3), 411-454.

Rogers, M. R., Conoley, J. C., Ponterotto, J. G., \& Wiese, M. J. (1992). Multicultural training in school psychology: A national survey. School Psychology Review, 21, 603-616.

Rogers, M. R., Hoffman, M. A., \& Wade, J. (1998). Notable multicultural training in APA-approved counseling psychology and school psychology programs. Cultural Diversity and Mental Health, 4, 212-226. doi:10.1037/1099-9809.4.3.212

Roscigno, V. J., \& Ainsworth-Darnell J. W. (1999). Race, cultural capital, and educational resources: Persistent inequalities and achievement Returns. Sociology of Education 72(3), 158-178. doi:10.2307/2673227

Rosenthal, R., \& Jacobson, L. (1968). Pygmalion in the classroom. New York: Holt, Rinehart, and Winston.

Ross, S. I., \& Jackson, J. M. (1991). Teachers’ Expectations for Black Males' and Black Females' Academic Achievement. Personality and Social Psychology Bulletin, 17, 78-82. doi:10.1177/0146167291171012

Santrock, J. W. (2001). Educational Psychology. Boston: McGraw-Hill.

Schnoes, C., Reid, R., Wagner, M., \& Marder, C. (2006). ADHD among students receiving special education services: A national survey. Exceptional Children, 72(4), 483-496.

Scuitto, M. J., Terjesen, M. D., \& Bender-Frank, A. S. (2000). Teachers’ Knowledge and Misperceptions of Attention-deficit/Hyperactivity Disorder. Psychology in the Schools, 37, 115-122. doi:10.1002/(SICI)1520-6807(200003)37:2<115::AIDPITS3>3.0.CO;2-5

Shaw, S. R., \& Braden, J. P. (1990). Race and Gender Bias in the Administration of Corporal Punishment. School Psychology Review, 19, 378-383.

Sherman, M., \& Hertzig, M. E. (1991). Prescribing practices of Ritalin: The Suffolk County, New York study, New York: Liebert Publishers. 
Soldatenko, M. (2001). How Chicano studies joined the curriculum. In E. Morgolis (Ed.), The hidden curriculum in higher education (pp. 193-212). New York, NY: Routledge.

Steele, C. M. (1997). A threat in the air: How stereotypes shape intellectual identity and performance. American Psychologist, 52, 613-629. doi:10.1037/0003066X.52.6.613

Steele, C. M., \& Aronson, J. (1995). Stereotype threat and the intellectual test performance of African Americans. Journal of Personality and Social Psychology, 69, 797-811. doi:10.1037/0022-3514.69.5.797

Stephan, W. (1999). Reducing prejudice and stereotyping in schools. New York: Teachers College Press.

Stevens, J., Quittner, A. L., \& Abikoff, H. (1998). Factors Influencing Elementary School Teachers' Ratings of ADHD and ODD Behaviors. Journal of Clinical Child Psychology, 27, 406-414. doi:10.1207/s15374424jccp2704_4

Strange, C., \& Alston, L. (1998). Voicing differences: Encouraging multicultural learning. Journal of College Student Development, 39, 87-99.

Strauss, R. S. (2000). Childhood obesity and self-esteem. Pediatrics, 105(1). Retrieved August 2, 2008, from www.pediatrics.org/cgi/content/full/105/1/e15

Szatmari, P., Offord, D. R., \& Boyle, M. H. (1989). Ontario Child Health Study: Prevalence of Attention Deficit Disorder with Hyperactivity. Journal of Child Psychology Psychiatry, 30, 219-230. doi:10.1111/j.1469-7610.1989.tb00236.x

U.S. Bureau of Labor Statistics. (2011). Labor Force Characteristics by Race and Ethnicity, 2010. Retrieved February 18, 2012, from http://www.bls.gov/cps/cpsrace2010.pdf

U.S. Census Bureau. (2010). Overview of Race and Hispanic Origin: 2010. Retrieved February 18, 2012, from http://www.census.gov/prod/cen2010/briefs/c2010br02.pdf

U.S. Department of Education. (2010). National Student Demographics. Retrieved February 18, 2012, from

http://www.eddataexpress.ed.gov/statereport.cfm?state=US\&submit.x=14\&submi t. $\mathrm{y}=11$

Watts, K., \& Cranney, J. (2009). The nature and implications of implicit weight bias. Current Psychiatry Reviews, 5, 110-126. doi:10.2174/157340009788167338 
Wegner, D. M. (1994). Ironic processes of mental control. Psychological Review, 101, 34-52. doi:10.1037/0033-295X.101.1.34

Wegner, D. M. \& Erber, R. (1992). The hyperaccessibility of suppressed thoughts. Journal of Personality and Social Psychology, 63, 903-912. doi:10.1037/00223514.63.6.903

Wegner, D. M., Schneider, D. J., Carter, S. R. III., \& White, T. L. (1987). Paradoxical effects of thought suppression. Journal of Personality and Social Psychology, 53, 5-13. doi:10.1037/0022-3514.53.1.5

Weiner, B., Perry, R. P., \& Magnusson, J. (1988). An attributional analysis of reactions to stigmas. Journal of Personality and Social Psychology, 55, 738-748. doi:10.1037/0022-3514.55.5.738

Weyandt, L. L., Fulton, K. M., Schepman, S. B., Verdi, G. R., \& Wilson, K. G. (2009). Assessment of Teacher and School Psychologist Knowledge of Attentiondeficit/Hyperactivity Disorder. Psychology in the Schools, 46, 951-961. doi:10.1002/pits.20436

Wille, K. S., McFarland, M. \& Archwamety, T. (2009). Factors related to school psychologists' comfort working with poverty: Are training institutions doing enough to ensure competence in this area? International Journal of Psychology: A Biopsychosocial Approach, 4, 109-118.

Wineburg, S. S. (1987). The self-fulfillment of the self-fulfilling prophecy. Educational Researcher, 16, 28-37. doi.org/10.3102/0013189X016009028

Young-Bruehl, E. (1996). The anatomy of prejudices. Cambridge: Harvard University Press.

Zimmerman, R. S., Khoury, E. L., Vega, W. A., Gill, A. G., \& Warheit, G. J. (1995). Teacher and Parent Perceptions of Behavior Problems among a Sample of African American, Hispanic, and Non-Hispanic White Students. American Journal of Community Psychology, 23, 181-198. doi:10.1007/BF02506935 


\section{APPENDIX A \\ PRELIM CRITIQUE QUESTIONNAIRE}

Name:

Date:

1) Total Time to Complete Survey:

2) Were there any questions/directions that were confusing? Please list the question number and why it was confusing.

3) Were the pictures clearly visible? If not, list the questions where the pictures were hard to see.

4) Did you get stuck at a question (i.e., could not move to the next question)? If so, list the questions where you stopped. 
5) Additional Comments:

Thanks so much for providing this feedback. It will be very helpful to the data collection of my dissertation! :) 


\section{APPENDIX B}

\section{PARTICIPATION EMAIL}

Dear Dr. [Training Director's Name]:

For my dissertation research, I am conducting a study examining the training in School Psychology programs. Specifically, your graduate students will be asked to complete measures focused on their perceptions of the training in their School Psychology program. This study has been approved by the Institutional Review Board at Illinois State University.

It is my hope that you will forward the message below to your graduate students as their participation is essential to my research. Also, could you respond to this email informing me of the number of students to whom you have forwarded this request? Your response would be most appreciated and will help me to effectively track response rates. I will send a reminder email in 2-4 weeks.

Thank you very much for considering my request. If you have any questions or concerns, please contact ShaErica Jackson at srjack@ilstu.edu or my advisor, Dr. John Pryor, at pryor@ilstu.edu or (309) 438-5191.

Thank you,

ShaErica Jackson, M.S.

Advanced Doctoral Student

Illinois State University
John Pryor, Ph.D.

Distinguished Professor of Psychology

Illinois State University 


\section{Dear Trainee,}

I am in the process of collecting data for my dissertation and would greatly appreciate your participation in this study. The purpose of this study is to examine your perceptions of the training in your School Psychology program. It should take you approximately 30 minutes to complete this study. Students who participated in the pilot of this study completed it in about 20 minutes. If you are interested in participating, please go to: http://psychology.illinoisstate.edu/pryor/research/studyShaErica/informedconsent.shtml.

At the end of the study, you will be given the opportunity to enter a drawing for ONE OF FOUR \$50 WAL-MART GIFT CARDS. Please be aware that if you decide to enter the drawing, you will be asked to provide personal information such as your name and email address. This study has been approved by the Institutional Review Board at Illinois State University.

It is our hope that you find this study interesting and meaningful. If you have any questions or concerns, please contact ShaErica Jackson at srjack@ilstu.edu or my advisor, Dr. John Pryor, at pryor@ilstu.edu or (309) 438-5191.

Thank you very much for your participation,

ShaErica Jackson, M.S.

Advanced Doctoral Student

Illinois State University
John Pryor, Ph.D.

Distinguished Professor of Psychology

Illinois State University 
APPENDIX C

\section{CASE STUDY PICTURES}
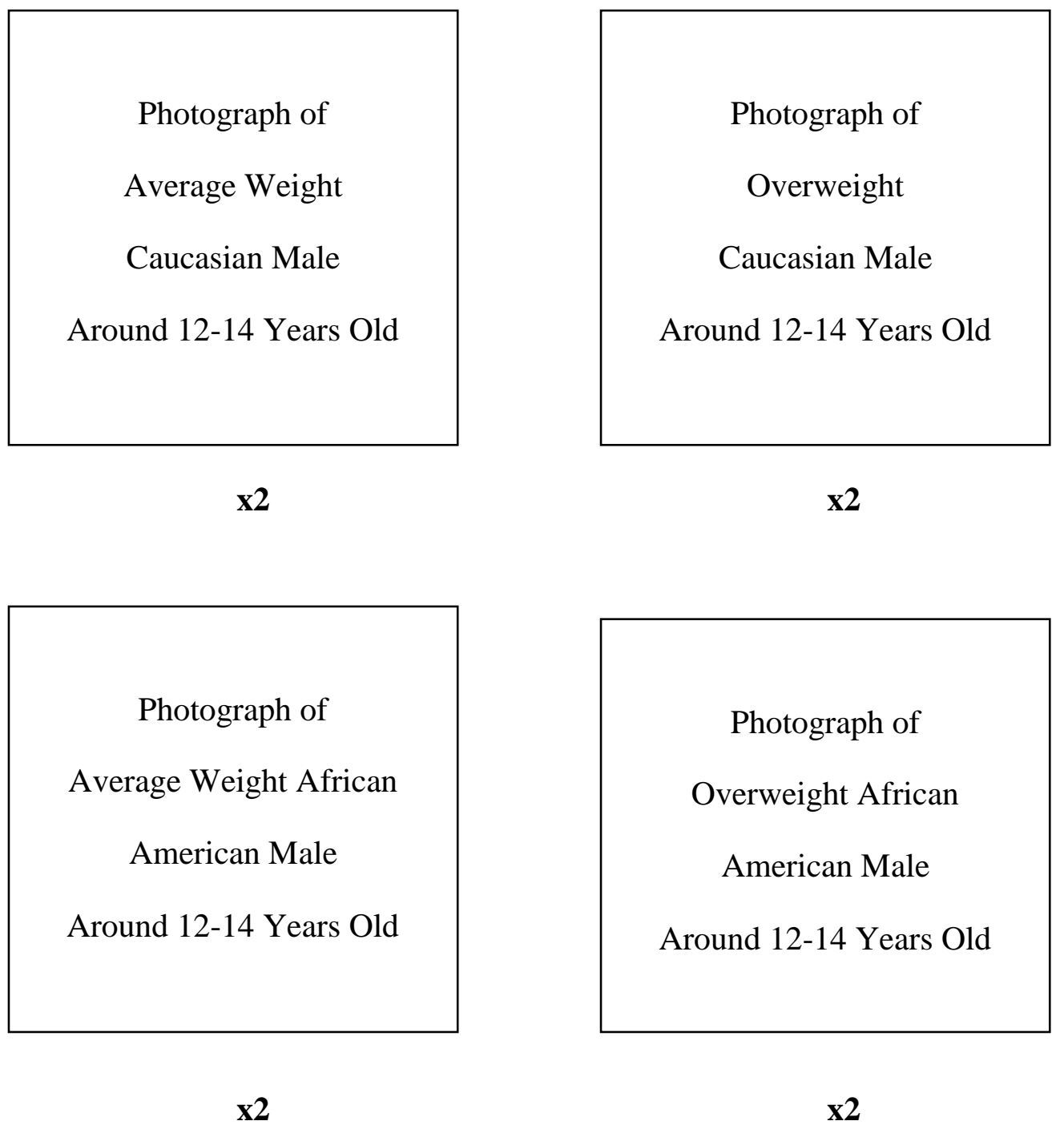


\section{APPENDIX D}

\section{CASE STUDY AND QUESTIONS}

Above is a photo of a student named Jacob. Please imagine that Jacob is a student in a school where you are employed as a school psychologist. Toward the end of the first grading period in Jacob's $8^{\text {th }}$ grade year, his teachers speak to you about his behavior. When he completes his homework and assignments, he does fine. But he rarely finishes his seatwork or turns in his homework. Jacob's teachers state that he never pays attention in class and they have to constantly remind him to do his work. Instead of doing his work, Jacob is often seen tapping his pen against the desk or his feet on the floor as if he is listening to music in his head. He often seems to be "daydreaming" or staring off into space as if the assignment he has to complete is unimportant. Even when he's working on assignments, Jacob never seems to have all of the necessary materials (e.g., books, papers, and pencils) to complete the assignments.

Jacob's parents state that they have heard similar remarks about Jacob since kindergarten. They state that teachers have always complimented Jacob's obvious potential to achieve academic excellence, only to follow the compliment with "if only" he would give his best effort, get his work done, or "if only" he would pay attention. They mention that Jacob often procrastinates on homework each evening, always complaining that his teachers have given him too much homework. Jacob's parents state that he would rather play video games and watch TV instead of completing his chores and homework. When speaking to Jacob, his parents have to constantly repeat things, because it seems like Jacob is never listening or paying attention especially when he's being told to do something he doesn't want to do. They have worked with his schools to try to find a way to motivate him to attend to his teachers and complete his assignments; however, nothing has worked.

You request a special education staffing with the resource teacher, Jacob's teachers, the principal, and the social worker to discuss the causes of Jacob's problem. The group is divided on the issue. The school social worker thinks that Jacob has ADHD since he seems inattentive, disorganized, and unable to complete his homework. His teachers say that he is lazy and unconcerned about his grades, which they support citing his average intelligence and capability to complete homework when he tries. The principal thinks that perhaps his family environment and lack of concern on behalf the parents was the cause. As the school psychologist, they ask for your opinion on the cause of his problems. Please answer the following questions in regard to Jacob and his academic problems. 
Next, we want you to make some ratings about your impressions of Jacob based upon the description you just read. 
Based on the description you just read, please rate your impressions of Jacob on the following scales.

1. What is your impression of Jacob's athleticism?

$\begin{array}{cccccc}\text { Athletic } & & & & \text { Avoid physical activity } \\ 1 & 2 & 3 & 4 & 5 & 6\end{array}$

2. What is your impression of Jacob's honesty?

Truthful, honest

Lies, dishonest

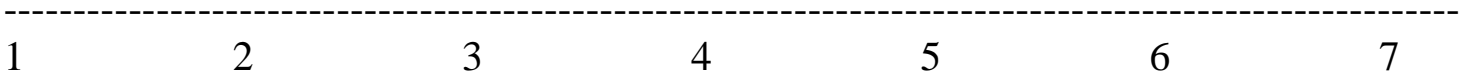

3. What is your impression of Jacob's work skills?

Hardworking

Lazy

$\begin{array}{llllllll}1 & 2 & 3 & 4 & 5 & 6 & 7\end{array}$

4. What is your impression of Jacob's motivational level?

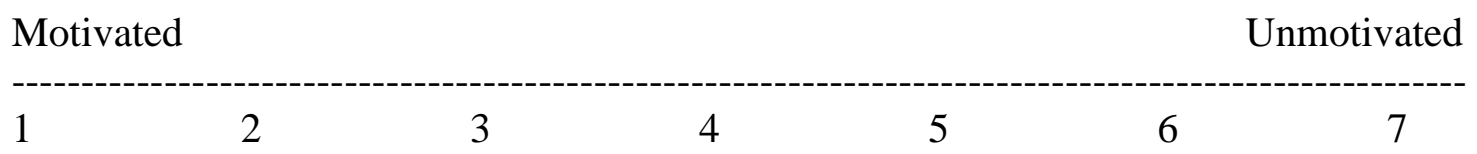

5. What is your impression of Jacob's ability to self-discipline?

Self-disciplined

1

2
3
Poor self-discipline

4

5 
Please indicate the degree to which you agree or disagree with each statement.

\begin{tabular}{|c|c|c|c|c|c|c|}
\hline 1 & 2 & 3 & 4 & 5 & 6 & 7 \\
\hline $\begin{array}{c}\text { Strongly } \\
\text { Disagree }\end{array}$ & Disagree & $\begin{array}{c}\text { Slightly } \\
\text { Disagree }\end{array}$ & $\begin{array}{c}\text { Neither } \\
\text { Agree } \\
\text { nor } \\
\text { Disagree }\end{array}$ & $\begin{array}{c}\text { Slightly } \\
\text { Agree }\end{array}$ & Agree & $\begin{array}{c}\text { Strongly } \\
\text { Agree }\end{array}$ \\
\hline
\end{tabular}

1. This student does not try very hard.

2. This student has symptoms of Attention-Deficit/Hyperactivity Disorder (ADHD).

3. This student is sloppy.

4. This student's main problem is a lack of sufficient support from the family.

5. This student is lazy.

6. This student has not received adequate support from his teachers.

7. This student has symptoms of Oppositional Defiant Disorder (ODD. 
Now, please rank the following hypotheses for Jacob's behavior.

We are not asking you to make a diagnosis. However, using the information given, which hypothesis would you investigate further? Please rank the different hypotheses in the order that you would test them (e.g., 1 - being your first investigation, 2 - being your second investigation, and so forth).

Attention-Deficit/Hyperactivity Disorder (ADHD)

Inadequate Instructional Practices by the Teacher

Lack of Motivation

Lack of Parental Support/ Discipline

Laziness

Oppositional Defiant Disorder (ODD) 


\section{APPENDIX E}

\section{AMP RATING SCALE (IMPLICIT MEASURE)}

Next, we are going to ask you to "SWITCH GEARS" and do something completely different. In the next few screens, your task is to judge the visual pleasantness of some abstract paintings. Individuals' reactions to abstract paintings vary widely: some people find them visually pleasant, while others don't. We are interested in your judgments of paintings under conditions of very brief exposure (1 second). You are about to see a series of abstract paintings that are presented very rapidly. After each painting, we will ask you to rate how pleasant or unpleasant you found it. Before each painting, you will see a signal that the painting is about to appear. Each signal will be a different real-life photo. The real-life image simply will serve as a warning signal that the abstract painting is about to appear. You should do nothing with the signal image. Instead, your job will be to judge the visual pleasantness of each abstract painting. Remember that the real-life images just serve as warning signals. Please do not let them influence your judgments of the abstract paintings. Once you have made your rating, please click on the next button to see the next pair of pictures.

Before we begin showing you the abstract paintings, we need to do a test to make sure that you have the appropriate software on your computer to view the screens that display the signal photos and the paintings. On the next screen, you will see a photo ( 1 second) followed by an abstract painting ( 1 second). We will then ask you to identify the photo you saw. This is just a software test. After the test, we will begin the judgments of the abstract paintings. Please advance to the next screen.

\section{Software Test}

"Photo of an elephant"

What animal did you see in the picture?

Cat

Dog

Elephant

Lion

I Did Not See An Animal 


\begin{tabular}{|c|c|c|c|c|c|c|}
\hline $\begin{array}{l}\text { Abstract } \\
\text { Painting\# }\end{array}$ & $\begin{array}{c}\text { Very } \\
\text { Unpleasant }\end{array}$ & Unpleasant & $\begin{array}{c}\text { Mildly } \\
\text { Unpleasant }\end{array}$ & $\begin{array}{c}\text { Mildly } \\
\text { Pleasant }\end{array}$ & Pleasant & $\begin{array}{c}\text { Very } \\
\text { Pleasant }\end{array}$ \\
\hline \#01 & -3 & -2 & -1 & 1 & 2 & 3 \\
\hline \#02 & -3 & -2 & -1 & 1 & 2 & 3 \\
\hline \#03 & -3 & -2 & -1 & 1 & 2 & 3 \\
\hline \#04 & -3 & -2 & -1 & 1 & 2 & 3 \\
\hline$\# 05$ & -3 & -2 & -1 & 1 & 2 & 3 \\
\hline \#06 & -3 & -2 & -1 & 1 & 2 & 3 \\
\hline \#07 & -3 & -2 & -1 & 1 & 2 & 3 \\
\hline \#08 & -3 & -2 & -1 & 1 & 2 & 3 \\
\hline \#09 & -3 & -2 & -1 & 1 & 2 & 3 \\
\hline$\# 10$ & -3 & -2 & -1 & 1 & 2 & 3 \\
\hline \#11 & -3 & -2 & -1 & 1 & 2 & 3 \\
\hline \#12 & -3 & -2 & -1 & 1 & 2 & 3 \\
\hline$\# 13$ & -3 & -2 & -1 & 1 & 2 & 3 \\
\hline$\# 14$ & -3 & -2 & -1 & 1 & 2 & 3 \\
\hline$\# 15$ & -3 & -2 & -1 & 1 & 2 & 3 \\
\hline$\# 16$ & -3 & -2 & -1 & 1 & 2 & 3 \\
\hline$\# 17$ & -3 & -2 & -1 & 1 & 2 & 3 \\
\hline \#18 & -3 & -2 & -1 & 1 & 2 & 3 \\
\hline$\# 19$ & -3 & -2 & -1 & 1 & 2 & 3 \\
\hline$\# 20$ & -3 & -2 & -1 & 1 & 2 & 3 \\
\hline$\# 21$ & -3 & -2 & -1 & 1 & 2 & 3 \\
\hline$\# 22$ & -3 & -2 & -1 & 1 & 2 & 3 \\
\hline$\# 23$ & -3 & -2 & -1 & 1 & 2 & 3 \\
\hline$\# 24$ & -3 & -2 & -1 & 1 & 2 & 3 \\
\hline
\end{tabular}




\section{APPENDIX F}

\section{EXAMPLES OF AMP PROCEDURE (IMPLICIT MEASURE)}

Warning Signals

(Displayed for 1 second)
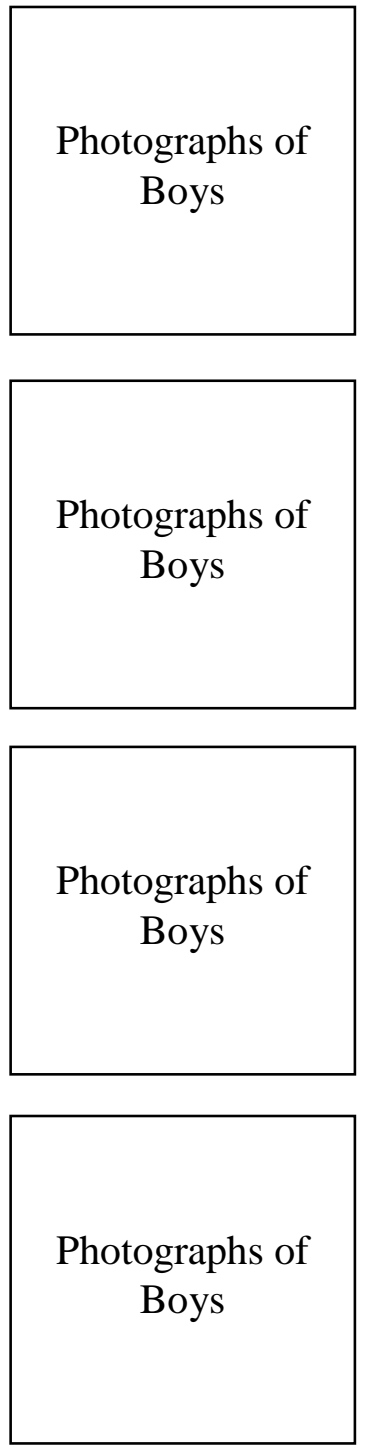

Abstract Paintings

(Displayed for 1 second)

\section{Ratings}

(Using the rating scale directly above)

\section{Rating of}

Abstract Painting

Normal Painting
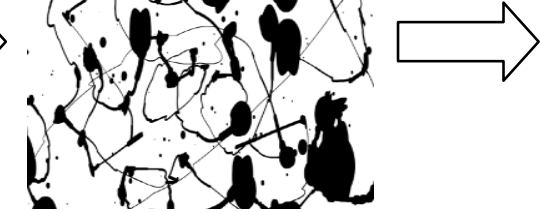

.
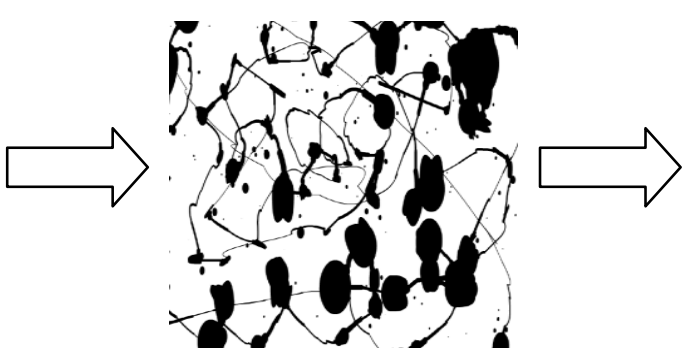

Rating of

Abstract Painting

Painting Flipped

Vertically
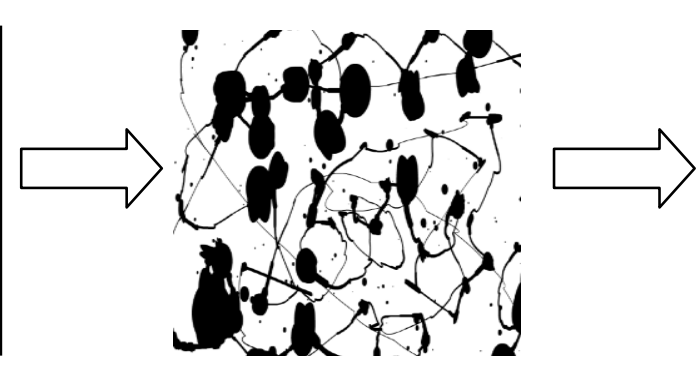

Rating of

Abstract Painting

Painting Flipped

Horizontally

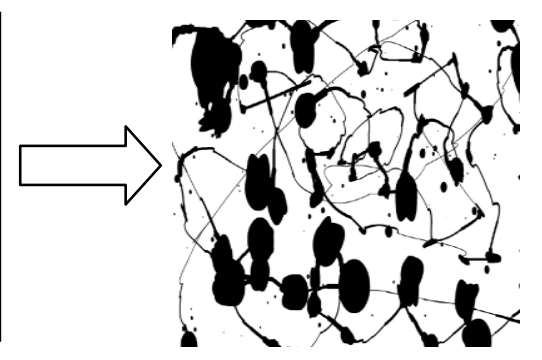

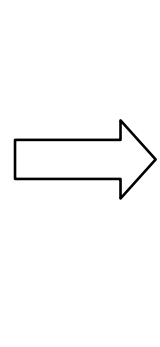

\section{Rating of}

Abstract Painting

Painting Flipped

Vertically and

Horizontally 


\section{APPENDIX G \\ FEELING THERMOMETERS (EXPLICIT MEASURE)}

Now, we turn to a different task. The following questions require you to use what we call a FEELING THERMOMETER. The Feeling Thermometer is shown below. Using the Feeling Thermometer, please select the best choice that describes your feelings about the following groups of people:

\begin{tabular}{|c|c|c|}
\hline & degrees & \\
\hline & $=100^{\circ}$ & Extremely favorable feelings \\
\hline \multirow{9}{*}{ POSITIVE } & $=90^{\circ}$ & Very favorable \\
\hline & $二 80^{\circ}$ & Quite favorable \\
\hline & $=70^{\circ}$ & Fairly favorable \\
\hline & $=60^{\circ}$ & Slightly favorable \\
\hline & $=50^{\circ}$ & Neither favorable nor unfavorable \\
\hline & $=40^{\circ}$ & Slightly unfavorable \\
\hline & 二 $30^{\circ}$ & Fairly unfavorable \\
\hline & $=20^{\circ}$ & Quite unfavorable \\
\hline & $=10^{\circ}$ & Very unfavorable \\
\hline NEGATIVE & $=0^{\circ}$ & Extremely unfavorable feelings \\
\hline
\end{tabular}

How do you feel about Muslims?

How do you feel about Christians?

How do you feel about People with East Indian Religions (e.g., Sikhs, Hindus, etc.)?

How do you feel about Jews?

How do you feel about Atheists?

How do you feel about Blacks (e.g., African Americans, Jamaicans, etc.)?

How do you feel about Whites (e.g., European Americans, etc.)? 
How do you feel about Asians (e.g., Chinese, Japanese, etc.)?

How do you feel about People from the Middle East (e.g., Arabs, etc.)?

How do you feel about Native Americans?

How do you feel about Hispanics (e.g., Mexicans, etc.)?

How do you feel about People who are Overweight?

How do you feel about People with Eating Disorders?

How do you feel about People who are Gay, Lesbian, Bisexual, Transgender, or Questioning (GLBTQ)?

How do you feel about People with Intellectual Disabilities?

How do you feel about People with Mental Illness?

How do you feel about People with Physical Disabilities?

How do you feel about Overweight Blacks (e.g., African Americans, Jamaicans, etc.)?

How do you feel about Overweight Whites (e.g., European Americans, etc.)? 


\section{APPENDIX H}

\section{MOTIVATION TO CONTROL WEIGHT PREJUDICE}

The following questions concern various reasons or motivations people might have for trying to respond in non-prejudiced ways towards obese (overweight) people. Some of the reasons reflect internal/personal motivations whereas others reflect more external/social motivations. Of course people may be motivated for both internal and external reasons. We want to emphasize that neither type of motivation is by definition better than the other. In addition, we want to be clear that we are not evaluating you or your individual responses. We are simply trying to get an idea of the types of motivations that students in general have for responding in non-prejudiced ways. If we are to learn anything useful, it is important that you respond openly and honestly. Please give your response according to the scale below.

\begin{tabular}{|c|c|c|c|c|c|c|}
\hline 1 & 2 & 3 & 4 & 5 & 6 & 7 \\
\hline $\begin{array}{c}\text { Strongly } \\
\text { Disagree }\end{array}$ & Disagree & $\begin{array}{c}\text { Slightly } \\
\text { Disagree }\end{array}$ & $\begin{array}{c}\text { Neither } \\
\text { Agree } \\
\text { nor } \\
\text { Disagree }\end{array}$ & $\begin{array}{c}\text { Slightly } \\
\text { Agree }\end{array}$ & Agree & $\begin{array}{c}\text { Strongly } \\
\text { Agree }\end{array}$ \\
\hline
\end{tabular}

1. Because of today's PC (politically correct) standards I try to appear nonprejudiced towards overweight people.

2. I attempt to act in non-prejudiced ways towards overweight people because it is personally important to me.

3. I try to hide any negative thoughts about overweight people in order to avoid negative reactions from others.

4. If I acted prejudiced toward overweight people, I would be concerned that others would be angry with me.

5. According to my personal values, using stereotypes about fat people is OK.

6. I am personally motivated by my beliefs to be non-prejudiced towards overweight people. 
7. I appear to be non-prejudiced towards fat people in order to avoid disapproval from others.

8. Because of my personal values, I believe that using stereotypes about overweight people is wrong.

9. I try to act non-prejudiced towards fat people because of pressure from others.

10. Being non-prejudiced towards overweight people is important to my selfconcept. 


\section{APPENDIX I \\ DIVERSITY EXPOSURE QUESTIONNAIRE}

Now, you will answer questions about the type of exposure you have had during your graduate training for different groups of people.

Please indicate the area(s) in which the following groups were covered during your graduate training. Check all that apply.

\begin{tabular}{|l|l|l|l|l|l|l|l|}
\hline & $\begin{array}{c}\text { Case- } \\
\text { Centered } \\
\text { Presen- } \\
\text { tations }\end{array}$ & $\begin{array}{c}\text { Didactic } \\
\text { Seminars }\end{array}$ & $\begin{array}{c}\text { Dis- } \\
\text { cussions }\end{array}$ & $\begin{array}{c}\text { Experi- } \\
\text { ential } \\
\text { Exercises }\end{array}$ & $\begin{array}{c}\text { Outside/ } \\
\text { Invited } \\
\text { Speakers }\end{array}$ & Readings & N/A \\
\hline Muslims & & & & & & & \\
\hline Christians & & & & & & & \\
\hline $\begin{array}{l}\text { People } \\
\text { with East } \\
\text { Indian } \\
\text { Religions } \\
\text { (e.g., } \\
\begin{array}{l}\text { Sikhs, } \\
\text { Hindus, } \\
\text { etc.) }\end{array}\end{array}$ & & & & & & & \\
\hline $\begin{array}{l}\text { Jews } \\
\text { Jamaicans, } \\
\text { etc.) }\end{array}$ & & & & & & & \\
\hline $\begin{array}{l}\text { Atheists } \\
\text { Alacks }\end{array}$ & & & & & & & \\
\hline
\end{tabular}




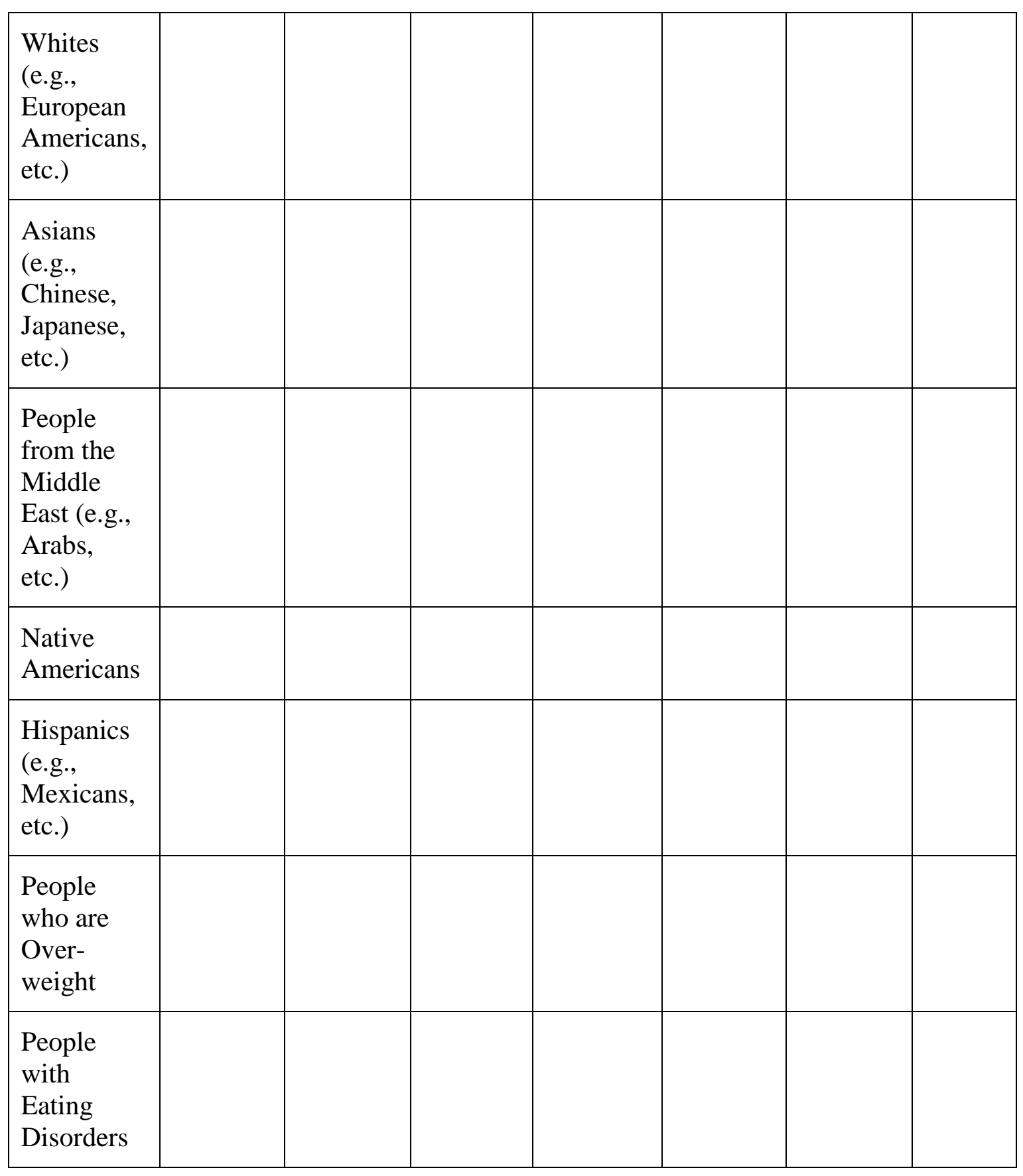




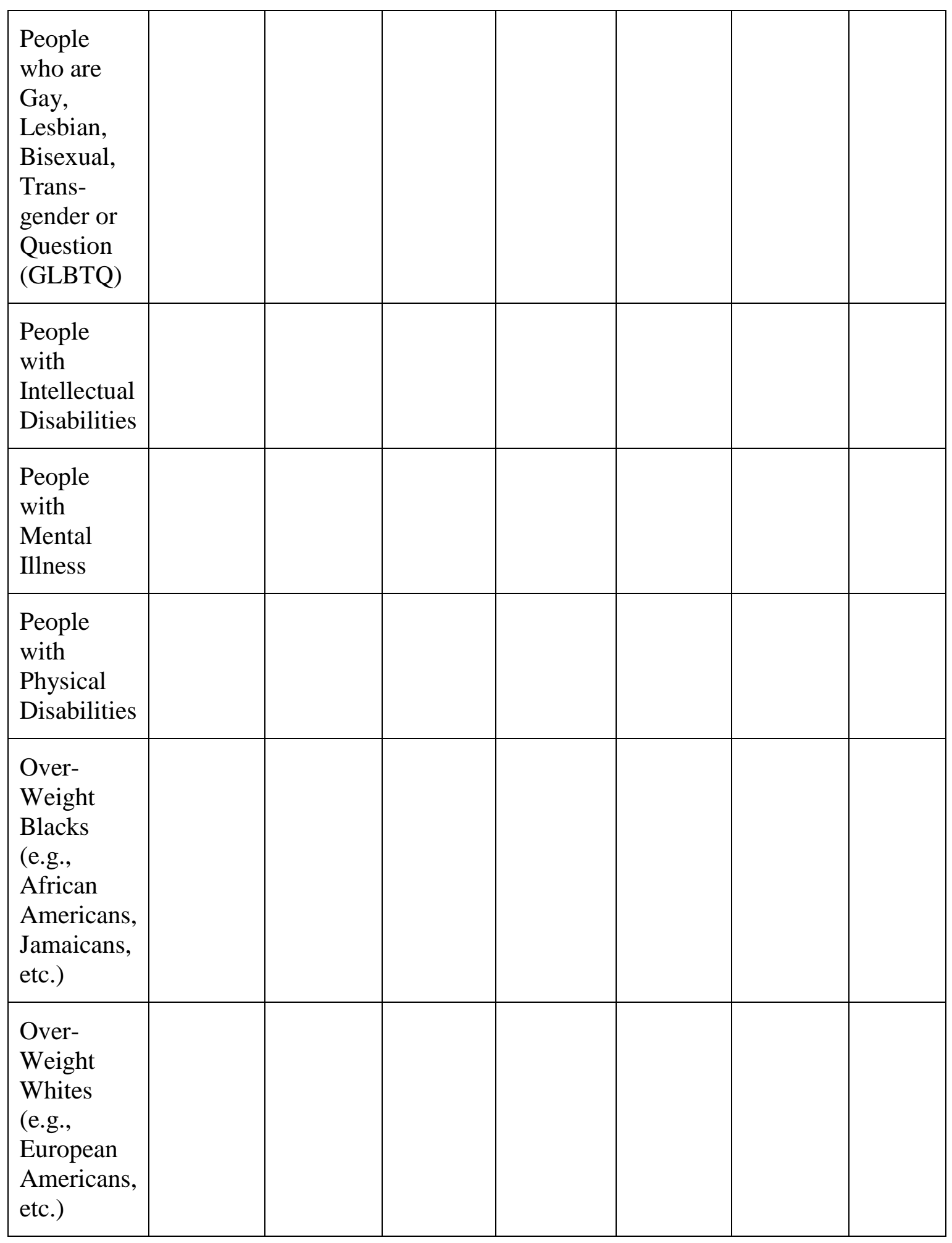




\section{APPENDIX J \\ DEMOGRAPHICS QUESTIONNAIRE}

Gender:

Male

Female

Age:

18 to 65 or Older (Listed Individually)

What is your race/ethnicity?

Please select all that apply.

American Indian/Alaskan Native

Asian/Pacific Islander

Black/African American

Hispanic/Latino

White, Non-Hispanic

Other, please specify:

What is your nationality?

U.S. Citizen

Other, please specify:

What is your Religious Affiliation?

Protestant

Roman Catholic

Jewish

Christian

Muslim

Buddhist

Hindu

None

Other, please specify: 
How often do you attend religious services?

Never

1-2 times a year

3-11 times a year

1-3 times a month

Once a week or more

Class Level:

Graduate - Masters

Graduate - Specialist

Graduate - Psy.D.

Graduate - Ph.D.

Other, please specify:

Year in Program:

$1^{\text {st }}$ Year

$2^{\text {nd }}$ Year

$3^{\text {rd }}$ Year

$4^{\text {th }}$ Year

$5^{\text {th }}$ Year

Intern

Other, please specify:

Is your graduate program:

APA Accredited

NASP Approved

Both

Neither

Don't Know

In what region is your graduate program located?

Pacific (WA, OR, CA, ID, NV, AZ)

Northwest (MT, WY, UT, CO)

Midwest (ND, SD, NE, MN, IA, WI, IL, IN, MI, OH)

Southwest (NM, TX, KS, OK, MO, AR, LA)

Southeast (MS, AL, GA, FL, KY, TN, WV, VA, NC, SC)

Northeast (PA, DE, MD, NJ, CT, NY, VT, NH, MA, RI, ME) 
Have you ever worked in a school?

$$
\begin{aligned}
& \text { Yes } \\
& \text { No }
\end{aligned}
$$

How long did you work in a school?

1 Year

2-5 Years

6-10 Years

10 or More Years

Not Applicable

What was the racial/ethnic make-up of the students in the school where you worked?

\begin{tabular}{|l|l|l|l|l|l|l|}
\hline & $\begin{array}{c}\text { No } \\
\text { Students }\end{array}$ & $\begin{array}{c}\text { Less Than } \\
\text { Half }\end{array}$ & Half & $\begin{array}{c}\text { More } \\
\text { Than Half }\end{array}$ & $\begin{array}{c}\text { All } \\
\text { Students }\end{array}$ & $\begin{array}{c}\text { Not } \\
\text { Applicable }\end{array}$ \\
\hline $\begin{array}{l}\text { American } \\
\text { Indian/ } \\
\text { Alaskan } \\
\text { Native }\end{array}$ & & & & & & \\
\hline $\begin{array}{l}\text { Asian } \\
\text { American }\end{array}$ & & & & & & \\
\hline $\begin{array}{l}\text { Black/ } \\
\text { African } \\
\text { American }\end{array}$ & & & & & & \\
\hline $\begin{array}{l}\text { Hispanic/ } \\
\text { Latino }\end{array}$ & & & & & & \\
\hline $\begin{array}{l}\text { Whites/ } \\
\text { Non- } \\
\text { Hispanic }\end{array}$ & & & & & & \\
\hline \begin{tabular}{l} 
Other \\
\hline
\end{tabular} & & & & & & \\
\hline
\end{tabular}




\section{APPENDIX K}

\section{CONSENT FORM}

PLEASE READ THIS DOCUMENT CAREFULLY. CLICK TO CONTINUE BELOW ONLY IF YOU AGREE TO PARTICIPATE. YOU MUST BE 18 YEARS OF AGE TO GIVE YOUR CONSENT TO PARTICIPATE IN RESEARCH. FOR THIS PROJECT, YOU MUST BE 18 YEARS OF AGE TO PARTICIPATE. IF YOU DESIRE A COPY OF THIS CONSENT FORM, YOU MAY PRINT THIS FORM.

The policy of the Department of Psychology at Illinois State University is that all research participants in the Department is voluntary, and you have the right to withdraw at any time, without prejudice, should you object to the nature of the research. Your responses are confidential. Any report of the data collected will be in summary form, without identifying individuals. You are entitled to ask questions and to receive an explanation after your participation.

If you have concerns about your participation in this study, you may contact:

Dr. John B. Pryor Email: pryor@ilstu.edu

\section{Description of the Study:}

This is a one-session study in which you will be asked to perform several tasks.

To do this, we will ask you to do the following:

- The first involves reading a case scenario about a hypothetical student and answering a set of questions regarding that student.

- The second involves making rapid judgments about a series of abstract paintings.

- Following these judgments, you will then be asked to complete several brief questionnaires.

- Finally, you will be asked some basic demographic questions about yourself.

\section{Nature of Participation:}

You will simply be asked to make some simple ratings. You should be able to complete this survey in about 30 minutes. Most students who participated in a pilot study completed it in less than 30 minutes. 


\section{Purpose of the Study:}

The major purpose of this research is to examine School Psychology graduate students' perceptions of the training in their School Psychology program. A secondary purpose is to study psychological processes that determine how people perform on several tasks including judging paintings and making attributions about students with education problems. We are only interested in an evaluation of these measures, and how they are related to one another. We are NOT interested in the responses of any specific individual.

\section{Possible Risks:}

a) When filling out questionnaires, you might come across a question or answer choice that you find unpleasant, upsetting, or otherwise objectionable. For instance, a few questions may cause you to think about negative emotional states.

b) While performing these tasks, you may feel that you have performed poorly. For this research, there are no right or wrong answers. Once more, we are not interested in specific individuals and their performance - we are only interested in how behave in general.

c) You will be asked to provide some general demographic information about yourself.

\section{Possible Benefits:}

a) When your participation is complete, you will be given an opportunity to learn about this research, which may be useful to you in understanding yourself and others.

b) You will have an opportunity to contribute to psychological research and provide insight into School Psychology training by participating in this research.

\section{Confidentiality:}

Participation in this research is completely confidential. There are no questions in this study that will ask you to provide any identifying information. No one will be able to know which responses are yours. Finally, remember that it is no individual person's responses that interests us; we are only interested in how people behave in general. All data will be kept on a secure server, in accord with the standards of the University, Federal regulations, and the American Psychological Association. Please be aware that if you decide to enter the drawing for one of four $\$ 50 \mathrm{Wal}$-Mart gift cards, you will be asked to provide personal information such as your name and email address. In any case, we will not be able to associate your responses to your identity. 


\section{Opportunities to Question:}

- Any technical questions about this research may be directed to the Principal Investigator, Dr. John B. Pryor, Distinguished Professor of Psychology, Illinois State University, pryor@ilstu.edu

- Any questions regarding your rights as a research participant may be directed to the ISU Research Ethics \& Compliance Office at (309) 438-2529.

\section{Opportunities to Withdraw at Will:}

If you decide now or at any point to withdraw this consent or stop participating, you are free to do so at no penalty to yourself. You are free to skip specific questions and continue participating at no penalty.

\section{Opportunities to be Informed of Results:}

In all likelihood, the results will be fully available around: December 2014. Preliminary results will be available earlier. If you wish to be told of the results of this research, please contact:

Principal Investigator: Dr. John B. Pryor, pryor@ilstu.edu

There is a chance that the results from this study will be published in a scientific Psychology journal, which would be available in many libraries. In such an article, participants would not be identified as individuals in any way.

I agree to participate in this study. I further acknowledge that I can print a copy of this consent form for my records if I so desire.

(By clicking yes, you are also stating that you are 18 years of age or older.)

Please indicate Yes or No

Yes

No (I am not 18 or I choose not to participate) 


\section{APPENDIX L}

\section{DEBRIEFING FORM}

First of all, I would like to personally thank you for participating in this study. Advancements in psychological research are only possible because of those who are willing to volunteer their time, such as you, to participate in research studies.

- Do you have any comments or questions about the experiment? If so, please contact Dr. John Pryor, the principal investigator, at (309) 438-5191.

Now let me tell you more explicitly about what we were studying in this research project. Our interest in this study is to examine the attributions that pre-service school psychologists make to black and overweight students. Generally, people have very negative reactions to black and obese people. Being overweight or being Black can be said to be a stigma. In the case scenarios you read, the same scenario was attached to either an overweight or normal weight, Black or White student. We wanted to see whether or not the weight or race of the child affected the adjectives that were attributed to the child or the perceived cause of his education problems.

Your ratings of the Chinese pictographs are also an important part of this study. Previous research suggests that people who hold more negative or rejecting attitudes toward Black or overweight people will rate the abstract paintings that follow a photo of a Black or overweight person as more unpleasant. So, this procedure was used to get a subtle measure of your attitudes about Black and overweight people.

Finally, we wanted to determine if your knowledge of diverse groups, specifically through diversity courses, influenced your perceptions of Black and overweight students.

Everyone has been the target of being socially rejected by other people at sometime in his/her life. In our society, people are often very rejecting of others who are Black or overweight. Obesity is a powerful stigma. Research shows people who are overweight are perceived as lacking in self-discipline, lazy, less conscientious, less competent, sloppy, and more likely to have negative personality traits. Research also shows people who are Black are perceived as being less intelligent, very aggressive, and more likely to have negative personality traits associated with their race. We wanted to know how this stigma might affect how school psychologists perceive the problems children have in school. That is the focus of the current study. We hope that you leave this research project with some sense of how you might feel about this experience if it were to happen 
to you. Because you are a caring person, we hope that you will remember this feeling of rejection and work to treat others with inclusion.

It is important for you to know that our study is interested in the responses of groups of people, and not individual responses. Your data will be assigned a number code. Neither your name nor any identifying information will be associated with your number coded data. Thus, no one will know your specific reactions and answers to our questions. Once again we are interested in group reactions, and not specific individuals. If you have any questions you may contact Dr. John Pryor in the Psychology department at (309) 4385191 , and if you are interested in the results of this study they will be available towards the end of December 2014 from him.

Once again, thank you for your participation and I wish you the best for the rest of the semester! 


\section{APPENDIX M \\ PARTICIPATION IN DRAWING}

If you would like to participate in the drawing for one of four $\$ 50$ Walmart gift cards, enter your name and email address below. Although you are providing personal information, this information in no way identifies the answers you provided. All data will be analyzed in group form.

Name:

Email Address: 